\title{
Perfil biodinâmico de entrada dos trocartes em
}

\section{cirurgias laparoscópicas}

Tese apresentada à Faculdade de Medicina da Universidade de São Paulo para obtenção do título de Doutor em Ciências

Programa de Urologia

Orientador: Prof. Dr. Carlo Camargo Passerotti

\section{São Paulo}

2018

Versão corrigida. Resolução CoPGr 6018, de 13 de outubrode 2011 
Danilo Galante Moreno

\section{Perfil biodinâmico de entrada dos trocartes em}

\section{cirurgias laparoscópicas}

Tese apresentada à Faculdade de Medicina da Universidade de São Paulo para obtenção do título de Doutor em Ciências

Programa de Urologia

Orientador: Prof. Dr. Carlo Camargo Passerotti

\section{São Paulo}

2018

Versão corrigida. Resolução CoPGr 6018, de 13 de outubrode 2011 


\section{Dados Internacionais de Catalogação na Publicação (CIP)}

Preparada pela Biblioteca da

Faculdade de Medicina da Universidade de São Paulo

Creprodução autorizada pelo autor

Moreno, Danilo Galante

Perfil biodinâmico de entrada dos trocartes em

cirurgias laparoscópicas / Danilo Galante Moreno.

Săo Paulo, 2018.

Tese (doutorado)--Eaculdade de Medicina da

Universidade de São Paulo.

Programa de Urologia.

orientador: Carlo Camargo Passerotti.

Descritores: 1.Laparoscopia 2.Animais 3.Segurança

4. Cirurgia geral 5 . Instrumentos cirúrgicos

6. Mortalidade 7. Prevenção de acidentes

$\mathrm{USP} / \mathrm{FM} / \mathrm{DBD}-471 / 18$

Responsável: Erinalva da Conceiçăo Batista, CRB-8 6755 
Autorizo a reprodução e divulgação total ou parcial deste trabalho, por qualquer meio convencional ou eletrônico, para fins de estudo e pesquisa, desde que citada a fonte. 


\section{Dedicatória}

Dedico essa tese aos meus pais, Sergio Moreno e Eliane Galante Moreno, por todo investimento, atenção, carinho, conforto e energia em todas as fases da minha vida. Eles são os meus pilares, responsáveis pela minha construção profisssional, intelectual e de caráter.

Dedico também a minha esposa Cláudia Maria Gazolla Patrão Moreno pelo companheirismo, pela atenção, pelo amor, carinho e paciência em todos os momentos desse e de todos os trabalhos da minha carreira.

Dedico aos meus filhos (Pedro Galante Patrão Moreno e meu futuro filho, ainda sendo gerado nesse momento) pela imensa alegria de viver, que a cada dia aumenta mais. Vocês viraram minha mais nova fonte de inspiração para continuar estudando e evoluindo. 


\section{Agradecimentos}

Primeiramente agradeço a Deus por todas as possibilidades ofertadas. Considerome um privilegiado por tantas oportunidades de desenvolvimento do meu trabalho e estudo.

Agradeço imensamente ao meu orientador Professor Doutor Carlo Camargo Passerotti, meu professor tanto da medicina, quanto do doutorado. A ele devo minha experiência em cirurgia robótica, meu aprendizado aos cuidados de pacientes diferenciados e meu desenvolvimento intelectual na elaboração de trabalhos científicos, além da oportunidade de realizar essa tese. Agradeço também ao Dr. Marco Antonio Nunes da Silva, Dr. Rafael Sakata e à Sabrina Reis pelo apoio durante toda a pós graduação. Sem eles, meus experimentos nunca sairiam do papel.

Muito obrigado aos ex alunos, agora médicos, Dr. Ricardo Kyoiti Sant Anna, Luiz Felipe Sávio e Rafael Ulysses de Azevedo e ao meu amigo Cesar Augusto Martins Pereira, do Laboratório de Ortopedia. Vocês foram fundamentais na realização dos experimentos, na aquisição e avaliação dos dados. Foram a melhor e mais parceira equipe que eu podia ter.

Agradeço ao Professor Sergio Delijaikov pelo interesse em meu trabalho e pela disponibilidade ímpar para elaboração do sensor usado nesse trabalho. Muito obrigado ao Dr. Iuri Tamasauskas e seu pai, Arthur Tamasauskas, professor da FEI. Foram os responsáveis pelo "pontapé” inicial do meu projeto. 
Minha profunda gratidão ao Dr. Fernando Augusto Martiros Herbella Fernandes, amigo e professor. Foram horas de ajuda, dias de paciência e anos de companheirismo. Agradeço por toda ajuda!

Grato também ao Dr. Alberto Azoubel Antunes pela atenção e disponibilidade nos momentos mais complicados da minha tese. Agradeço a secretária Elisa Cruz por facilitar sobremaneira toda a burocracia da minha tese e ao amigo Thiago Afonso Teixeira por toda ajuda.

Agradeço a minha equipe cirúrgica: Dr. Charles Rosenblatt e Rosane Zaborowsky Graicer. Em todos esses anos não me faltaram com companheirismo, atenção, paciência e amizade.

Por fim, agradeço a minha amiga fotógrafa Carla Formanek que contribuiu nas ilustrações desse trabalho e ao Professor Thiago Zilio Passerini, amigo, paciente e professor de português que revisou minha tese. 
Esta tese está de acordo com as seguintes normas, em vigor no momento desta publicação:

Documentação: Guia de apresentação de dissertações, teses e monografias. Elaborado por Annelise Carneiro da Cunha, Maria Julia de A. L. Freddi, Maria F. Crestana, Marinalva de Souza Aragão, Suely Campos Cardoso, Valéria Vilhena. 3ra edição, São Paulo: Serviço de Biblioteca e Documentação; 2011

Referências: adotadas do Internacional Committe of Medical Journals Editors (ABNT NBR 6023:2018)

Abreviaturas dos títulos dos periódicos de acordo com List of Journals Indexed in Index Medicus 


\section{Sumário}

Lista de Abreviaturas, Siglas e Símbolos

Lista de Figuras

Lista de Tabelas e Gráficos

Resumo

Summary

1 INTRODUÇÃO .....................................................................

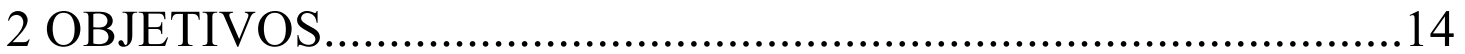

3 MÉTODOS

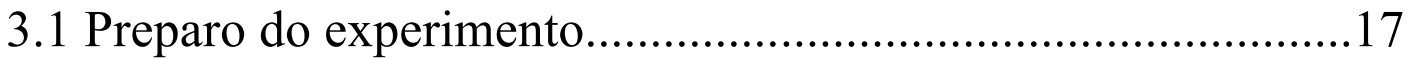

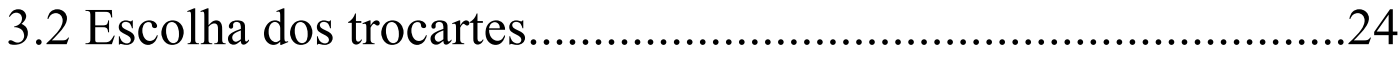

3.3 Sítios de punção dos trocartes...............................................26

3.4 Aquisiç̧ão dos dados.............................................................28

3.5 Avaliação das imagens e coleta dos dados..............................32

3.6 Metodologia estatística e análise de amostra..........................38





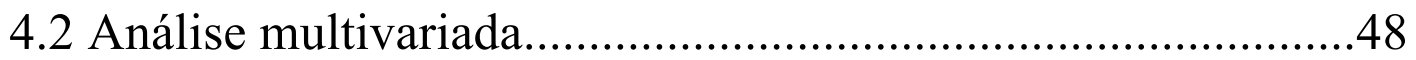

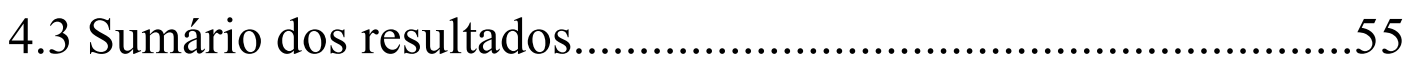


5.1 Aspectos gerais

5.2 Considerações finais .65

5.3 Perspectivas futuras. .66

6 CONCLUSÕES. .67

7 REFERÊNCIAS .69 APÊNDICES

1 Especificação dos modelos dos trocartes

2 Parecer do Comitê de Ética - Aprovado

3 Artigo enviado para publicação 


\section{Lista de Abreviaturas, Siglas e Símbolos}

$\mathrm{cm}$ - centimetros

Dd - Distância de deformação, medida imediatamente antes da perfuração

DLam - Distância percorrida pela lâmina exposta

Dt - Distância total percorrida pelo trocarte

et al. - e outros

F1 - Força necessária para perfuração da aponeurose

F2 - Força necessária para perfuração do peritônio

$\mathrm{kg}$ - quilograma

kgf - quilograma-força

LED - Diodo emissor de luz

M1L / M2L / M3L - Marcas 1 / 2 / 3 com lâmina

M4SL / M5SL - Marca 4 / 5 sem lâmina

n. - número

$\mathrm{N}$ - Newton

S - segundos

TLam - Tempo de lâmina exposta

Vol. - Volume 


\section{Lista de Figuras}

Figura 1 - Tipos de trocartes (piramidal, cônico e esférico)............................................5

Figura 2 - Sistema de agulha de TARNAY et al., 1999 ..........................................

Figura 3 - Pontas do trocartes de TARNAY et al., 1999.........................................

Figura 4 - Sensor de mão de NG et al., 2003 .......................................................... 10

Figura 5 - Máquina projetada por PASSEROTTI et al., 2009..................................10

Figura 6 - Gráfico de força de PASSEROTTI et al., 2009.........................................11

Figura 7 - Animal anestesiado em posição supina...................................................18

Figura 8 - Identificação de cicatriz umbilical e marcação do local de incisão...........18

Figura 9A e B - Incisão Bilateral (todas as camadas da parede abdominal)..............19

Figura 10A e B - Suporte metálico (detalhe para as medidas de cada haste).............20

Figura 11 - Suporte colocado no suíno............................................................20

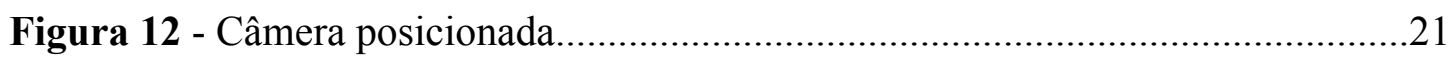

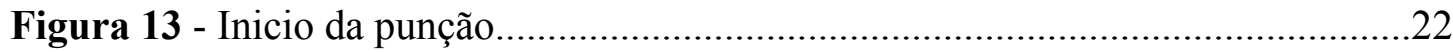

Figura 14 - Deformação imediatamente antes da perfuração.....................................22

Figura 15 - Após a perfuração com a lâmina exposta..............................................23

Figura 16 - Trocarte com lâmina já retraída............................................................23

Figura 17 - Trocartes utilizados com suas respectivas medidas..............................25 
Figura 18 - Medidas das lâminas dos trocartes. .25

Figura 19 - Técnica off-label para introdução de trocarte em laparoscopia.................26

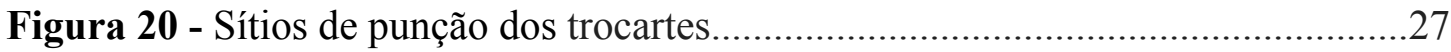

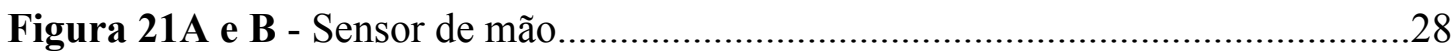

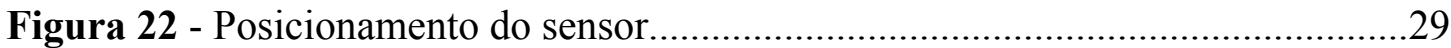

Figura 23 - Computador com Software (aquisição das curvas de força)......................30

Figura 24 - Gráfico gerado pelo computador com as informações F1 e F2.................31

Figura 25 - Primeiro momento da punção....................................................................33

Figura 26 - Barra azul vertical mostra distância aferida de deformação (Dd).............33

Figura 27 - Sequência de quadros da gravação .........................................................35

Figura 28 - Programa Final Cut Pro (avaliação das imagens)......................................36

Figura 29 - Sequência de quadros mostrando TLam..................................................37

Figura 30 - Comparação entre as ranhuras nos trocartes com lâmina.........................60

Figura 31 - Comparação entre as ranhuras nos trocartes sem lâmina.........................61 


\section{Lista de Tabelas e Gráficos}

Tabela 1 - Resumo - Deformação e forças $1^{\circ}$ e $2^{\circ}$ pico (Univariada)............................41

Tabela 2 - Resumo - Distância e tempo de lâmina exposta (Univariada)....................42

Tabela 3 - Resumo comparativo de trocartes com e sem lâmina..................................45

Tabela 4 - Correlação de Pearson entre a posição da perfuração em relação ao centro e deformação, lâmina exposta, tempo de exposição da lâmina e forças empregadas no $1^{\circ}$

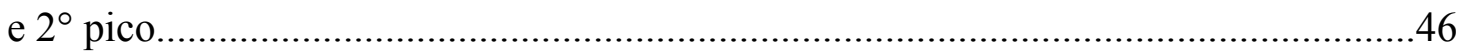

Tabela 5 - Teste de Kolmogorov-Smirnov para normalidade nos dados.....................48

Tabela 6 - Estimativas do modelo de regressão (Dd , F1 e F2).................................49

Tabela 7 - Estimativas do modelo de regressão (DLam e TLam)................................53

Tabela 8 - Resumo comparativo de trocartes (Univariada e Multivariada)..................55

Gráfico 1 - Médias das deformações por marca.........................................................42

Gráfico 2A e B - Médias das forças F1 e F2 por marca................................................43

Gráfico 3 - Média das distâncias de lâmina exposta...................................................44

Gráfico 4 - Média dos tempos de lâmina exposta.........................................................44

Gráfico 5 - Gráfico de dispersão (posição da perfuração X centro) para Dd...............46

Gráfico 6 - Gráfico de dispersão (posição da perfuração X centro) para F1 ................47

Gráfico 7 - Efeitos das demais marcas sobre a média da deformação do M1L............50

Gráfico 8 - Efeitos das demais marcas sobre a média de F1 do M1L..........................51

Gráfico 9 - Efeitos das demais marcas sobre a média de F2 do M1L..........................52

Gráfico 10 - Efeitos das demais marcas sobre a média de DLam do M1L...................53

Gráfico 11 - Efeitos das demais marcas sobre a média de TLam do M1L..................54 


\section{Resumo}

Moreno DG. Perfil biodinâmico de entrada dos trocartes em cirurgias laparoscópicas [tese]. São Paulo: Faculdade de Medicina, Universidade de São Paulo; 2018.

INTRODUÇÃO: A técnica laparoscópica tornou-se a via preferencial em grande parte dos procedimentos cirúrgicos, na tentativa de minimizar riscos e melhorar o pósoperatório. No entanto, o entusiasmo dos cirurgiões com a novas técnicas frequentemente omite uma avaliação clara das suas possíveis complicações. A laparoscopia pode oferecer alguns riscos tanto no acesso à cavidade abdominal (com trocartes sendo introduzidos muitas vezes às cegas), quanto na realização de todo o procedimento. Na literatura, poucos estudos compararam os diversos tipos de acesso e de trocartes, utilizando parâmetros objetivos e reprodutíveis do momento da punção. Nessa tese foram comparadas as diferenças no padrão biodinâmico de entrada de cinco diferentes trocartes, em modelos suínos. MÉTODOS: Foram utilizadas 11 porcas (fêmeas) e cinco tipos de trocartes (três marcas com lâmina - M1L, M2L, M3L e 2 sem lâmina - M4SL e M5SL). Todas as punções foram feitas pelo mesmo pesquisador e todos os trocartes eram novos no início do estudo. Realizada incisão bilateral a $4 \mathrm{~cm}$ da linha mediana do porco, endereçando toda a parede abdominal, desde as costelas (superiormente) até a crista ilíaca (inferiormente). Utilizado suporte metálico tracionando uma faixa mediana da parede abdominal do animal "in vivo" (posição supina). Desta forma, um espaço foi criado afastando a parede abdominal das vísceras e possibilitando a filmagem das punções. Para aferição da força na inserção foi desenvolvido um sensor de mão, ligado a um computador para aquisição dos dados. Avaliado força necessária para perfuração da aponeurose (F1) e do peritônio (F2). Utilizado uma câmera de alta resolução para captura de imagens durante a entrada dos trocartes e realizada análise comparativa da deformação da parede abdominal (Dd), do tempo (TLam) e distância (DLam) percorrida pela lâmina exposta para os cinco tipos de trocartes. Os sítios de punção foram predeterminados na linha mediana do suíno. Realizada análise uni e multivariada. RESULTADOS: Foram analisadas 180 punções, sendo 36 para cada um dos cinco modelos de trocartes. Comparando-se apenas trocartes com e sem lâminas, percebe-se maiores valores para os últimos quanto a força e deformação de parede (todos com $\mathrm{p}<0,001$ ). Comparando-se marca a marca temos: Dd (cm) - M1L $(5,92)$, M2L $(5,85)$ e M3L $(6,07)$ semelhantes entre si, menores que M4SL $(8,33)$ e M5SL $(8,15)$, semelhantes entre si; F1 e F2 (N) M1L $(5,73)$ e M2L $(6,22)$ semelhantes entre si, menores que M3L $(7,69)$, esse menor que M4SL $(8,29)$ e M5SL $(10,24)$, semelhantes entre si. DLam $(\mathrm{cm})$ - não houve diferença estatística entre os trocartes ( $p=0,197)$; TLam (s) - M1L $(0,5)$ e M2L $(0,37)$ semelhantes entre si, menores que M3L $(0,87)$. CONCLUSÕES: Trocartes com lâmina, em comparação aos sem lâmina, possuem menores forças e deformações em sua introdução. Os trocartes laminados cônicos e piramidais (M1L e M2L respectivamente) são semelhantes entre si em todos os parâmetros analisados. No entanto, esses dois tem menores deformações, força de inserção e tempo de lâmina expostos em comparação ao piramidal M3L. A análise da distância de lâmina exposta não mostrou diferença estatística entre os trocartes. Entre os trocartes sem lâmina, M5SL apresentou maiores forças de inserção e mesma deformação em comparação a M4SL.

Descritores: laparoscopia; animais; segurança; cirurgia geral; instrumentos cirúrgicos; mortalidade; prevenção de acidentes. 


\begin{abstract}
Moreno DG. Biodynamic profile of entry of trocars in laparoscopic surgeries [thesis]. Sao Paulo: "Faculdade de Medicina, Universidade de São Paulo"; 2018
\end{abstract}

INTRODUCTION: Laparoscopic surgery has become a preference for most surgeons, proving to be versatile and applicable to several surgical procedures. However, the enthusiasm of surgeons with new techniques often omits a clear evaluation of their possible complications. Comparative studies of trocars, showing objective and reproducible parameters at the time of puncture, are still lacking in the literature. The objective of this study is to evaluate the biodinamic profile of entry of 5 different trocars in laparoscopic surgeries. METHODS: Using a porcine model, we evaluated the following characteristics in 11 pigs about the insertion of 5 types of trocars ( 3 bladed and 2 blunt): 1) the force necessary to push trocar through the abdominal wall aponeurosis (F1) and through the peritoneum (F2); 2) the amount of time (in seconds) in which the blade of the trocar is exposed within the peritoneal cavity; 3 ) the amount of deformity of the abdominal wall (in $\mathrm{cm}$ ) prior to the blade of trocar cutting through the peritoneum; 4) the distance traveled by the blade within the peritoneal cavity (in $\mathrm{cm})$. All punctures were made by the same researcher. The bilateral incision was performed at $4 \mathrm{~cm}$ of the pig's median line, addressing the entire abdominal wall, from the ribs (superiorly) to the iliac crest (inferiorly). Metallic support was used by traction of a median range of the abdominal wall of the animal "in vivo" (supine position). A space was created by pushing the abdominal wall away from the viscera and allowing the punctures to be filmed. To measure the insertion force was used a mechanical device designed for this, connected to a computer for data acquisition. A high-speed camera made the acquisition of the images. Puncture sites were predetermined at the midline of the pig. RESULTS: A total of 180 punches were analyzed, of which 36 were analyzed for each of the 5 trocar models. Greater deformations forces occurred in non-bladed compared to the bladed one $(\mathrm{p}<0.001)$. Comparing the marks: $\mathrm{Dd}(\mathrm{cm})-$ M1L $(5,92)$, M2L $(5,85)$ and M3L $(6,07)$ are similar to each other, smallers than M4SL $(8,33)$ and M5SL $(8,15)$, similar to each other; F1 e F2 $(N)-$ M1L $(5,73)$ and M2L $(6,22)$ are similar to each other, smallers than M3L $(7,69)$, and this smaller than M4SL $(8,29)$ and M5SL $(10,24)$, similar to each other. DLam $(\mathrm{cm})$ - there is no diference between the all trocars $(\mathrm{p}=0,197)$; TLam $(\mathrm{s})-\operatorname{M1L}(0,5)$ and M2L $(0,37)$ are similar to each other, smallers than M3L $(0,87)$. CONCLUSIONS: The bladed trocars, compared to the non-bladed ones, have lower forces and deformations in their introduction. Conical (M1L) and pyramidal (M2L) trocars showed similar patterns of all analysed parameters. They have lower force and deformation, as well as time and distance of exposed blade in comparision of the pyramidal M3L. There is no diference in distance of exposed blade between the all bladed trocars. As for the non-bladed, the conical model (M5SL) required a greater deformation force than the pyramidal one (M4SL).

Descriptors: laparoscopy; animals: safety; general surgery; surgical instruments; mortality; accident prevention. 
1) INTRODUÇÃO 


\section{1) INTRODUÇÃO}

$\mathrm{Na}$ cirurgia geral, a primeira laparoscopia terapêutica (colecistectomia) foi realizada em 1989 na Alemanha. MÜHED et al. (1992) publicaram seus resultados, apresentando à comunidade científica a técnica revolucionária que se tornou preferência para grande parte dos cirurgiões (LEIBL et al., 1999), por se mostrar versátil e aplicável a vários procedimentos cirúrgicos (PASSEROTTI et al., 2009). De acordo com SPANER e WARNOK (1997), a crescente aceitação do procedimento foi o principal fator que motivou o aumento do número de laparoscopias abdominais.

Não é mais novidade que as cirurgias laparoscópicas, quando comparadas às ditas “a céu aberto", tenham benefícios como: incisões menores, redução das lesões teciduais, menor perda sanguínea e, consequentemente, menor dor pós-operatória e intervalo de recuperação reduzido (ISAZA et al., 2008). No entanto, o entusiasmo dos cirurgiões com as novas técnicas frequentemente omite uma avalição clara das suas possíveis complicações (LEIBL et al., 1999). HASHIZUME et al. (1997) foram os primeiros autores a demonstrarem que as complicações perioperatórias deveriam ser foco de estudo. Eles avaliaram 180 hospitais japoneses entre 1991 e 1995, identificando 3\% de taxa de complicações laparoscópicas em cirurgias abdominais, sendo as mais comuns: lesões de parede abdominal (hematomas, sangramentos e hérnias), lesões de vísceras ocas (intestino delgado principalmente) e lesões de grandes vasos. Nesse trabalho, não foram descritas complicações fatais. 
Estudos maiores foram então realizados para demonstrar quais lesões ocorriam com mais frequência nesse tipo de cirurgia. Um estudo realizado entre os anos de 1993 e 1996 demonstrou 629 comunicados de fabricantes de trocartes ao FDA (Food and Drug Administration). Quatrocentos e oito casos $(64,86 \%)$ foram relacionados a lesões de grandes vasos sanguíneos, $182(28,93 \%)$ relacionados a lesões viscerais (principalmente do intestino delgado) e $30(4,7 \%)$ hematomas da parede abdominal. Nesse estudo, houve relato de 32 mortes, sendo a maioria (81\%) relacionada a lesões de grandes vasos (BHOYRUL et al., 2001). Em outro estudo semelhante, com dados do FDA, entre 1997 e 2002, houve relato de 31 acidentes de punções fatais (2,23\% do total de lesões), além de 1353 não fatais (FULLER et al., 2005). À semelhança do outro estudo, a maior parte das lesões fatais também estava associada a lesões vasculares e repetiu-se o padrão de órgãos afetados nas lesões não fatais.

Estudos com crianças mostraram resultados semelhantes. ESPOSITO et al. (1997) fizeram uma pesquisa com 430 laparoscopias na população pediátrica (média de idade de cinco anos), identificando oito complicações (incluindo duas perfurações de órgãos intrabdominais, um pneumotórax, uma lesão vascular e quatro lesões de parede abdominal). Outro trabalho, analisando 806 laparoscopias urológicas em crianças, mostrou taxa de complicação global de $2 \%$, sendo a grande maioria $(1,6 \%)$ relacionada ao acesso (PASSEROTTI et al., 2008). Observou-se que, apesar das baixas taxas de complicações nos procedimentos laparoscópicos, quando elas ocorrem, há um alto potencial de graves consequências aos pacientes (sete pacientes necessitaram de nova intervenção cirúrgica ou endoscópica em decorrência de complicações do primeiro procedimento). 
Tornou-se claro aos cirurgiões que, quando não identificadas precocemente e adequadamente tratadas, tais complicações poderiam levar a altas taxas de morbimortalidade, mostrado por SCHAFER et al. (2001) em seu estudo com laparoscopias em hospitais suíços. Alguns autores, então, começaram a estudar os principais momentos críticos de risco das lesões: primeiramente, durante o acesso cirúrgico, através da inserção da agulha de Veress (SCHAFER et al., 2001) e/ou do primeiro trocarte (MONTES et al., 2015) e secundariamente, no decorrer da própria cirurgia, por lesão de vasos ou órgãos (CORSON et al., 2001; PASSEROTTI et al., 2008).

HASHIZUME et al. (1997) identificaram, em seu estudo japonês, que até 37,6\% das lesões deram-se durante a introdução da agulha de Veress ou do primeiro trocarte. Já MONTES et al. (2015) estudaram complicações apenas em laparoscopias urológicas, demonstrando que, apesar de a taxa global diferir de acordo com o tipo de cirurgia (23\% na nefrectomia parcial e $6,7 \%$ na prostatectomia), a porcentagem de lesões na inserção dos trocartes mantinha-se igual entre os grupos. Demonstra-se que há uma constância de lesões por trocartes, independentemente do tipo de cirurgia e especialidade estudada.

Quanto às técnicas de acesso laparoscópico, há três que se destacam na prática cirúrgica. O modelo de Hasson (HASSON et al., 1984) foi descrito com colocação do trocarte sob visão direta na cavidade peritoneal. Em contrapartida, HILGERS et al. (1992) descreveram a colocação do trocarte, introduzido na cavidade "às cegas" sem a produção do pneumoperitônio. Existe ainda a técnica descrita por CORCIONE et al. (2007), na qual a agulha de Veress é utilizada para insuflar o abdômen com posterior introdução dos trocartes com sistemas dilatadores axiais. $\mathrm{O}$ principal estudo comparativo das técnicas foi realizado por AHMAD et al. (2008). Os autores avaliaram 
7389 laparoscopias em revisão sistemática que inclui pacientes adultos e crianças de ambos os sexos, submetidos a todos os tipos de laparoscopias abdominais. Eles concluiram que não havia técnica superior a outra quando comparadas suas complicações. AHMAD et al. (2012) fizeram uma nova revisão sistemática, incluindo 28 estudos randomizados, somando 4860 laparoscopias, na qual mantiveram sua conclusão de não superioridade de técnicas quando avaliadas complicações vasculares ou de vísceras.

Outro fator a ser considerado é a ampla variedade de marcas e modelos de trocartes presentes no mercado, fazendo com que a escolha se deva a fatores como facilidade de uso, custo e preferência do cirurgião (Figura 1).
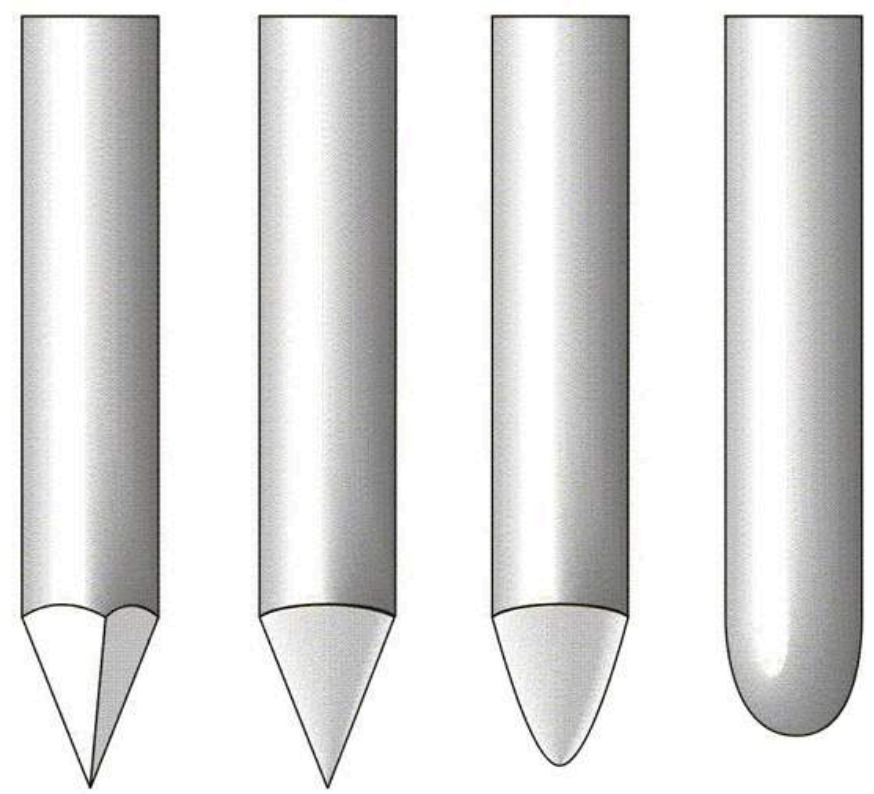

Figura 1 - Tipos de trocartes: Piramidal, cônico laminado, cônico não laminado e esférico (acesso aberto de Hasson) 
Os trocartes descartáveis com lâmina retrátil foram introduzidos em 1984 (BYRON et al. 1989). Desde essa data, houve interesse na comparação entre trocartes permanentes e descartáveis (laminados ou não). CORSON et al. (2001) revisaram 135 complicações em laparoscopias gastrointestinais e ginecológicas, envolvendo trocartes de ambos os tipos. Não houve distinção entre número de complicações quando a técnica de punção era o objeto de comparação. Entretanto, os autores relataram $12 \%$ de complicações associadas a trocarte permanente metálico e nenhuma relacionada a trocarte descartável. Já ANTONIOU et al. (2013), em sua metanálise de oito trabalhos randomizados, estudaram 720 cirurgias entre os anos de 2000 e 2007, sendo 289 apenas com uso de trocartes sem lâmina, 303 com lâmina e 128 com uso concomitante dos dois trocartes no mesmo paciente. Resultados mostraram morbidade total de $3 \%$ associada a trocartes sem lâmina em comparação a $10 \%$ dos com lâmina. Os autores destacam o sangramento da parede abdominal como a principal complicação descrita.

Outros estudos também levaram em consideração dados compilados pelo órgão americano FDA (ESPOSITO et al., 1997; VILOS et al., 2007; VILOS et al., 2017). Os autores descrevem complicações com ambos os trocartes, sem distinção estatística entre eles. VILOS et al. (2007) publicaram uma metanálise de todos os trabalhos relacionados com o tema até setembro de 2005, mais tarde revisado em 2017 com a mesma metodologia (VILOS et al., 2017). Neles foram avaliadas técnicas de punção, tipos de trocartes (descartáveis e permanentes) e suas complicações. Em ambos os trabalhos, os autores concluiram que não há recomendação formal para uso de um tipo específico de trocarte, já que as taxas de complicações entre trocartes não variou de forma significativa. 
Alguns autores publicaram seus estudos sobre parâmetros aferidos na entrada dos trocartes durante a punção abdominal. BÖHM et al. (1998) e TARNAY et al. (1999) investigaram a força para introdução de trocartes em modelos suínos quando em pneumoperitôneo, indiretamente medida por uma agulha introduzida com um sensor, que aferia a pressão intra-abdominal (Figura 2). Esses trabalhos mostraram que diferentes tipos de trocartes (no caso cônicos e piramidais) necessitavam de diferentes forças com riscos diferentes de complicações.

\section{Hollow Needle}

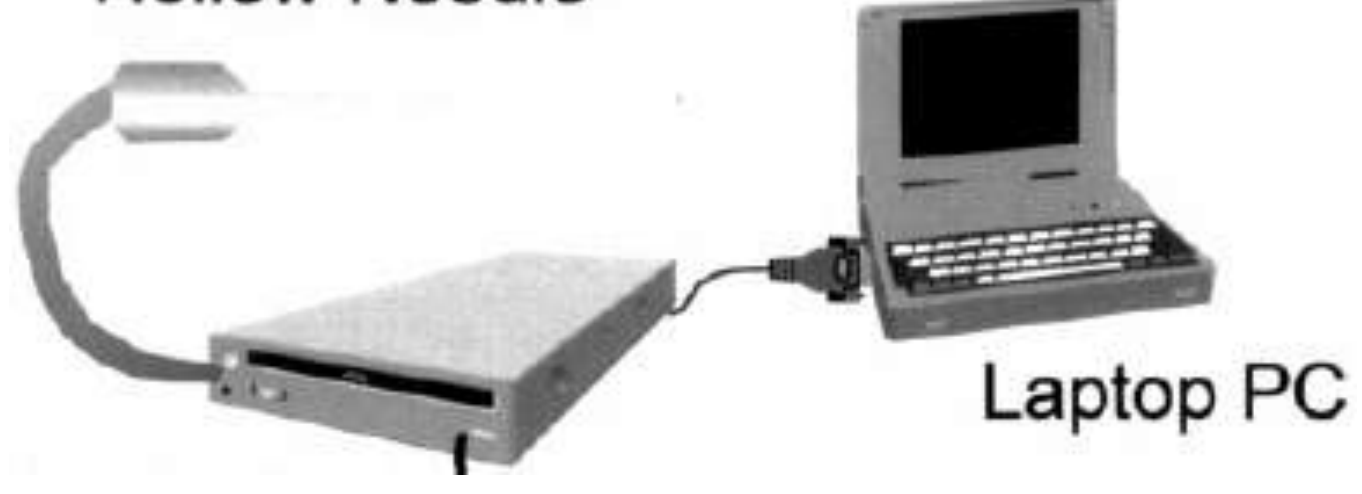

Figura 2 - Sistema de agulha (hollow needle) acoplado a computador (Laptop PC) que captava os dados, usada por TARNAY et al. 1999

BÖHM et al. (1998) tinham como objetivo definir um desenho ideal da ponta do trocarte, baseado na força de introdução deste e na falha (defeito adquirido) na parede abdominal após a punção. Eles estudaram o desenho de 19 tipos de trocartes (seis permanentes, seis descartáveis e seis que sua própria equipe desenhou) e os dividiu em grupos: cônico ou piramidal, com subdivisões entre laminados e não laminados. Uma limitação do estudo foi o número de punções (apenas quatro com cada marca). Como 
resultados, obtiveram: Trocartes cônicos, independentemente de serem laminados ou não, necessitaram de cerca de duas vezes mais força que os piramidais (médias de força de $54,3 \mathrm{~N}$ versus $29,4 \mathrm{~N}$, respectivamente). Em contrapartida, os trocartes piramidais causavam maior falha na parede abdominal do que os cônicos $(10 \mathrm{~mm}$ versus $8,5 \mathrm{~mm}$, respectivamente).

Os autores concluiram o trabalho afirmando ser muito difícil determinar um modelo ideal já que cônicos possuem maior força empregada (com maior risco de lesão de órgãos), mas têm menores orifícios de entrada (com menor risco de complicações de parede abdominal).

TARNAY et al. (1999) estudaram seis marcas de trocartes (Figura 3), com diferentes desenhos de pontas e comparou suas forças de entrada. Além do sistema de aferição indireto pelo pneumoperitôneo, os autores relatam uma tentativa de aferição direta por meio de dispositivo localizado entre a mão do examinador e o trocarte. Além disso, destacam que precisaram abandonar essa última aferição por quebra mecânica do sistema, logo na sexta punção. A conclusão foi que os trocartes piramidais têm em média duas vezes menos força de entrada que os cônicos $(13,48$ versus 31,91 libras/polegada ${ }^{2}$, respectivamente). Não há clareza quanto ao número de punções realizadas com cada trocarte. CORSON et al. (1989) já haviam publicado seu estudo, de mesmo desenho que os autores acima, chegando a resultados semelhantes: trocartes cônicos necessitam do dobro de força de introdução em comparação aos piramidais. 

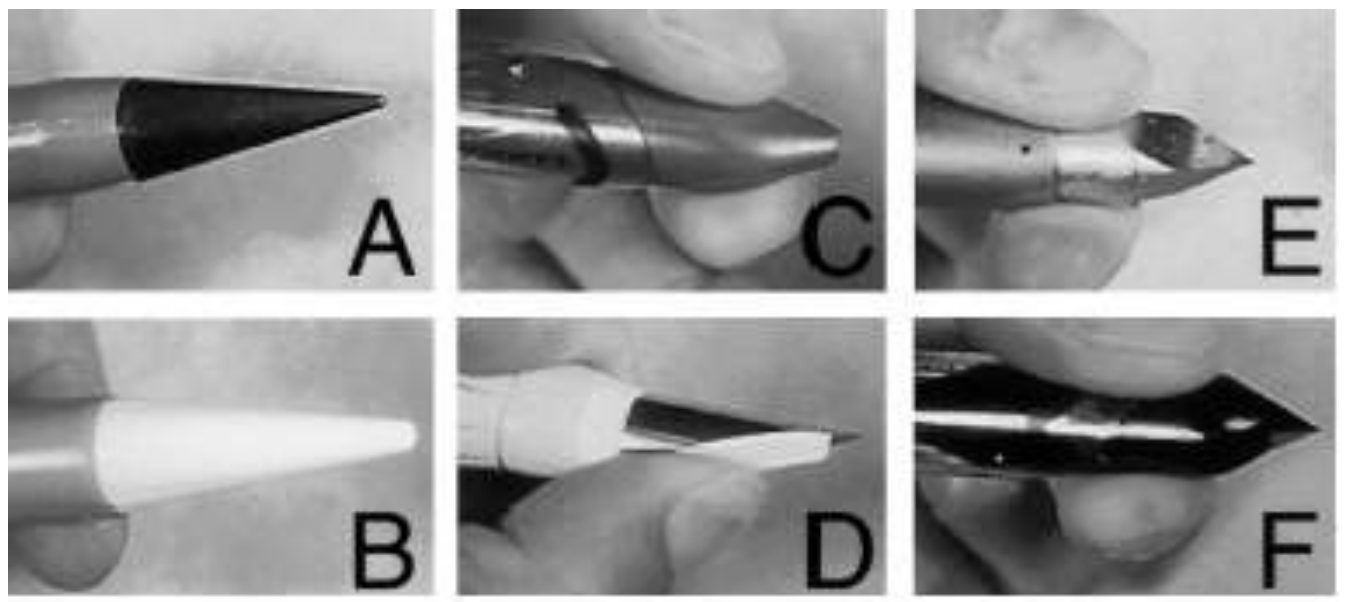

Figura 3 - Pontas dos trocartes utilizados por TARNAY et al. 1999

NG et al. (2003) publicaram um novo modelo de aferição da força empregada nas punções de trocarte. Eles desenvolveram células piezoelétricas que se deformavam ao serem comprimidas. Com isso, um sensor de palma de mão (Figura 4) era colocado entre esta e o trocarte para aferição e sua informação enviada a um computador. Foram realizadas três punções (um trocarte com diâmetro de $10 \mathrm{~mm}$ e dois de $5 \mathrm{~mm}$ ) em cada um dos oito pacientes (humanos). Os autores comparam a força de introdução entre trocartes de $5 \mathrm{~mm}$ e $10 \mathrm{~mm}$, concluindo que nesses últimos havia emprego de menor força $\left(4,7\right.$ versus 6,2 libras/polegada $\left.{ }^{2}\right)$. Não foram comparados tipos de trocartes nesse trabalho, apenas tamanhos de diâmetro. 




Figura 4 - Foto do sensor de mão desenvolvido por NG et al. (2003)

Em estudo pioneiro, PASSEROTTI et al. (2009) iniciaram uma linha de pesquisa em que foram estudados parâmetros biodinâmicos de entrada de trocartes e agulhas de punção em modelos animais. Através de um computador e uma máquina projetada para inserir trocartes (Figura 5), demonstrou-se que é possível medir objetivamente a força necessária na introdução, tanto destes quanto das agulhas de acesso.

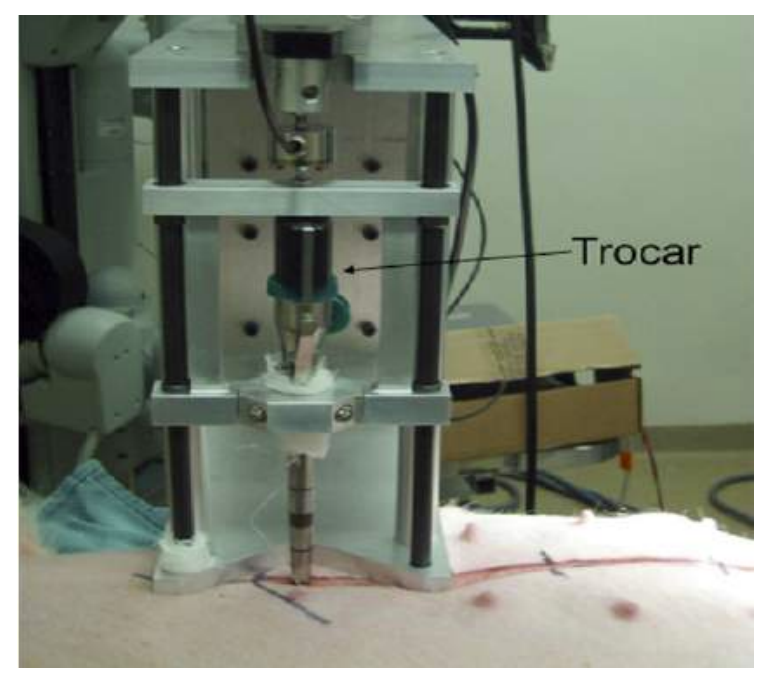

Figura 5 - Máquina projetada por PASSEROTTI et al. (2009) para inserir e medir a força de entrada de trocartes 
Mostrou-se também que, quando a força é avaliada, existe um perfil gráfico característico padrão, independente do trocarte quando na passagem do instrumento pela fáscia e peritônio. Esse gráfico possui dois picos de força (penetração na aponeurose e depois no peritônio), sendo reprodutível (Figura 6).

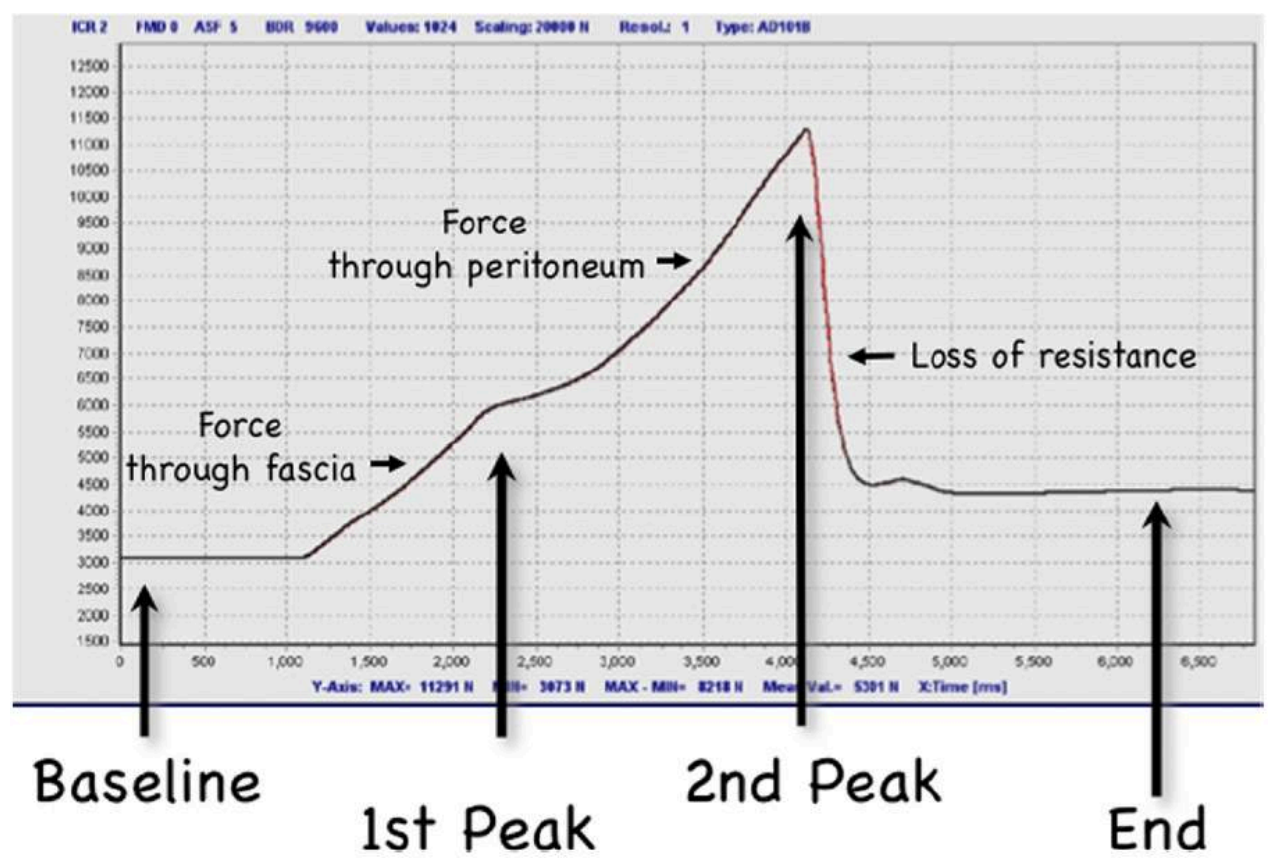

Figura 6 - Gráfico de PASSEROTTI et al. (2009), mostrando padrão da curva de força de entrada do trocarte com primeiro pico (1st peak) no momento da perfuração do aponeurose e segundo pico (2nd peak) no momento da perfuração do peritônio.

Além disso, esse estudo também analisou outras características de inserção do trocarte, como a deformação da parede abdominal, a perda de resistência e a exposição 
da lâmina e da agulha de Veress após sua introdução na cavidade peritoneal, parâmetros aqui chamados de biodinâmicos. PASSEROTTI et al. (2009) demonstraram para o sistema de agulha sem bainhas protetoras menores forças $(8,4 \mathrm{~N}$ versus $44,4 \mathrm{~N}$ em comparação às agulhas com proteção), menor deformação da parede $(1,8 \mathrm{~cm}$ versus 3,6 $\mathrm{cm})$, além de menor tempo de exposição de lâmina ( $0,05 \mathrm{~s}$ versus $0,17 \mathrm{~s})$.

Quanto aos trocartes, observou-se que os não retráteis (sem lâmina) tinham valores maiores de deformação da parede abdominal $(5,1 \mathrm{~cm}$ versus $2,9 \mathrm{~cm})$, requisitando maior força de inserção $(118 \mathrm{~N}$ vesus $81 \mathrm{~N})$, além de mais rápida perda de resistência $(55 \mathrm{~N}$ versus $35 \mathrm{~N}$ ) após atravessar a fáscia e o peritônio, em comparação aos trocartes com lâminas retráteis. Apesar da possível maior segurança dos aparelhos laminados (menor força e deformação), o autor destaca, em sua discussão, que os valores de tempo médio (1 s) e distância de lâmina exposta (até $5 \mathrm{~cm}$ ) na cavidade intraperitoneal não são desprezíveis, não os isentando de complicações.

Apesar de inovador, o estudo supracitado apresentou um importante fator limitante: o movimento de introdução na cavidade foi realizado por uma máquina, com velocidade constante e com pressão contínua. Além disso, nas cirurgias laparoscópicas, as punções são realizadas com movimento rotacional. Dessa forma, uma situação mais próxima da real não pode ser testada. Nessa tese de doutorado prossegue-se a linha de stapesquisa de PASSEROTTI et al., 2009 avaliando outros aspectos dos trocartes laminados e não laminados (ponta cônica ou piramidal, tamanho de lâmina e ranhuras dos trocartes) e seus parâmetros de entrada na parede abdominal, agora com um humano realizando todo movimento, além de um sensor de força entre a mão do cirurgião e o trocarte. 
A avaliação objetiva dos diferentes tipos de trocartes e das diferentes técnicas de inserção pode ser útil no entendimento dos pontos de risco de uma cirurgia laparoscópica. Como consequência a isso, riscos inerentes ao procedimento poderão ser minimizados, além de identificação de um melhor desenho de trocarte que facilite sua introdução. Mais que isso, modelos de treinamento de novos cirurgiões podem ser desenhados a partir de pesquisas como essa. 
2) Objetivo 


\section{2) OBJETIVO}

Comparar diferenças no padrão biodinâmico de entrada de cinco trocartes diferentes em modelos suínos. 
3) Métodos 


\section{3) MÉTODOS}

\section{1) Preparo do experimento}

Após aprovação do Comitê de ética da FMUSP (protocolo de pesquisa 036/11), foram utilizadas 11 porcas (fêmeas), todas da mesma raça e com peso semelhantes, entre 20 - 22 quilos. Todos os animais foram comprados da empresa Granja RG, que os trazem de Granjas Multiplicadoras com certificado do Ministério da Agricultura do Brasil. Todo o experimento foi realizado no CEPEC (Centro de Ensino e Pesquisa em Cirurgia) da FMUSP. Todas as porcas foram anestesiadas da mesma forma, com indução anestésica através de uma injeção intramuscular de telazol (4.4 a 6.6 mg/kg), xylazina $(1.1$ a $2.2 \mathrm{mg} / \mathrm{kg})$ e atropina $(0.04 \mathrm{mg} / \mathrm{kg})$, intubação oro traqueal e manutenção da sedação com isoflurano ( $1 \%$ a $4 \%)$, administrado, através de tubo endotraqueal, além de oxigênio 1 a 2 L/minuto (Figura 7). Não foi utilizado relaxante muscular na anestesia dos animais (LEARY et al. 2013). 


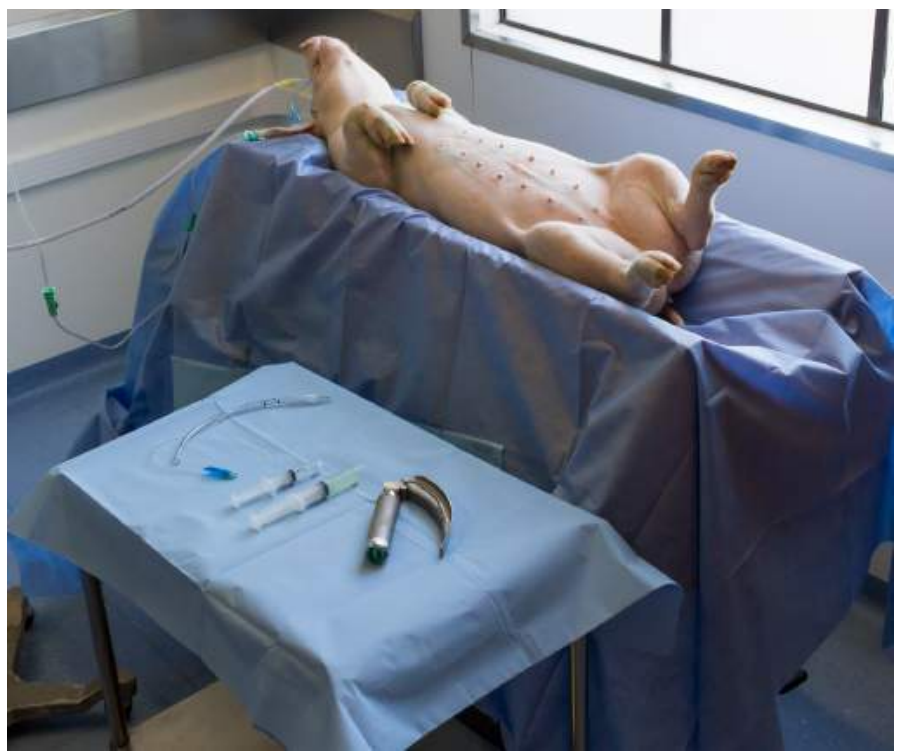

Figura 7 - Animal anestesiado em posição supina

Utilizando o mesmo modelo de estudo de PASSEROTTI et al. (2009), as porcas foram então colocadas em posição supina, sendo identificada cicatriz umbilical (ponto ZERO ou centro) e realizada marcação bilateral com caneta (Figura 8).

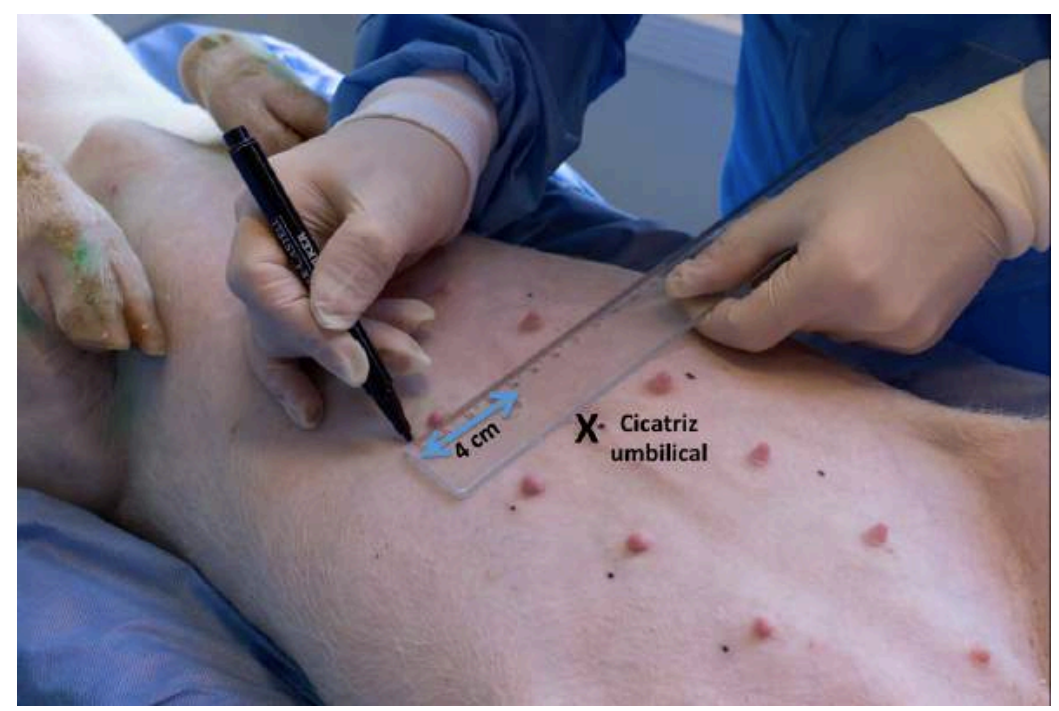

Figura 8 - Identificação de cicatriz umbilical (X) e marcação do local de incisão 
Foi realizada incisão bilateral a $4 \mathrm{~cm}$ da linha mediana da porca, incluindo todas as camadas da parede abdominal, desde as costelas (superiormente) até a crista ilíaca inferiormente (Figura 9A e B).

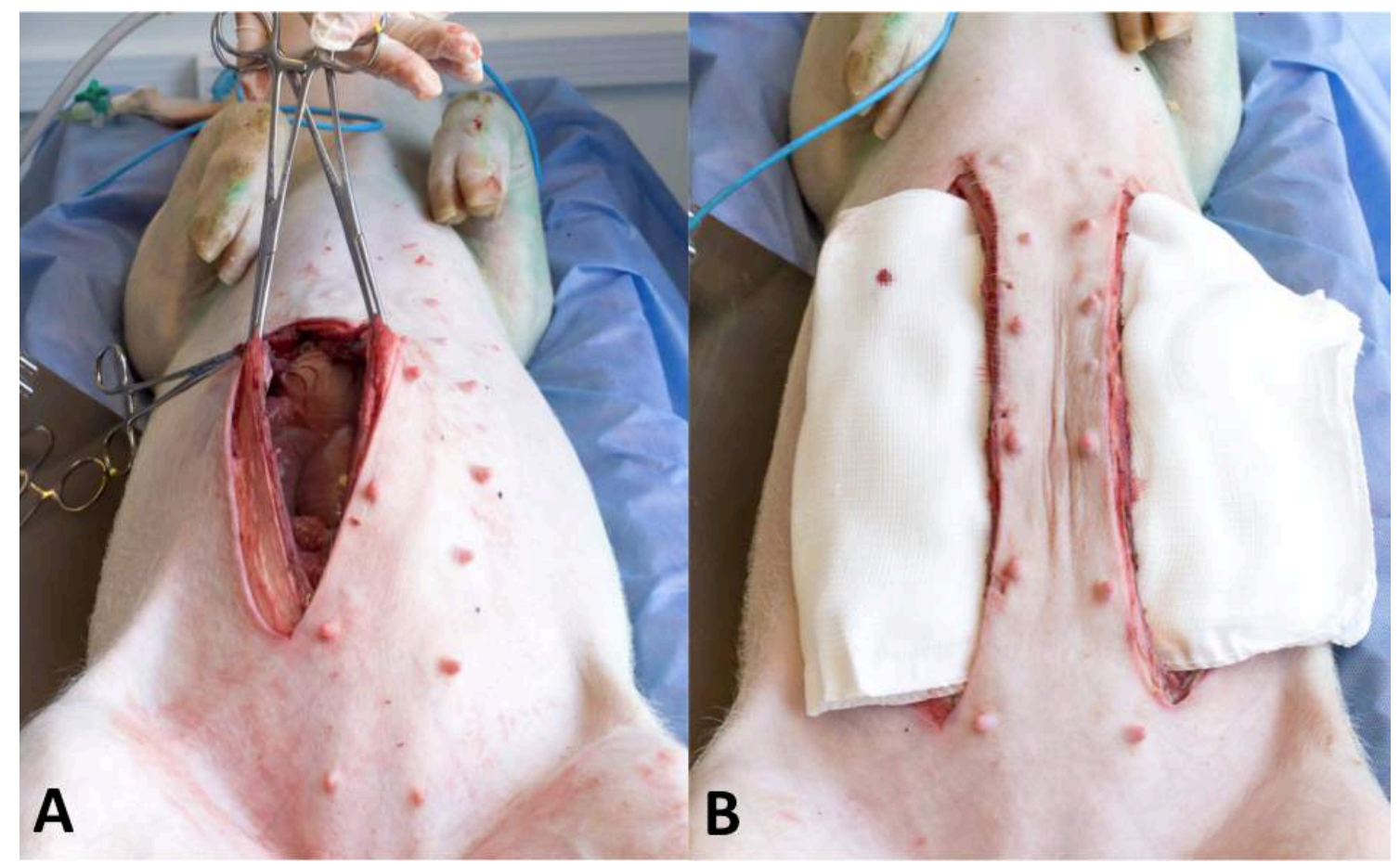

Figura 9A e B - Incisão bilateral (todas as camadas da parede abdominal)

Um suporte metálico foi criado a partir de canos de cobre soldados e utilizado para tracionar uma faixa mediana da parede abdominal do porco. Todo o experimento foi realizado com os animais vivos. O mesmo suporte foi utilizado em todos os experimentos e suas medidas de hastes estão descritas na Figura 10A e B. 


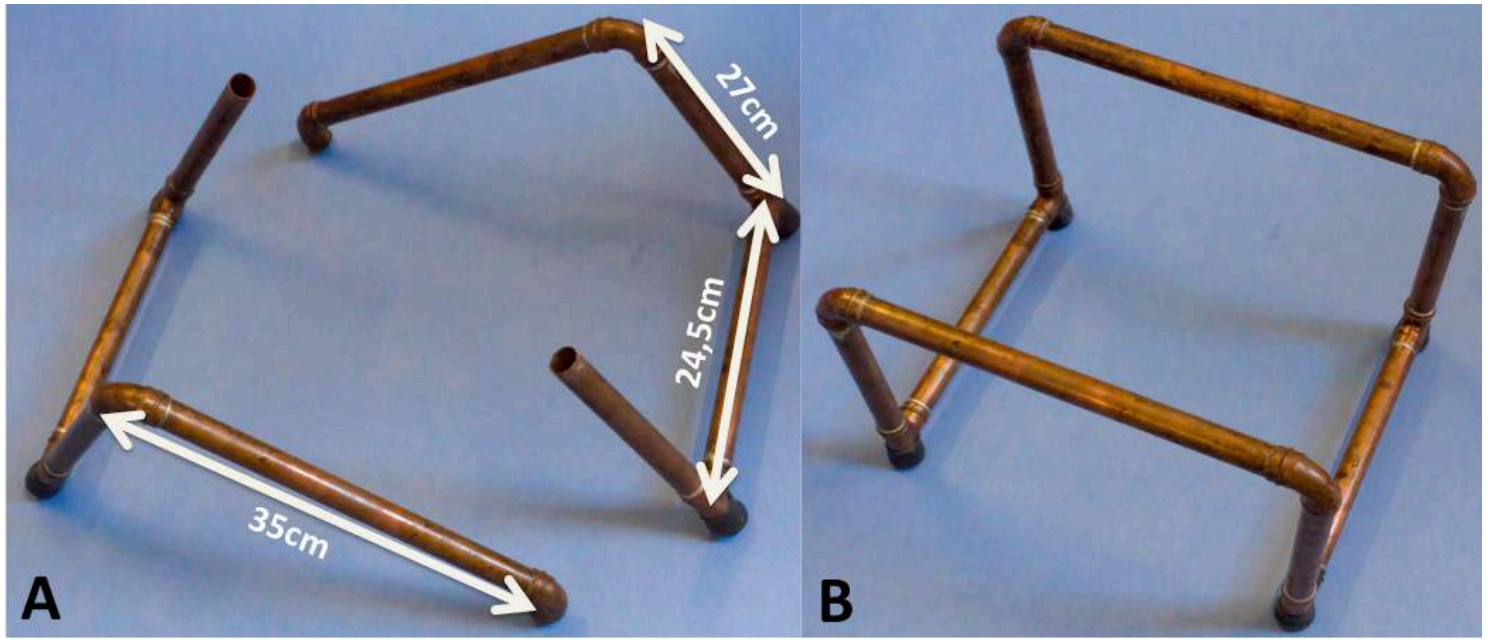

Figura 10A e B - Suporte metálico (medidas de cada haste)

Dessa forma, uma distância foi criada entre a parede abdominal e as vísceras do animal, possibilitando a filmagem de todo o movimento do trocarte (Figura 11).

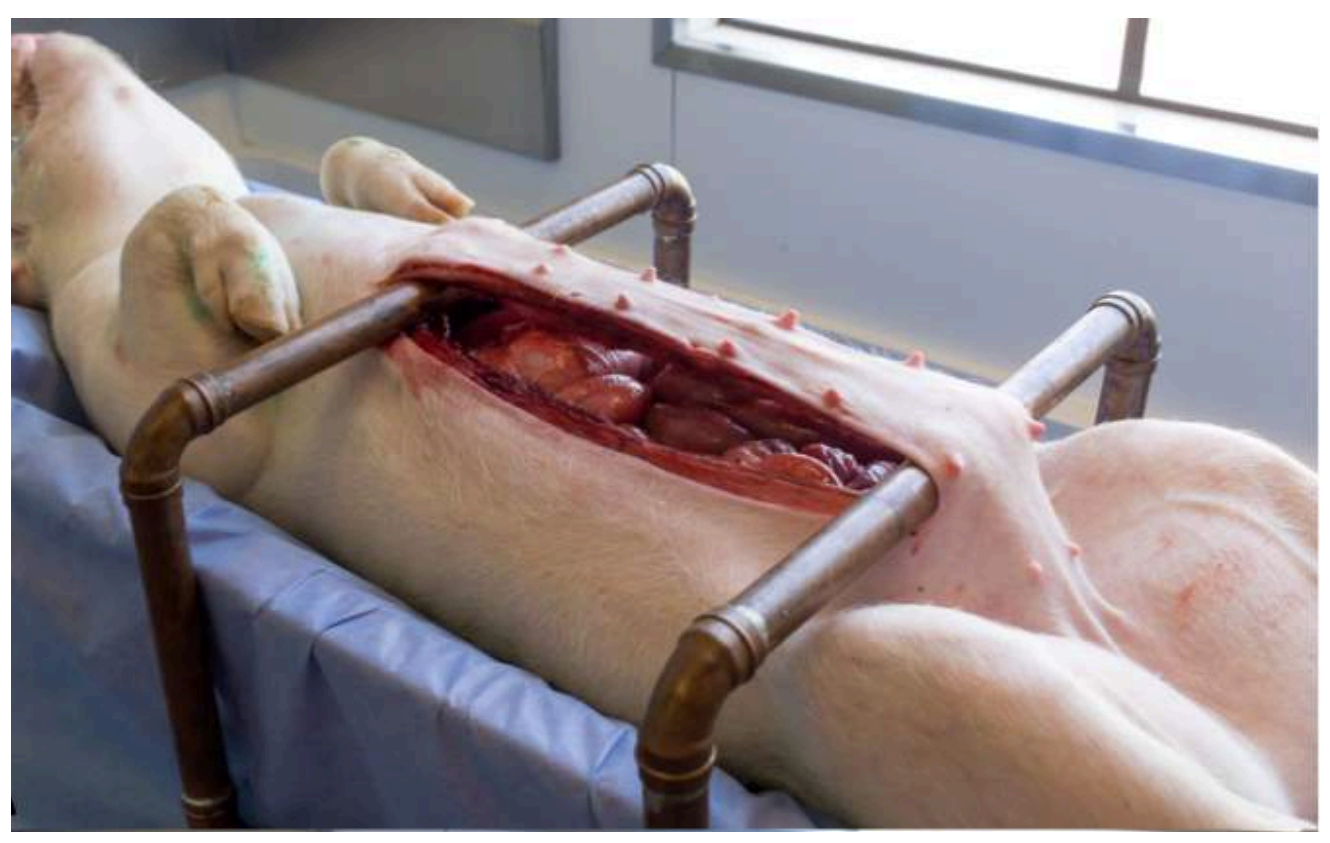

Figura 11 - Suporte colocado no suíno 
A câmera para aquisição das imagens foi sempre posicionada a $30 \mathrm{~cm}$ da linha mediana da porca e a $6 \mathrm{~cm}$ de altura em relação a posição da mesa operatória. As punções foram filmadas em câmera lenta por aparelho de alta definição, que possui capacidade de até 250 quadros por segundo e captura de imagens coloridas. Tal câmera foi colocada em tripé, paralela à parede abdominal do suíno (Figura 12)



Figura 12 - Câmera posicionada

As medidas das "pernas" do tripé e da distância câmera-linha mediana da porca foram padronizadas e repetidas em todas as punções. Todas elas foram gravadas e armazenadas em computador. Foi então analisada a deformação de toda parede abdominal (Figura 13 e 14), além das medidas do tempo e da distância percorrida pela superfície cortante do trocar - lâmina exposta (Figuras 15 e 16). Para garantir o sincronismo entre as gravações feitas pela câmera de alta velocidade e pelo programa de aquisição das forças do dispositivo mecânico, um LED (diodo emissor de luz), conectado ao equipamento eletrônico, foi colocado no campo visual da câmera. 
Primeiramente, a câmera de alta velocidade era acionada. O LED, aceso, indicava o início do movimento e da gravação de forças.

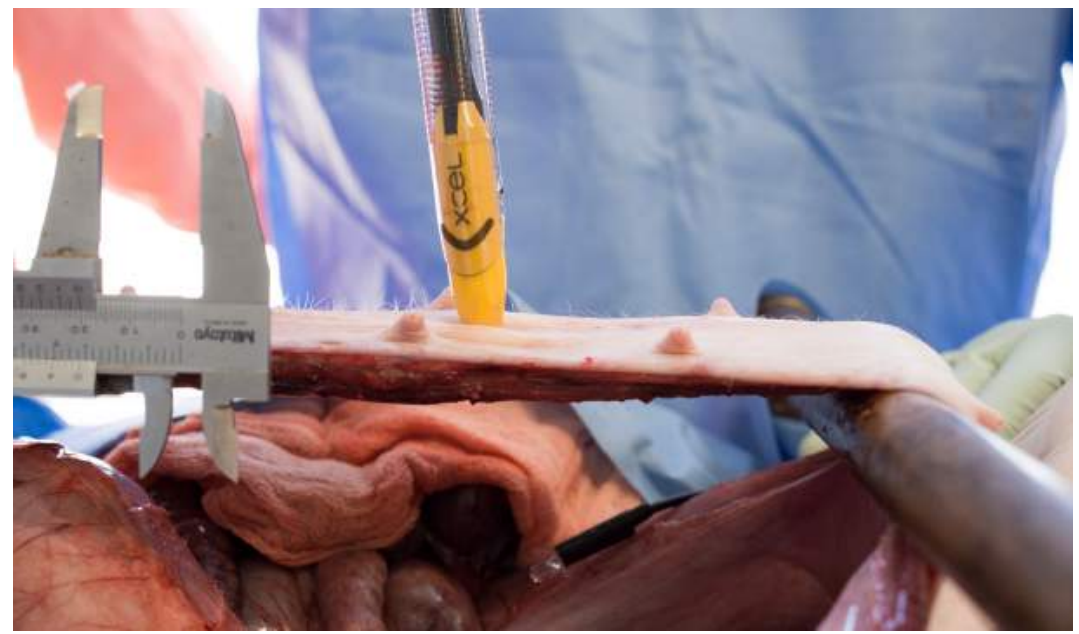

Figura 13- Inicio da punção. Detalhe para o LED apagado, mostrando movimento ainda não iniciado

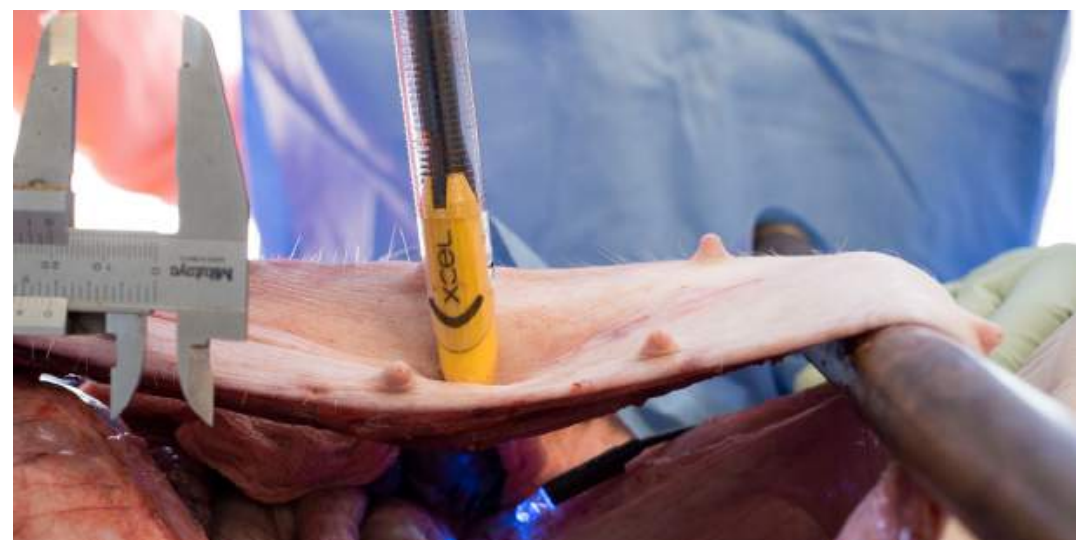

Figura 14 - Deformação imediatamente antes da perfuração. Detalhe para o LED aceso, mostrando movimento em curso 


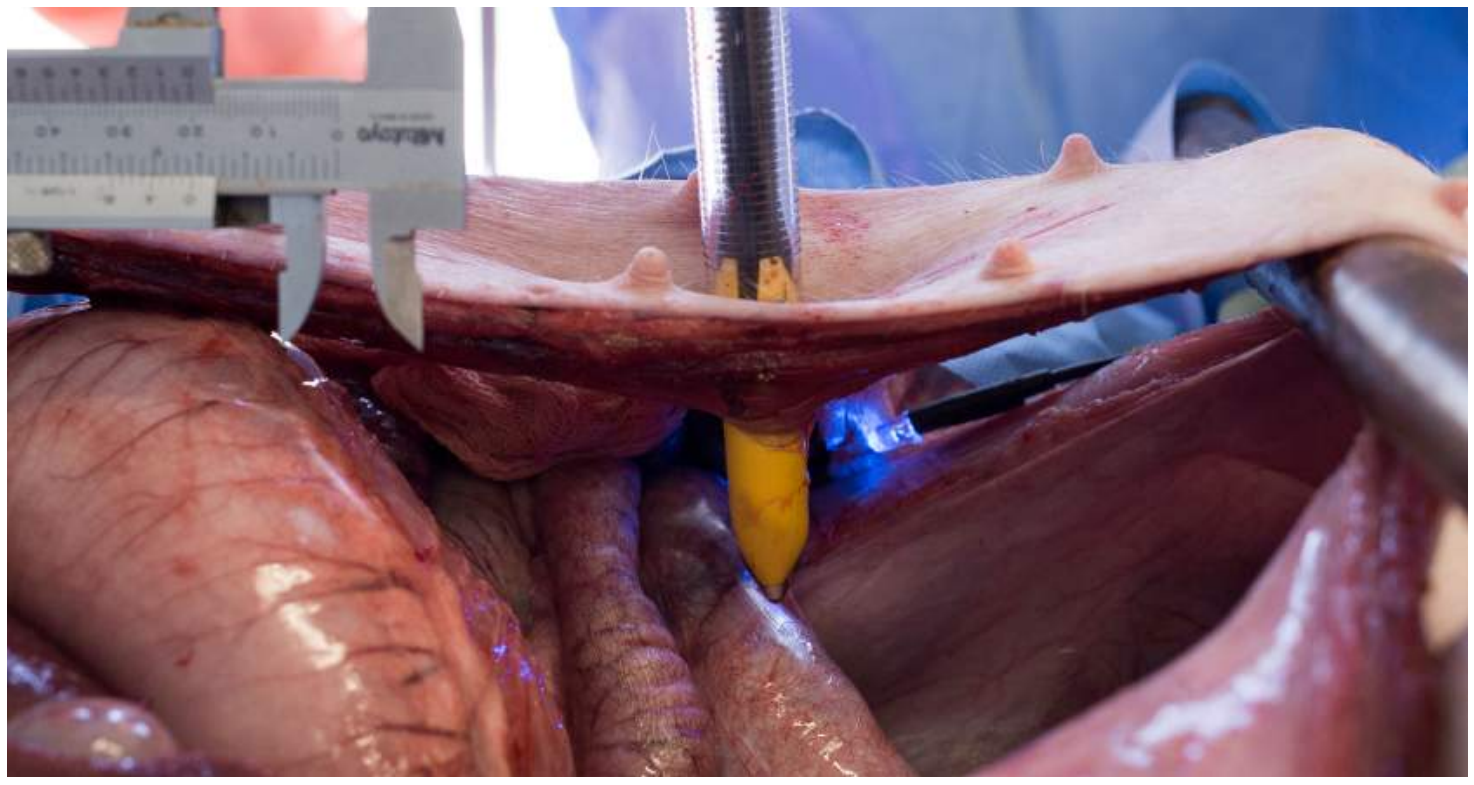

Figura 15 - Após a perfuração com a lâmina exposta

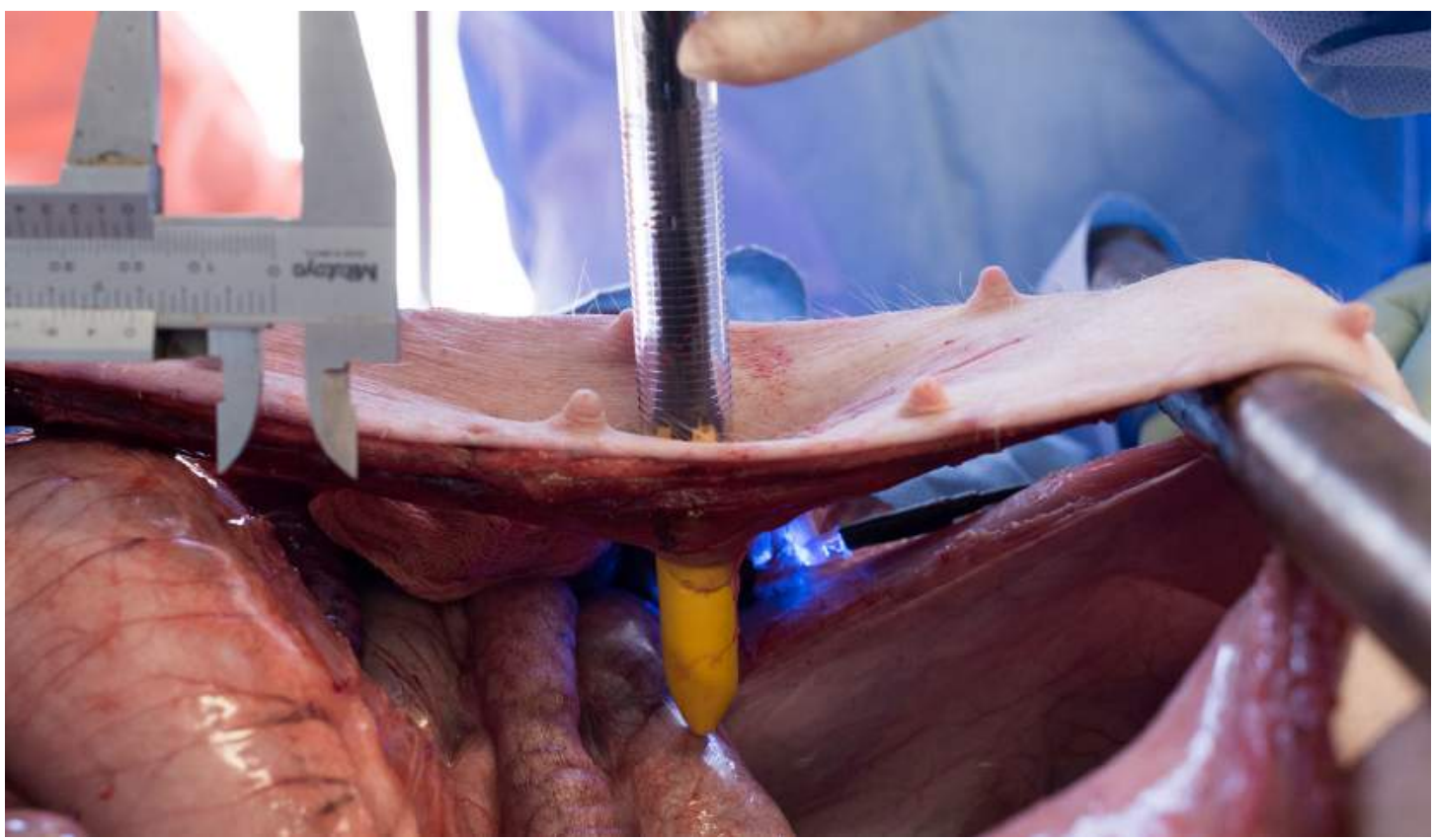

Figura 16 - Trocarte com lâmina já retraída 
3.2) Escolha dos trocartes

Foram utilizados cinco tipos de trocartes diferentes, das principais marcas existentes no mercado brasileiro. Todos os trocartes eram novos no início do trabalho, com diâmetro de $12 \mathrm{~mm}$ (segundo o fabricante), sendo suas demais medidas representadas na Figuras 17 e 18. As marcas dos trocartes estão no setor "Apêndice", padronizados da seguinte forma:

M1L - Marca 1: Trocarte cônico com lâmina

M2L - Marca 2: Trocarte piramidal com lâmina

M3L - Marca 3: Trocarte piramidal com lâmina

M4SL - Marca 4: Trocarte piramidal sem lâmina

M5SL - Marca 5: Trocarte cônico sem lâmina 


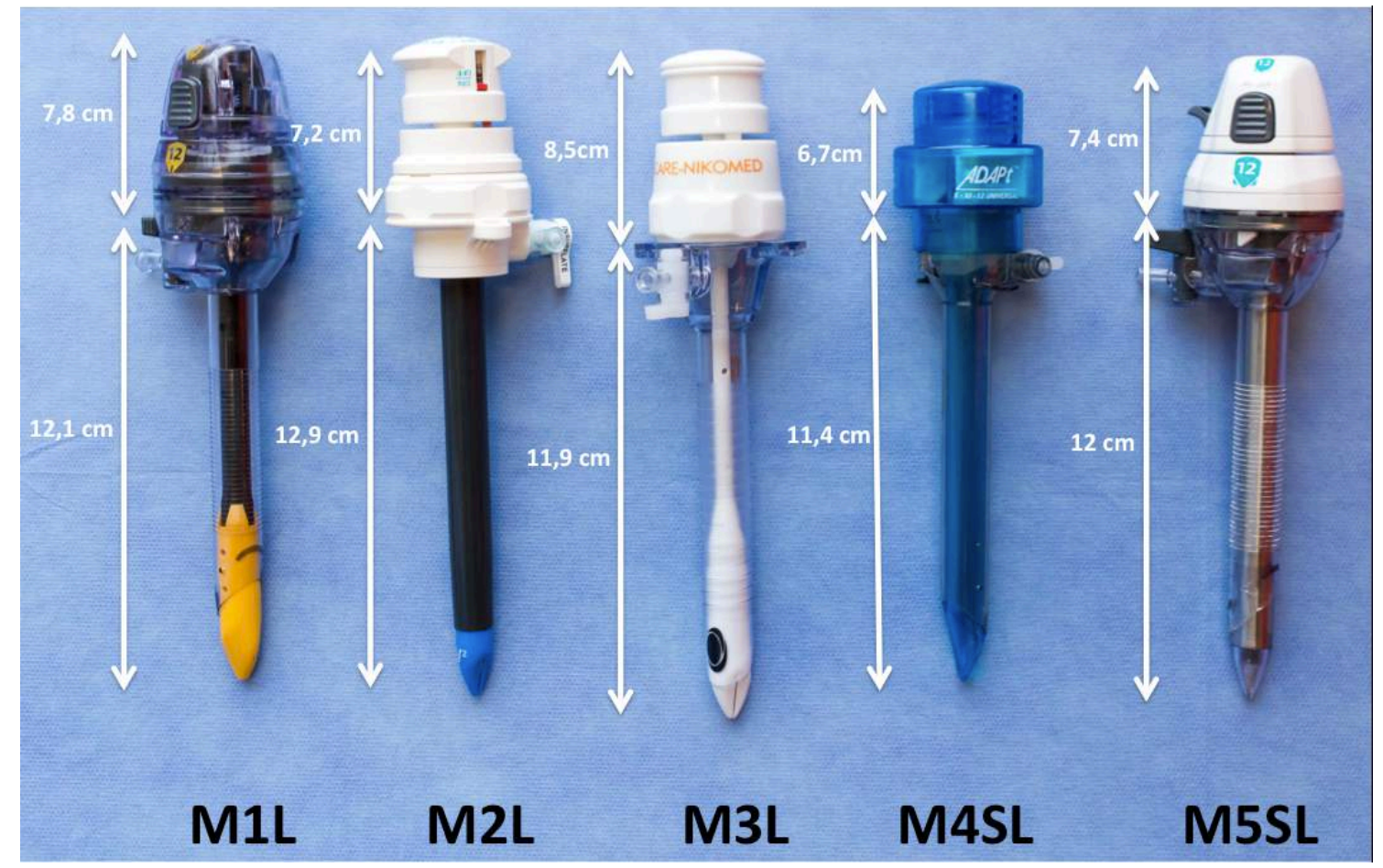

Figura 17 - Trocartes utilizados com suas respectivas medidas



Figura 18 - Detalhe para o tamanho das lâminas de cada trocarte 
3.3) Sítios de punção dos trocartes

Todas as punções foram feitas pelo mesmo pesquisador, de forma manual, com rotação e pressão contínua (Figura 19), sobre a linha média abdominal e a um ângulo de 90 graus com a superfície abdominal do suíno.
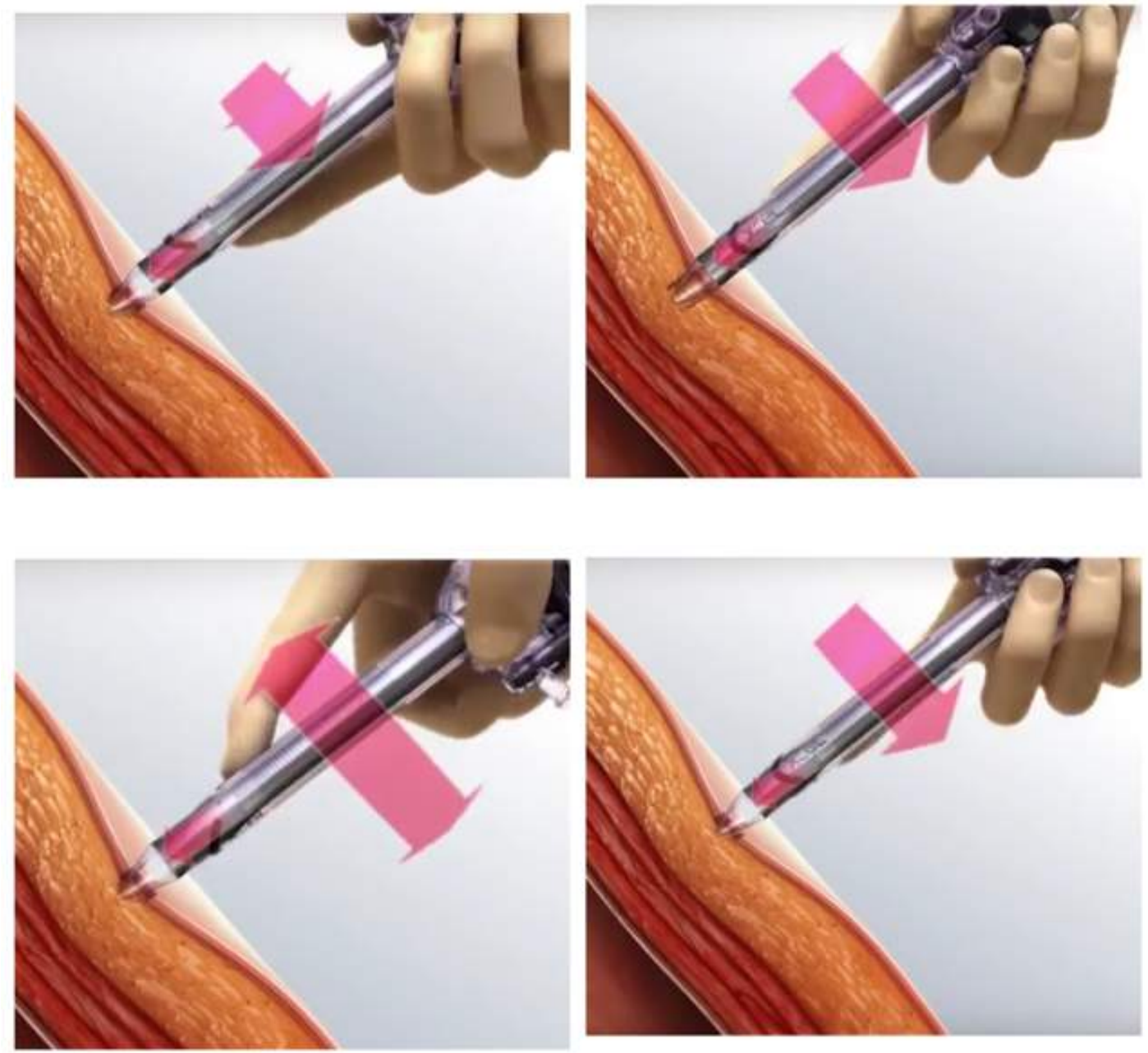

Figura 19. Técnica "off-label” para introdução de trocarte em laparoscopia 
Após incisão apenas da pele com lâmina de bisturi, foram feitas punções com distâncias de $1 \mathrm{~cm}$ entre si (Figura 20), iniciando-se a $1 \mathrm{~cm}$ da cicatriz umbilical centro, marcado na figura com um "X". Todas as perfurações de uma mesma marca foram feitas de forma sequencial, sucessivamente a cada $1 \mathrm{~cm}$, podendo, no máximo, ter distância de $10 \mathrm{~cm}$ da cicatriz umbilical.

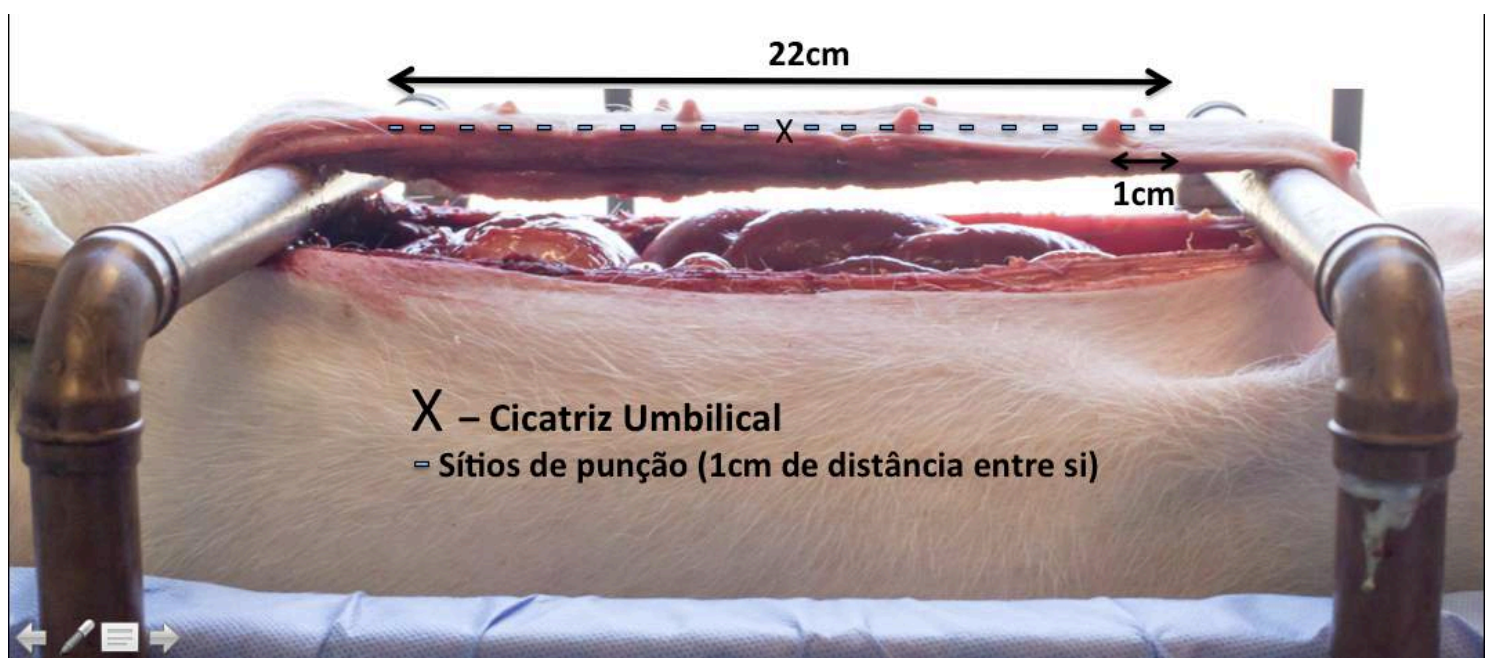

Figura 20. Sítios de punção dos trocartes, representados pelos traços. Cicatriz umbilical marcada com um "X". 
3.4) Aquisição dos dados

Para medição da força de inserção do trocarte na parede abdominal do porco foi utilizado um dispositivo mecânico instrumentalizado, especialmente desenvolvido para tal finalidade, a que definimos como "sensor de mão" (Figura 21A e B).
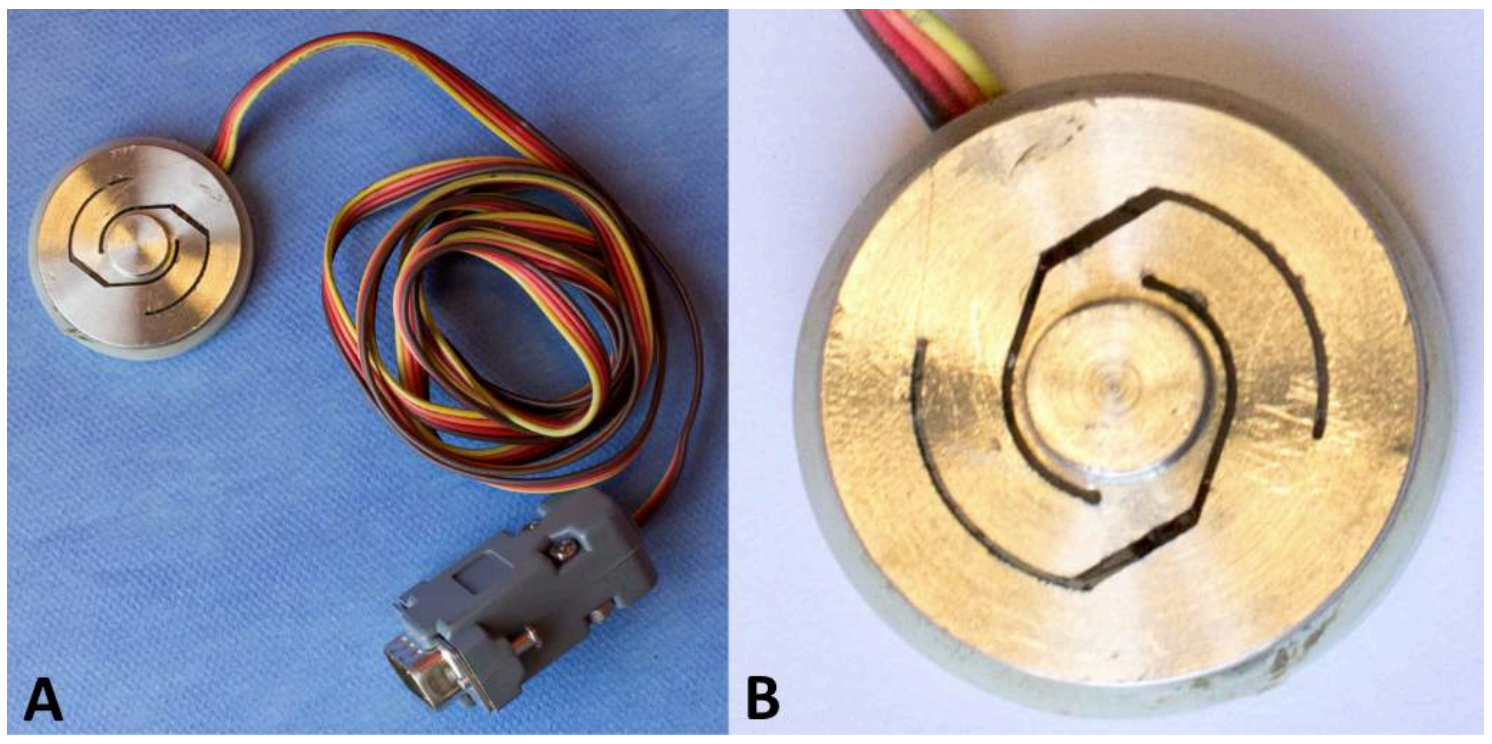

Figura 21A e B - Sensor de mão (inteiro e em detalhe respectivamente)

O dispositivo foi projetado pelo Professor Sergio Delijaicov, especialista em dinamômetros de mola, na Faculdade de Engenharia Industrial (FEI), de São Bernardo do Campo (SP). Para sua confecção, utilizaram-se células "strain gage", materiais piezoelétricos, semicondutores de eletricidade que funcionam por um princípio de mudança na resistência de acordo com a força aplicada sobre eles (CHAPMAN et al.,1970). Essa mudança de resistência é transformada em diferença de voltagem elétrica, medida através do material e transformada eletronicamente em um gráfico de 
força, formado em um software de computador especialmente projetado para esse fim. O dispositivo foi desenvolvido para ficar na palma da mão, entre esta e o trocarte, sendo composto internamente por quatro dinamômetros (Figura 22).

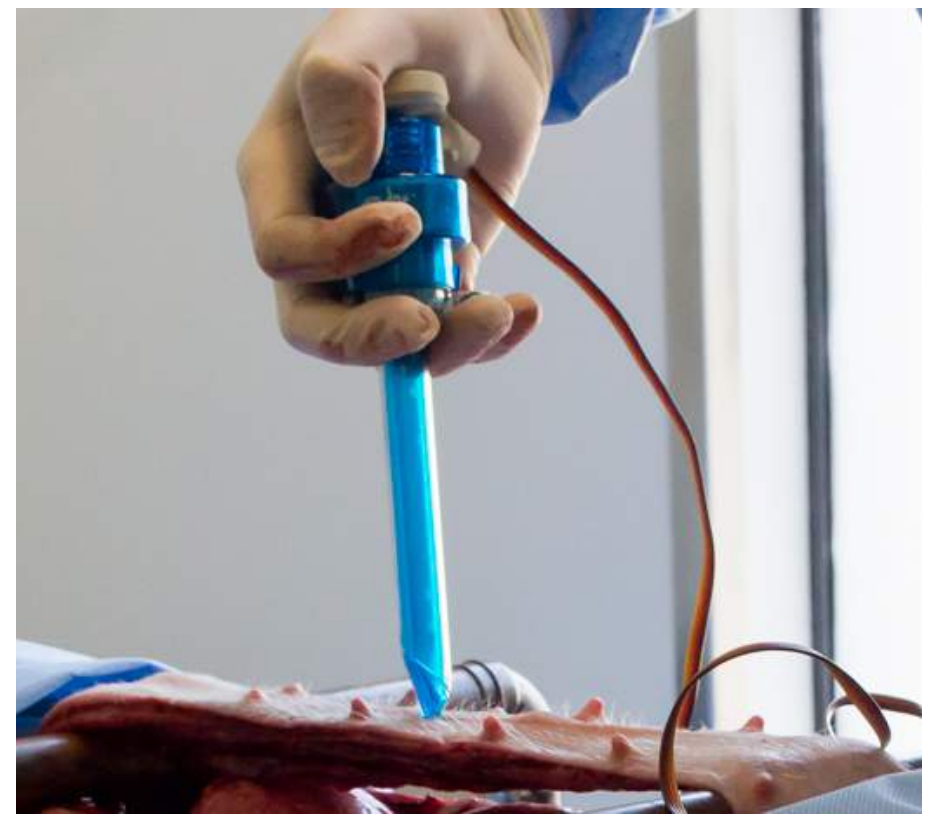

Figura 22 - Posicionamento do sensor entre a mão do cirurgião e o trocarte

Foi desenvolvido também um "software" em Delphi 2006 (Borland Software Corporation, Austin - Texas - EUA) com a função de amplificar os sinais elétricos provenientes dos dinamômetros, convertê-los para digital e enviá-los ao computador pessoal através de uma porta USB (Figura 23). O programa montava gráficos em tempo real a partir dos registros de força captados no sensor. 


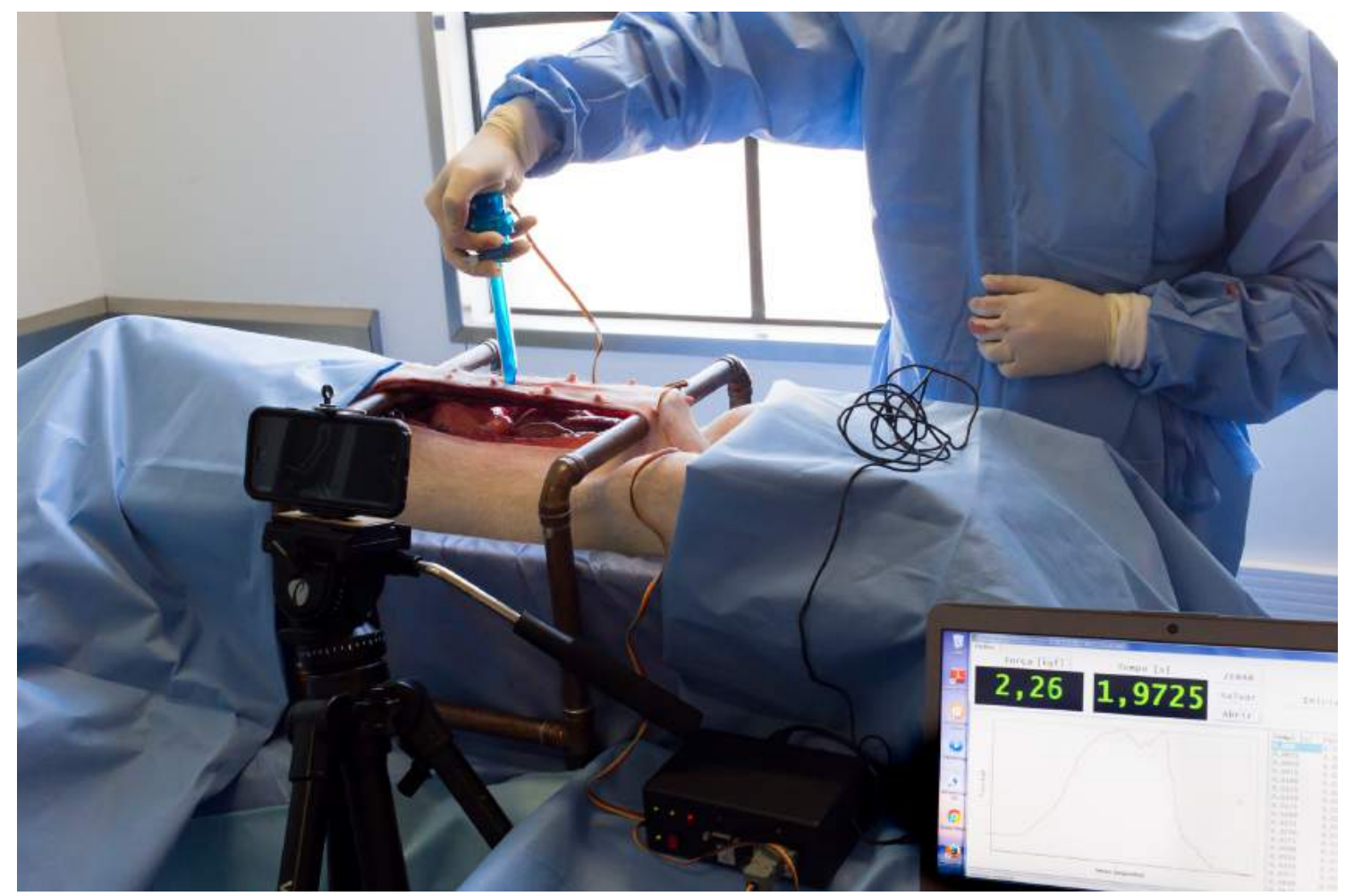

Figura 23 - Computador com Software (aquisição das curvas de força)

Todas as punções tiveram suas forças registradas, sendo designadas: F1, primeiro pico de força, necessária para perfuração de aponeurose e F2, segundo pico de força. A diferença entre F1 e F2 representa a força necessária para perfuração do peritônio (Figura 24). 


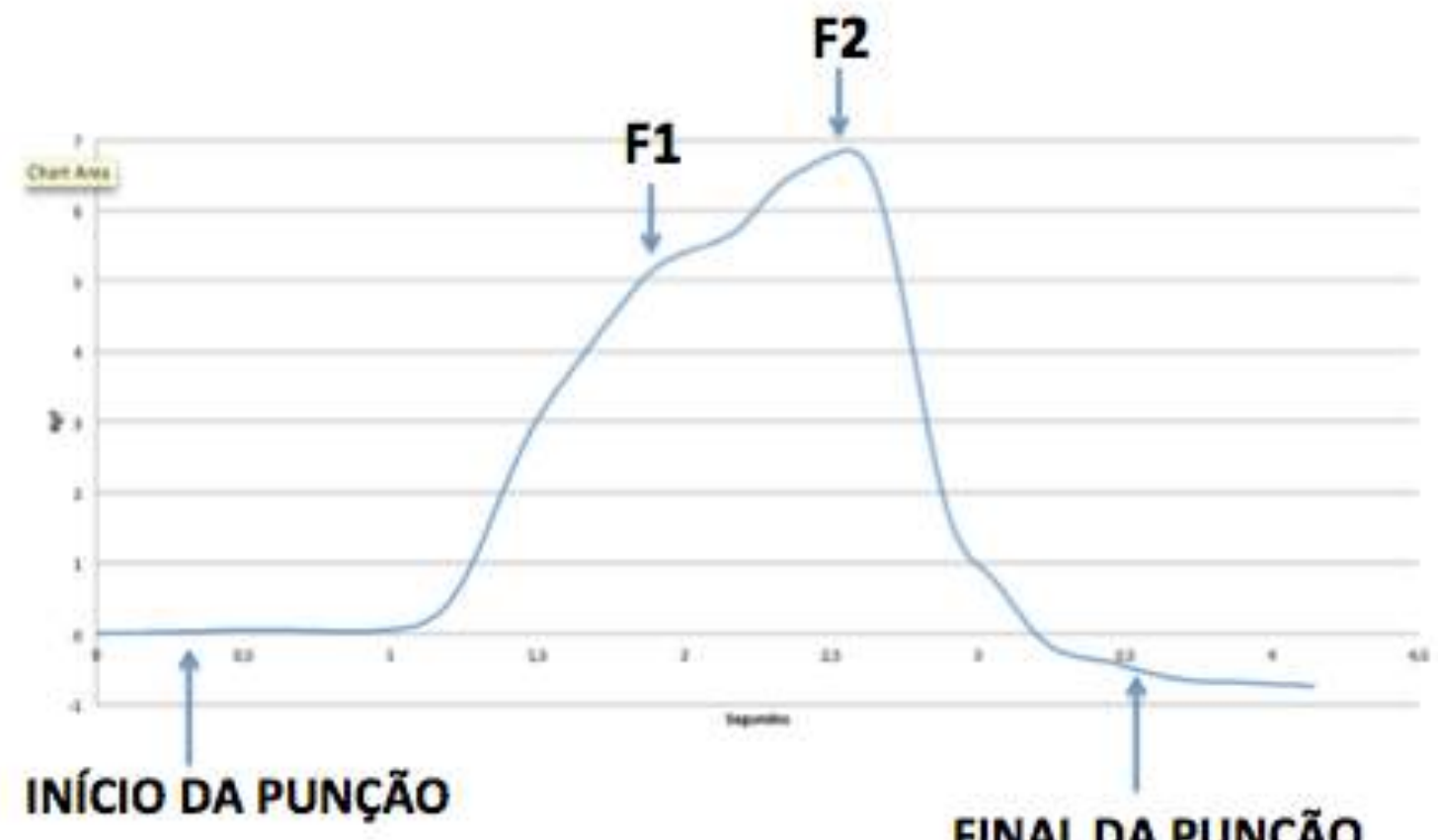

Figura 24 - Gráfico gerado pelo computador com as informações F1 e F2

Todos os dinamômetros conectados ao equipamento eletrônico foram calibrados utilizando uma máquina de ensaios mecânicos modelo K5002, marca Kratos, dotada de célula de carga (padrão ouro) de $100 \mathrm{kgf}(981 \mathrm{~N})$, ajustada para a escala de $20 \mathrm{kgf}$ (196,1 N). A resolução da célula de carga (padrão ouro) foi de 0,010 $\mathrm{kgf}(0,0981 \mathrm{~N})$. 
3.5) Avaliação das imagens e coleta dos dados

Após a realização das punções, todos os vídeos gravados foram avaliados. Para isso usaram-se fotos dos quadros dos vídeos que mostrassem os momentos de interesse, ilustrados abaixo. Para conversão de proporção entre medida aferida no quadro do vídeo para medida real $(\mathrm{em} \mathrm{cm})$ usou-se, como referência, os diâmetros dos trocartes. Eles são padronizados de fábrica, idênticos dentro de um mesmo modelo e sempre estavam no mesmo plano de imagem que a perfuração realizada. Os dados aferidos foram:

1. Dd - Distância de deformação. Corresponde a deformidade da parede abdominal imediatamente antes da perfuração de sua última camada (peritôneo) pela lâmina. Definido Dd como a distância entre a parede abdominal em descanso (início da gravação) e a ponta do trocarte no quadro do vídeo imediatamente antes da perfuração do peritônio (Figura 25 e 26). 


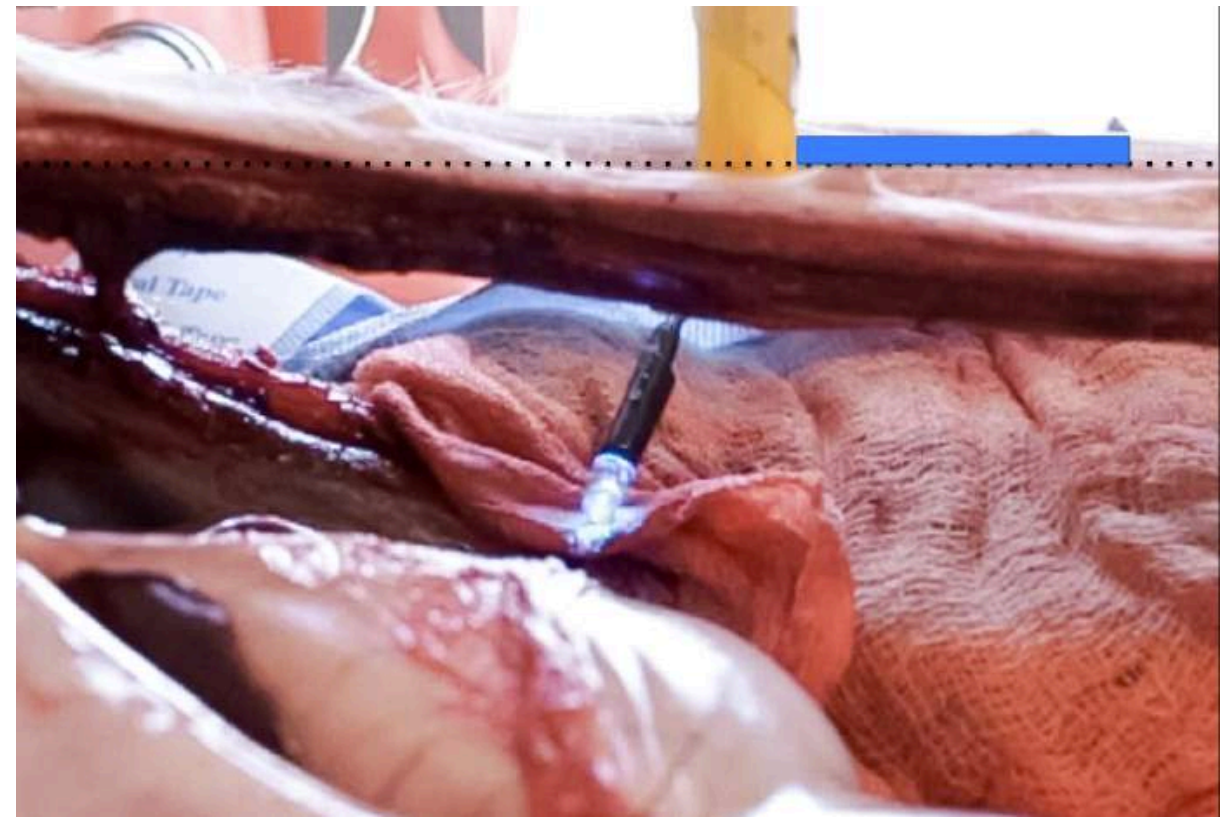

Figura 25 - Primeiro momento da punção, ainda sem força aplicada. Barra azul e linha pontilhada mostram a referência do ponto inicial da parede abdominal

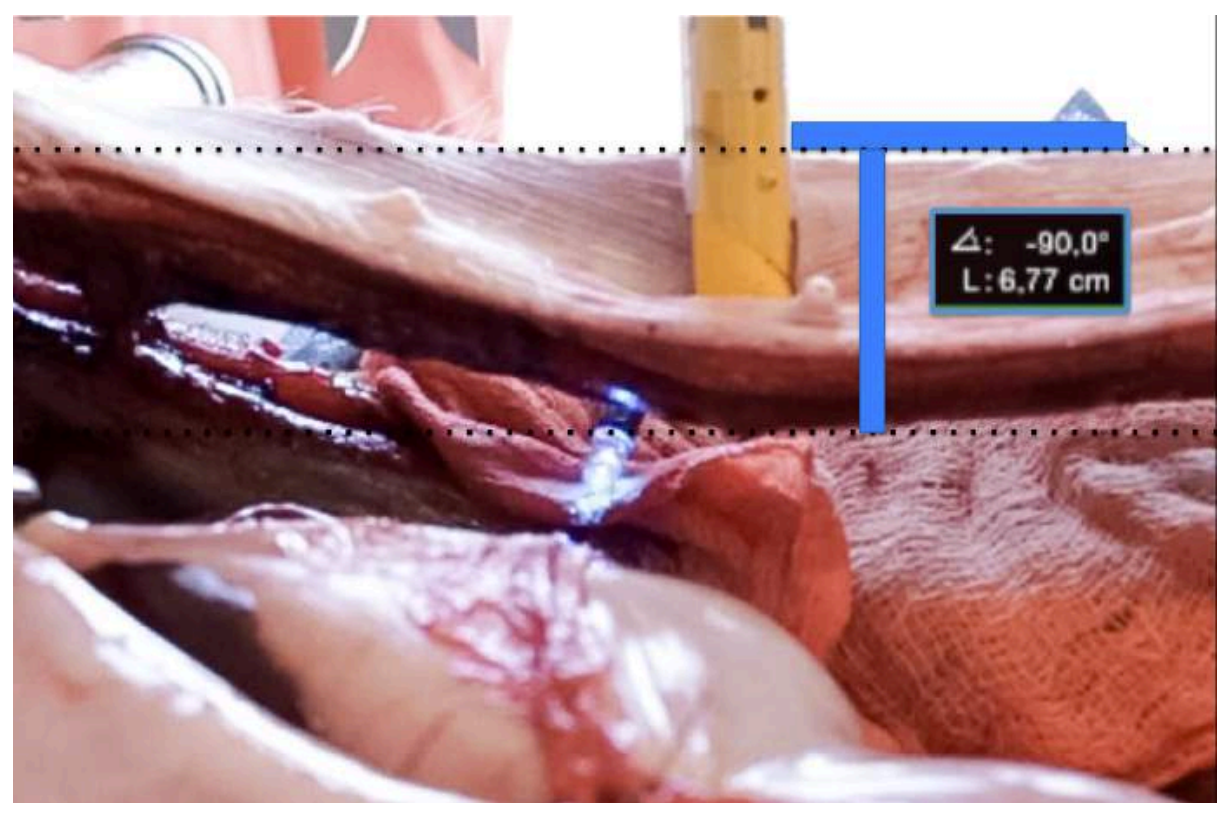

Figura 26 - Barra azul vertical (entre as linhas pontilhadas) mostra distância aferida de deformação (Dd), nesta punção especificamente de $6,77 \mathrm{~cm}$ 
2. DLam - Distância percorrida pela lâmina exposta dentro da cavidade peritoneal. Definido DLam como a distância entre a ponta do trocarte no quadro do vídeo imediatamente antes da perfuração do peritônio e sua mesma ponta imediatamente antes do recolhimento da lâmina, visto no último quadro em que aparece a lâmina (Figura 27).

3. Dt - Distancia total percorrida pelo trocarte. Definido Dt como a soma de Dt e DLam $(\mathrm{Dt}=\mathrm{Dd}+\mathrm{DLam})$, sendo iniciada no primeiro quadro do movimento (quando a lâmpada de LED acende) e terminando no último quadro em que aparece a lâmina. 


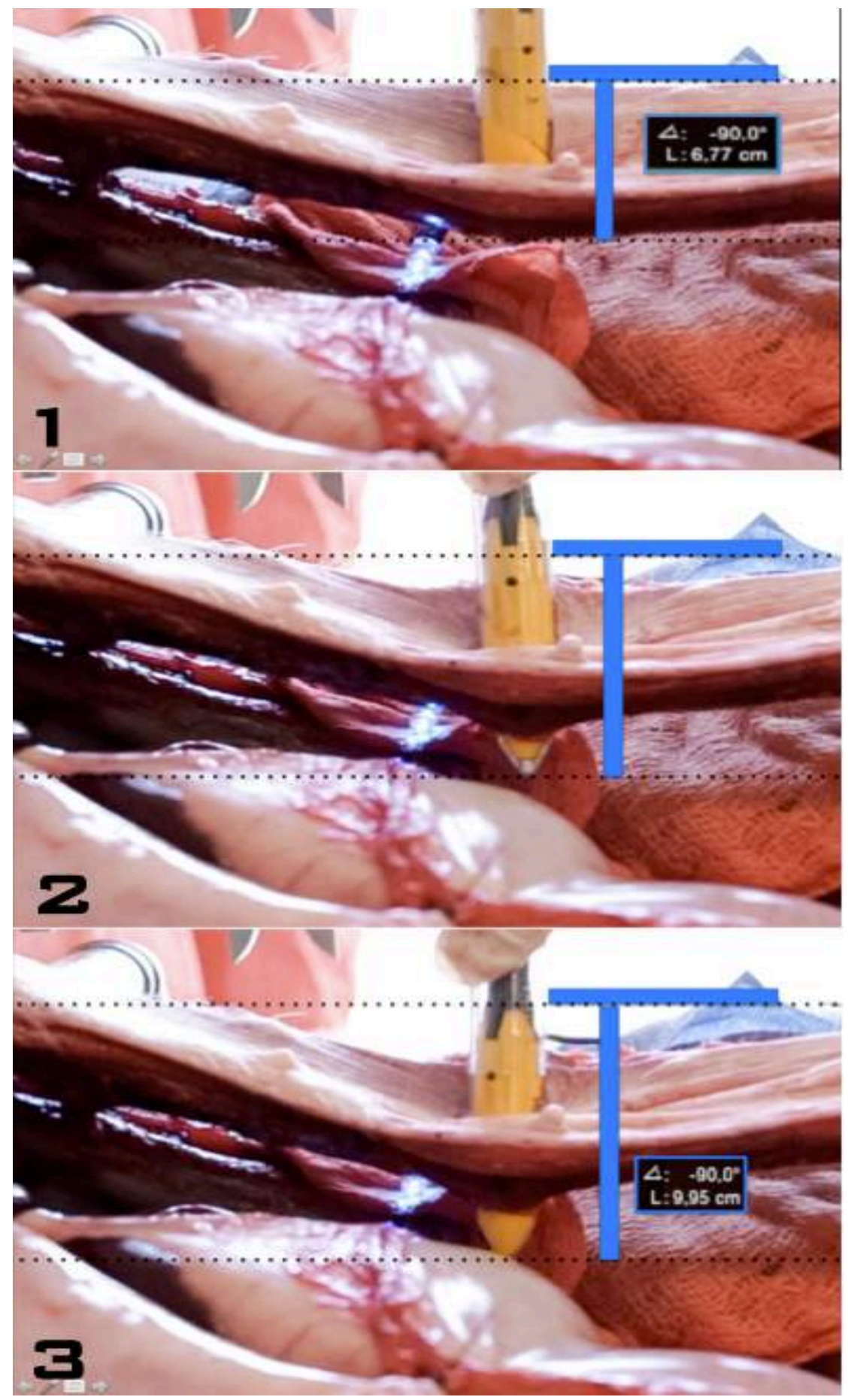

Figura 27 - Sequência de quadros da gravação mostrando aferição da DLam (distância de lâmina exposta). 1 - Barra vertical sinaliza distância de deformação (Dd); 2 - Foto intermediária mostrando lâmina ainda exposta; 3 - Barra vertical mostrando distância total (Dt), sendo Dt $=\mathrm{Dd}+$ DLam 
4. TLam - Tempo de exposição da lâmina do trocarte dentro da cavidade peritonial (TLam). Para isso, foram avaliadas as gravações no programa Final Cut Pro, em computador MacBook (Figura 28), desde o momento em que o trocarte perfura o peritôneo (primeiro quadro com exposição de lâmina) até o último momento em que essa lâmina é visualizada em gravação (Figura 29).

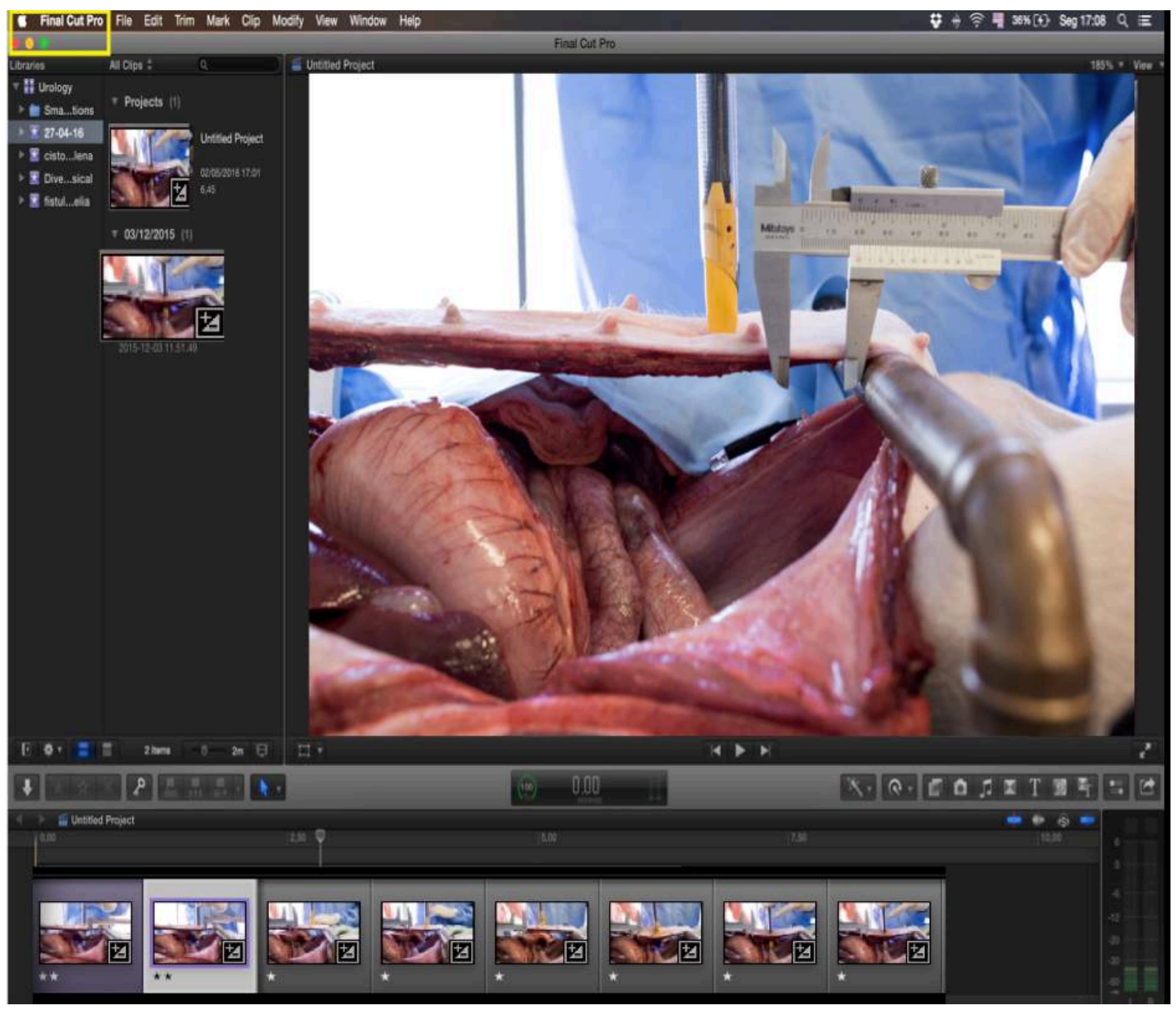

Figura 28 - Programa Final Cut Pro utilizado na avaliação das imagens do vídeo 

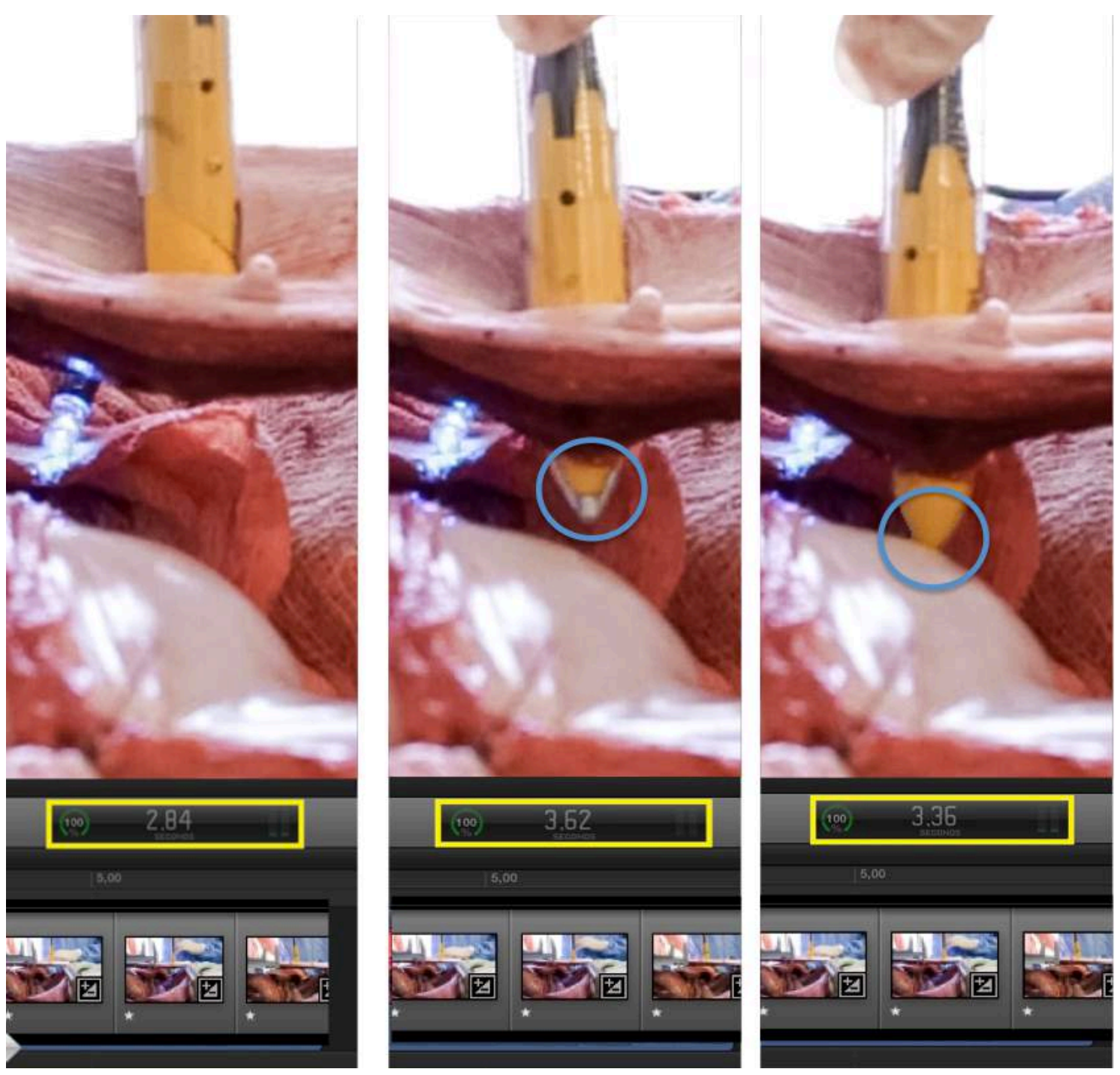

Figura 29 - Sequência de quadros mostrando TLam (em segundos) nas caixas em amarelo. Nos detalhes dos círculos em azul a ponta do trocarte: com lâmina no meio do movimento e ao final da avaliação

Ao término do experimento, todos os animais foram sacrificados com dose letal (2 $\mathrm{mEq} / \mathrm{kg}$ ) intravenosa de Cloreto de Potássio (LEARY et al., 2013). O descarte foi feito conforme protocolo convencional do complexo HCFMUSP: os animais foram colocados em um saco plástico, devidamente identificado e então encaminhados para a sessão de descarte do departamento. A coleta foi feita por uma empresa terceirizada. 
3.6) Metodologia estatística e análise de amostra

Os dados foram analisados descritivamente. Para as variáveis categóricas, foram apresentadas frequências absolutas e relativas e, para as variáveis numéricas, medidasresumo (média, quartis, mínimo, máximo e desvio padrão).

A comparação de médias entre dois grupos foi realizada utilizando-se o teste $t$ de Student $^{1}$ para amostras independentes. Já na comparação de médias de mais de dois grupos, empregou-se a Análise de Variâncias (ANOVA). Tanto o teste t de Student como a ANOVA apresentam como um dos pressupostos a normalidade na distribuição dos dados, verificado via teste de Kolmogorov-Smirnov. Em caso de violação da normalidade dos dados na ANOVA, as médias foram comparadas alternativamente, empregando-se o teste não-paramétrico de Kruskal-Wallis. Os grupos foram novamente comparados via "comparações múltiplas" de C de Dunnett ${ }^{2}$ ou Dunn-Bonferroni ${ }^{3}$ respectivamente para ANOVA e Kruskal-Wallis, mantendo-se um nível de significância global de 5\%. A associação linear entre duas variáveis numéricas foi avaliada via correlação de Pearson.

Para o cálculo da amostra, a deformação foi adotada como variável de dimensionamento. Assim, estimou-se uma amostra de pelo menos 36 perfurações para cada uma das cinco marcas, perfazendo um total de 180 perfurações, para que seja possível: identificar uma diferença de $1 \mathrm{~cm}$ na deformação entre as marcas, sendo esperada uma média de deformação de $5 \mathrm{~cm}$ nas três marcas com lâmina e $6 \mathrm{~cm}$ nas

\footnotetext{
${ }^{1}$ De acordo com o teorema do Limite Central, para as amostras suficientemente grandes ( $\left.N \geq 30\right)$, a média das variáveis tende a apresentar distribuição normal - desta forma, para comparação de duas médias com mais de 30 casos por grupo não foi necessário realizar o teste de normalidade.

${ }^{2}$ Devido à violação do pressuposto de honocedasticidade (variâncias iguais entre grupos).

${ }^{3}$ Dunn, O. J. Multiple comparisons using rank sums. Technometrics; 1964: 6, 241-252.
} 
duas marcas sem lâmina. Admitiu-se ainda um desvio padrão na deformação de 1,5 cm. Para esses cálculos foi utilizado o software estatístico PASS 2008 (Power Analysis and Sample Size System) - NCSS" (KIRK et al. 2013; DESU et al. 1990).

As análises estatísticas permitiram as seguintes comparações:

1) Deformação da parede, forças para perfuração de aponeurose e peritônio entre os cinco trocartes estudados;

2) Tempo e distância de lâmina expostos entre os três trocartes laminados (M1L, M2L e M3L);

3) Comparação de todos os parâmetros (análise multivariada), segundo posição, a partir da cicatriz umbilical (centro) entre os cinco trocartes. 
4) Resultados 


\section{4) RESULTADOS}

\section{1) Análise Univariada}

Foram analisadas 180 punções, sendo 36 para cada um dos cinco modelos de trocartes. As Tabelas 1 e 2 mostram a análise univariada comparativa entre eles. Notamse diferenças estatísticas significantes em todos os parâmetros analisados: deformação $(p<0,001)$, forças empregadas no $1^{\circ}(p<0,001)$ e $2^{\circ}$ picos $(p<0,001)$ (Tabela 1$)$, além de distância $(p=0,0012)$ e tempo de lâmina exposta $(p<0,001)$ (Tabela 2) por tipo de trocarte.

Tabela 1 - Medidas-resumo da deformação e forças empregadas no $1^{\circ}(\mathrm{F} 1)$ e $2^{\circ}$ pico (F2) por modelo de trocarte

\begin{tabular}{|c|c|c|c|c|c|c|c|c|c|}
\hline & Média & $\begin{array}{c}\text { Desvio } \\
\text { Padrão }\end{array}$ & Mínimo & Máximo & $1^{\circ}$ Quartil & Mediana & $3^{\circ}$ Quartil & $\mathbf{N}$ & $\mathbf{p}$ \\
\hline Deformação - Dd (cm) & & & & & & & & & $<0,001$ \\
\hline M1L & $5,03^{\mathrm{B}}$ & 0,55 & 3,88 & 6,04 & 4,64 & 4,95 & 5,51 & 36 & \\
\hline M2L & $4,26^{\mathrm{C}}$ & 1,19 & 2,29 & 7,36 & 3,15 & 4,17 & 5,07 & 36 & \\
\hline M3L & $4,33^{\mathrm{C}}$ & 0,99 & 1,74 & 6,06 & 3,63 & 4,28 & 5,12 & 36 & \\
\hline M4SL & $7,20^{\mathrm{A}}$ & 1,27 & 4,95 & 9,90 & 6,23 & 7,19 & 8,15 & 36 & \\
\hline M5SL & $7,00^{\mathrm{A}}$ & 0,74 & 5,23 & 8,68 & 6,52 & 6,95 & 7,63 & 36 & \\
\hline Força $1^{\circ}$ pico - F1 (N) & & & & & & & & & $<0,001$ \\
\hline M1L & $5,27^{\mathrm{C}}$ & 0,77 & 2,63 & 6,83 & 5,05 & 5,33 & 5,60 & 36 & \\
\hline M2L & $5,46^{\mathrm{C}}$ & 1,11 & 3,06 & 8,00 & 4,56 & 5,41 & 6,30 & 36 & \\
\hline M3L & $6,82^{\mathrm{B}}$ & 1,74 & 2,90 & 11,20 & 5,69 & 6,47 & 7,54 & 36 & \\
\hline M4SL & $7,73^{\mathrm{B}}$ & 1,71 & 4,78 & 11,30 & 6,21 & 7,74 & 8,60 & 36 & \\
\hline M5SL & $9,67^{\mathrm{A}}$ & 2,36 & 3,58 & 15,38 & 8,16 & 9,87 & 11,12 & 36 & \\
\hline Força $2^{\circ}$ pico - F2 (N) & & & & & & & & & $<0,001$ \\
\hline M1L & $5,22^{\mathrm{C}}$ & 1,22 & 1,84 & 7,49 & 4,88 & 5,25 & 6,02 & 36 & \\
\hline M2L & $5,84^{\mathrm{C}}$ & 1,28 & 3,62 & 8,82 & 4,86 & 5,65 & 6,67 & 36 & \\
\hline M3L & $8,07^{\mathrm{B}}$ & 1,79 & 4,61 & 11,90 & 6,88 & 7,62 & 9,07 & 36 & \\
\hline M4SL & $9,17^{\mathrm{B}}$ & 1,84 & 5,91 & 12,98 & 7,60 & 9,04 & 10,66 & 36 & \\
\hline M5SL & $11,46^{\mathrm{A}}$ & 2,65 & 7,22 & 19,18 & 9,89 & 10,98 & 13,41 & 36 & \\
\hline
\end{tabular}

p - Nível descritivo associado a ANOVA ou do teste de Kruskal-Wallis ( ${ }^{\mathrm{a}}$ )

A, B e C apresentam médias distintas segundo comparações múltiplas de Duncan.

A' e B' apresentam médias distintas segundo comparações múltiplas de Dunn-Bonferroni. 
Tabela 2 - Medidas-resumo da distância (DLam) e tempo (TLam) de lâmina exposta

\begin{tabular}{|c|c|c|c|c|c|c|c|c|c|}
\hline & Média & $\begin{array}{l}\text { Desvio } \\
\text { Padrão }\end{array}$ & Mínimo & Máximo & $\begin{array}{c}1^{\circ} \\
\text { Quartil }\end{array}$ & Mediana & $\begin{array}{c}3^{\circ} \\
\text { Quartil }\end{array}$ & $\mathbf{N}$ & $\mathbf{p}$ \\
\hline Lâmina Exposta - Dlam (cm) & & & & & & & & & 0,012 \\
\hline M1L & $1,88^{\mathrm{B}}$ & 0,49 & 1,05 & 2,96 & 1,54 & 1,75 & 2,21 & 36 & \\
\hline M2L & $1,86^{\mathrm{B}}$ & 0,91 & 0,52 & 4,94 & 1,22 & 1,68 & 2,35 & 36 & \\
\hline M3L & $2,34^{\mathrm{A}}$ & 0,83 & 0,27 & 4,34 & 1,82 & 2,45 & 2,96 & 36 & \\
\hline Tempo de exposição da lâmina & & & & & & & & & $<0 \Omega 01^{\mathrm{a}}$ \\
\hline M1L & $0,39^{\mathrm{B}^{\prime}}$ & 0,30 & 0,05 & 1,45 & 0,19 & 0,34 & 0,42 & 36 & \\
\hline M2L & $0,23^{\mathrm{B}^{\prime}}$ & 0,17 & 0,06 & 0,58 & 0,10 & 0,14 & 0,35 & 36 & \\
\hline M3L & $0,75^{\mathrm{A}^{\prime}}$ & 0,47 & 0,06 & 2,00 & 0,35 & 0,72 & 1,03 & 36 & \\
\hline
\end{tabular}

p - Nível descritivo associado a ANOVA ou do teste de Kruskal-Wallis $\left({ }^{a}\right)$

A, B e C apresentam médias distintas segundo comparações múltiplas de Duncan.

A' e B' apresentam médias distintas segundo comparações múltiplas de Dunn-Bonferroni.

Dessa forma, verificou-se que para:

- Deformação (Dd) - os trocartes M4SL e M5SL apresentaram as maiores médias, similares entre si. Já o M1L apresentou a segunda maior média, superior a M2L e M3L, similares entre si (Gráfico 1).

Gráfico 1 - Médias das deformações $(\mathrm{cm})$ por marca




- Forças F1 e F2 - empregaram-se, em média, maiores forças $\left(1^{\circ}\right.$ e $2^{\circ}$ pico $)$ na marca M5SL. As marcas M3L e M4SL apresentaram as segundas maiores médias empregadas, similares entre si e superiores às médias de M1L e M2L, similares entre si (Gráficos 2a e 2b)

Gráfico 2a e 2b - Médias das forças F1 e F2 (N) empregadas por marca
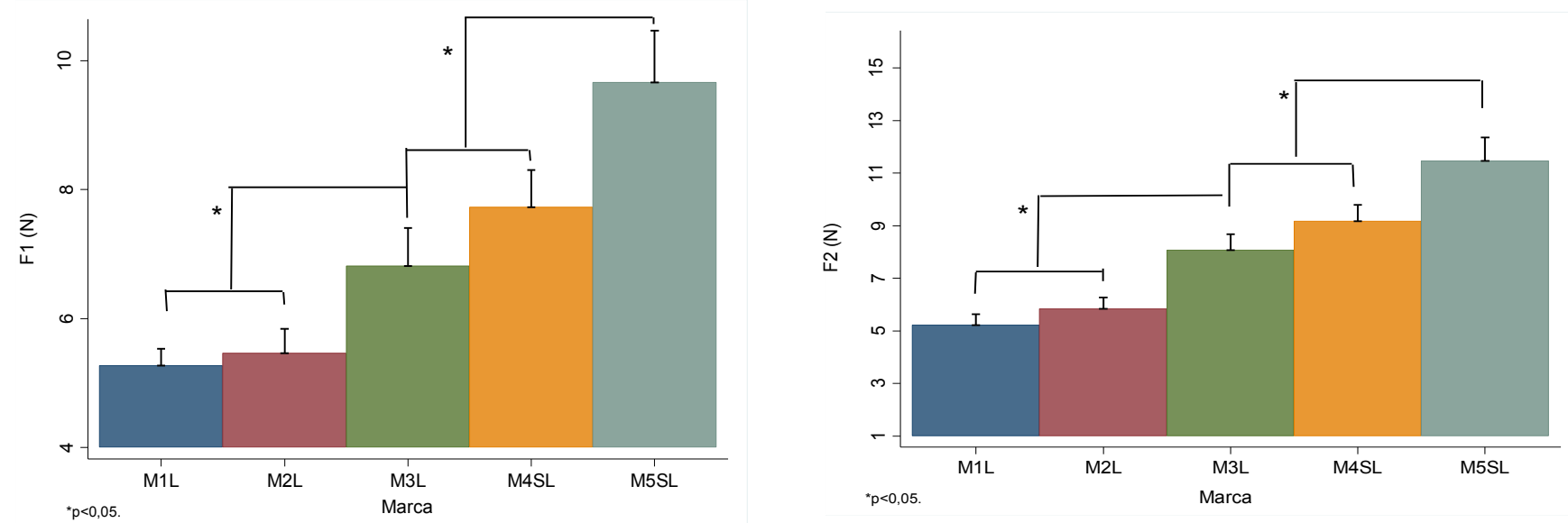
- Lâmina Exposta (DLam) - A marca M3L apresentou maior média de distância lâmina exposta comparativamente às médias de M1L e M2L, similares entre si (Gráfico 3).

Gráfico 3 - Média das distâncias de lâmina exposta $(\mathrm{cm})$ por marca



- Tempo de lâmina exposta (TLam) - A marca M3L apresentou maior média de tempo comparativamente às de M1L e M2L, similares entre si (Gráfico 4).

Gráfico 4 - Média dos tempos de lâmina exposta (s) por marca

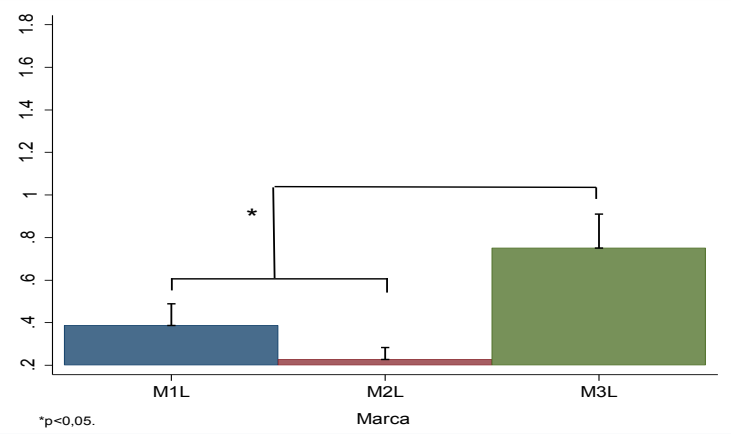


Foi feita também uma comparação entre os grupos de trocartes com e sem lâmina. De acordo com a Tabela 3, verificaram-se diferenças de médias de todos os parâmetros: deformação $(p<0,001)$, força $F 1(p<0,001)$ e $F 2(p<0,001)$. Nota-se que, em média, ocorreram maiores deformações e usos de forças em trocartes sem lâmina comparativamente aos com lâmina.

Tabela 3 - Medidas-resumo comparativa dos trocartes com e sem lâmina

\begin{tabular}{|c|c|c|c|c|c|c|c|c|c|}
\hline & Média & $\begin{array}{c}\text { Desvio } \\
\text { Padrão }\end{array}$ & Mínimo & Máximo & $\begin{array}{c}1^{\circ} \\
\text { Quartil }\end{array}$ & Mediana & $\begin{array}{c}3^{\circ} \\
\text { Quartil }\end{array}$ & $\mathbf{N}$ & $\mathbf{p}$ \\
\hline Deformação - Dd (cm) & & & & & & & & & $<0,001$ \\
\hline Sem lâmina & 7,10 & 1,04 & 4,95 & 9,90 & 6,49 & 7,02 & 7,72 & 72 & \\
\hline Com lâmina & 4,54 & 1,00 & 1,74 & 7,36 & 3,88 & 4,65 & 5,17 & 108 & \\
\hline Força $1^{\circ}$ pico - F1 (N) & & & & & & & & & $<0,001$ \\
\hline Sem lâmina & 8,70 & 2,27 & 3,58 & 15,38 & 7,31 & 8,49 & 10,33 & 72 & \\
\hline Com lâmina & 5,85 & 1,44 & 2,63 & 11,20 & 5,10 & 5,54 & 6,47 & 108 & \\
\hline Força $2^{\circ}$ pico - F2 (N) & & & & & & & & & $<0,001$ \\
\hline Sem lâmina & 10,32 & 2,54 & 5,91 & 19,18 & 8,56 & 10,18 & 11,96 & 72 & \\
\hline Com lâmina & 6,38 & 1,89 & 1,84 & 11,90 & 5,12 & 6,25 & 7,36 & 108 & \\
\hline
\end{tabular}

Realizada análise do impacto que a posição da punção (distância da cicatriz umbilical) teria em relação aos parâmetros analisados. Ilustrando isso, a tabela 4, mostra associação moderada negativa entre deformação e posição $(r=-0,576, p<0,001)$ e fracas negativas entre posição e F1 $(r=-0,152, p=0,042)$. Dessa forma, quanto mais distante do centro ocorrer a perfuração, menor a deformação e a força empregada no $1^{\circ}$ pico (F1). 
Tabela 4 - Correlação de Pearson entre a posição da perfuração em relação ao centro e deformação, lâmina exposta, tempo de exposição da lâmina e forças empregadas no $1^{\circ}$ e $2^{\circ}$ pico

\begin{tabular}{lccc}
\hline & \multicolumn{2}{c}{ Correlação de Pearson } & \multirow{2}{*}{$\mathrm{N}$} \\
\cline { 2 - 3 } & Estimativa & $\mathbf{P}$ & \\
\hline Deformação - Ld (cm) & $-0,576^{* *}$ & $<0,001$ & 180 \\
Lamina Exposta - Llam (cm) & 0,075 & 0,438 & 108 \\
Tempo de exposição da lamina (s) & 0,020 & 0,834 & 108 \\
F1 (N) & $-0,152^{*}$ & 0,042 & 180 \\
F2 (N) & $-0,107$ & 0,152 & 180 \\
\hline${ }^{*}<<0,050 .{ }^{* *} \mathrm{p}<0,010$. & & &
\end{tabular}

Essas relações podem ser visualizadas nos gráficos 5 e 6 . Não foram verificadas correlações entre posição e as variáveis lâmina exposta, tempo de exposição e força empregada no $2^{\circ}$ pico.

Gráfico 5 - Gráfico de dispersão entre posição da perfuração em relação ao centro e deformação

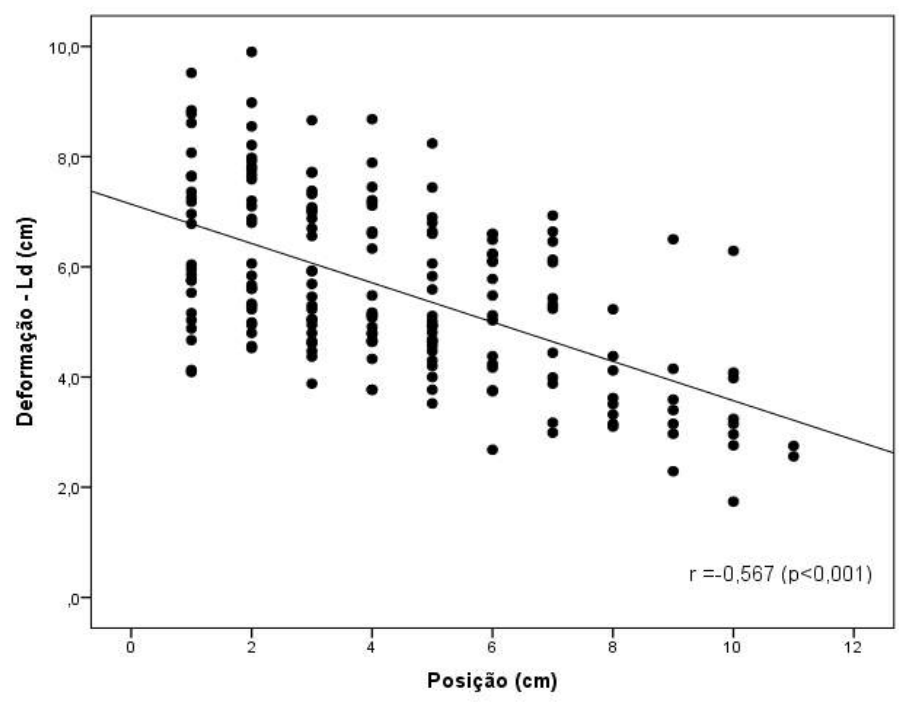


Gráfico 6 - Gráfico de dispersão entre posição da perfuração em relação ao centro e força empregada no $1^{\circ}$ pico

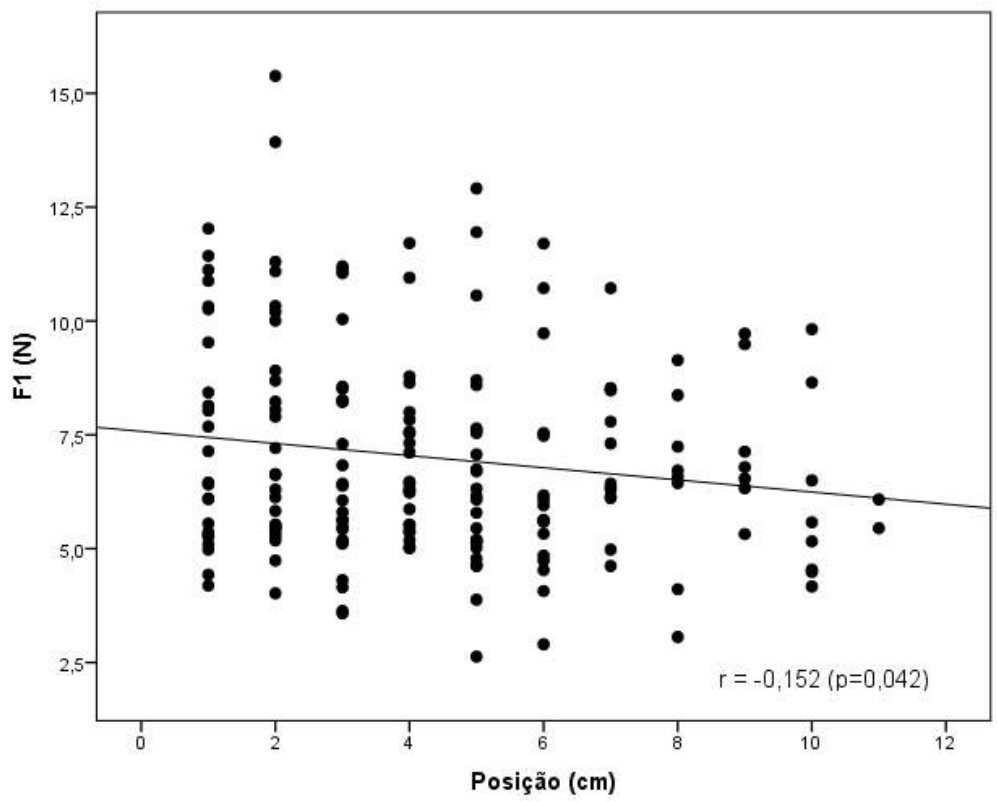




\section{2) Análise Multivariada}

Para avaliar simultaneamente os efeitos da marca, controlada pela distância da perfuração em relação ao centro (variável explicativa) sobre cada uma das variáveis dependentes (forças, deformação, lâmina exposta e tempo de exposição da lâmina), foi utilizada a regressão linear múltipla. Esta apresenta também como um dos pressupostos a normalidade dos dados verificada via teste de Kolmogorov-Smirnov (Tabela 5).

Tabela 5 - Teste de Kolmogorov-Smirnov para normalidade nos dados

\begin{tabular}{lccc}
\hline & \multicolumn{2}{c}{ Teste de Kolmogorov- } & \multirow{2}{*}{ Smirnov } \\
\cline { 2 - 3 } & $\mathbf{z}$ & $\mathbf{P}$ & \\
\hline Marca & & & \\
Dd (cm) & 0,77 & 0,598 & 180 \\
DLam (cm) & 0,63 & 0,817 & 108 \\
TLam (s) & 1,48 & 0,024 & 108 \\
F1 (N) & 0,96 & 0,319 & 180 \\
F2 (N) & 0,98 & 0,288 & 180 \\
& & & \\
Regressão & & & \\
Dd (cm) & & & 180 \\
F1 (N) & 0,79 & 0,568 & 180 \\
F2 (N) & 1,09 & 0,186 & 180 \\
DLam (cm) & 1,05 & 0,218 & 108 \\
TLam (s) & 0,84 & 0,487 & 108 \\
\hline
\end{tabular}


Para todos os testes estatísticos foi utilizado um nível de significância de 5\%, considerando M1L como marca referência. A Tabela 6 resume os resultados de deformação e forças da análise multivariada.

Tabela 6 - Estimativas do modelo de regressão linear múltipla para deformação e forças, sendo M1L como marca referência

\begin{tabular}{|c|c|c|c|c|c|c|}
\hline & \multicolumn{2}{|c|}{ Deformação - Dd (cm) } & \multicolumn{2}{|c|}{ Força $1^{\circ}$ pico - F1 (N) } & \multicolumn{2}{|c|}{ Força $2^{\circ}$ pico - F2 (N) } \\
\hline & $\begin{array}{c}\text { Coeficiente } \\
\text { (IC95\%) }\end{array}$ & $\mathbf{p}$ & Coeficiente (IC95\%) & $\mathbf{p}$ & $\begin{array}{c}\text { Coeficiente } \\
\text { (IC95\%) }\end{array}$ & p \\
\hline Constante & $5,92(5,63 ; 6,21)$ & $<0,001$ & $5,73(5,07 ; 6,39)$ & $<0,001$ & $5,77(5,03 ; 6,51)$ & $<0,001$ \\
\hline Marca $($ ref $=M 1 L)$ & & $<0,001$ & & $<0,001$ & & $<0,001$ \\
\hline $\mathrm{M} 2 \mathrm{~L}$ & $-0,07(-0,42 ; 0,27)$ & 0,679 & $0,49(-0,3 ; 1,28)$ & 0,225 & $0,93(0,04 ; 1,81)$ & 0,041 \\
\hline M3L & $0,15(-0,26 ; 0,56)$ & 0,463 & $1,96(1,02 ; 2,90)$ & $<0,001$ & $3,30(2,26 ; 4,35)$ & $<0,001$ \\
\hline M4SL & $2,41(2,08 ; 2,74)$ & $<0,001$ & $2,56(1,80 ; 3,32)$ & $<0,001$ & $4,06(3,21 ; 4,91)$ & $<0,001$ \\
\hline M5SL & $2,23(1,90 ; 2,56)$ & $<0,001$ & $4,51(3,75 ; 5,27)$ & $<0,001$ & $6,36(5,51 ; 7,20)$ & $<0,001$ \\
\hline Posição (cm) & $-0,29(-0,33 ;-0,24)$ & $<0,001$ & $-0,12(-0,22 ;-0,02)$ & 0,017 & $-0,13(-0,24 ;-0,01)$ & 0,028 \\
\hline $\mathrm{N}$ & 180 & & 180 & & 180 & \\
\hline $\mathrm{R}^{2}(\%)$ & 81,7 & & 51,8 & & 62,7 & \\
\hline
\end{tabular}


- Deformação (Dd) - Marca $(p<0,001)$ e posição $\quad(p<0,001)$ foram estatisticamente significantes. Os trocartes M4SL e M5SL foram significantes, similares entre si $\left(p=0,288^{4}\right)$, apresentando maiores deformações $(2,41 \mathrm{~cm}$ e 2,23 cm, respectivamente) do que o M1L. Já M2L e M3L não se mostraram significantes, apresentando deformações similares ao M1L. Com relação à posição, observa-se que, a cada aumento de $1 \mathrm{~cm}$ no afastamento em relação ao centro, ocorre uma redução de 0,29 cm na deformação (Gráfico 7).

Gráfico 7 - Efeitos das marcas M2L, M3L, M4SL e MS5L sobre a média de deformação $(\mathrm{cm})$ do M1L ajustada pela posição, estimadas pelo modelo de regressão linear

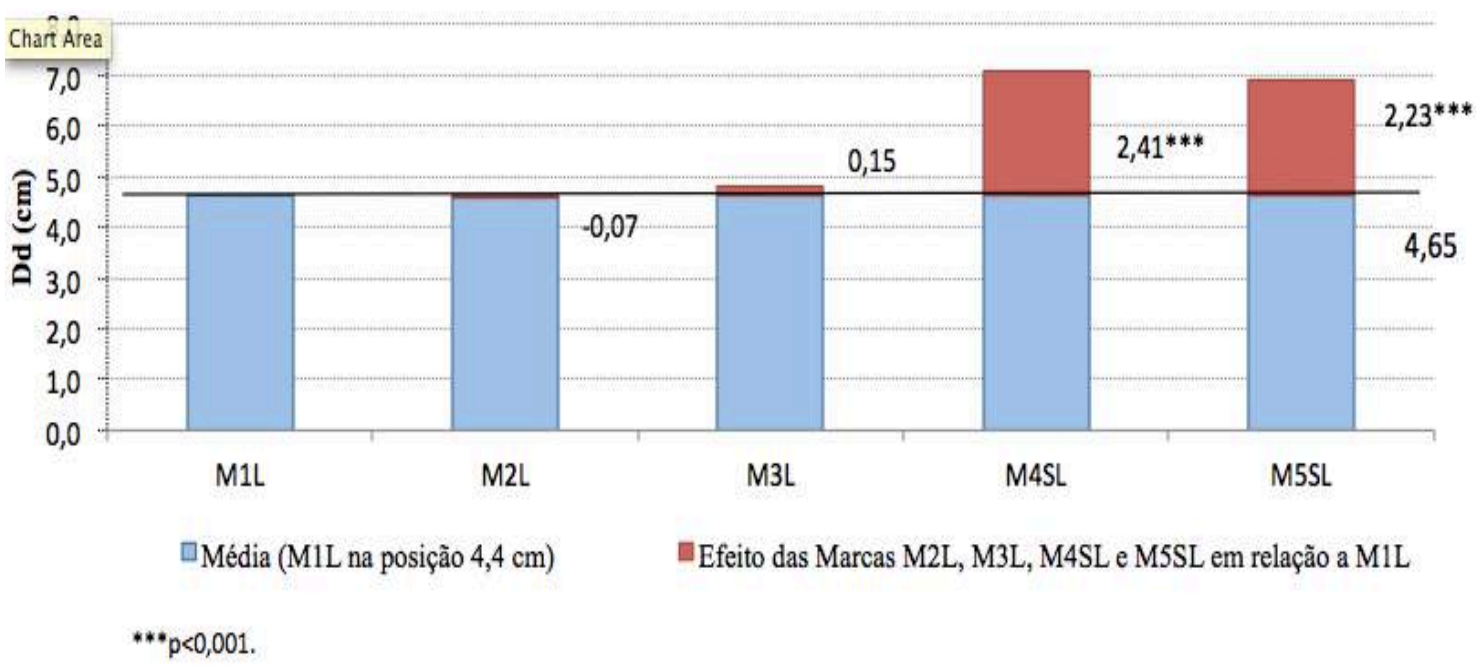

${ }^{4}$ Teste de Wald para comparação dos coeficientes entre as marcas. 
- Força F1 - Marca $(p<0,001)$ e posição $(p<0,017)$ foram estatisticamente significantes. Os trocartes M3L, M4SL e M5SL necessitaram de maiores usos de força no $1^{\circ}$ pico do que os M1L $(1,96 \mathrm{~N}, 2,56 \mathrm{~N}$ e 4,51 N, respectivamente). Já a força empregada para M2L foi similar ao do M1L ( $p=0,225)$. Verificou-se também que a força para M3L foi similar ao do M4SL $\left(p=0,197^{4}\right)$ e ambas se mostraram inferiores ao do M5SL $\left(p<0,001^{4}\right)$. Com relação à posição, observase que, a cada aumento de $1 \mathrm{~cm}$ no afastamento em relação ao centro, ocorre uma redução de $0,12 \mathrm{~N}$ na força (Gráfico 8).

Gráfico 8 - Efeitos das marcas M2L, M3L, M4SL e MS5L sobre a média de F1 (N) do M1L ajustada pela posição, estimadas pelo modelo de regressão linear

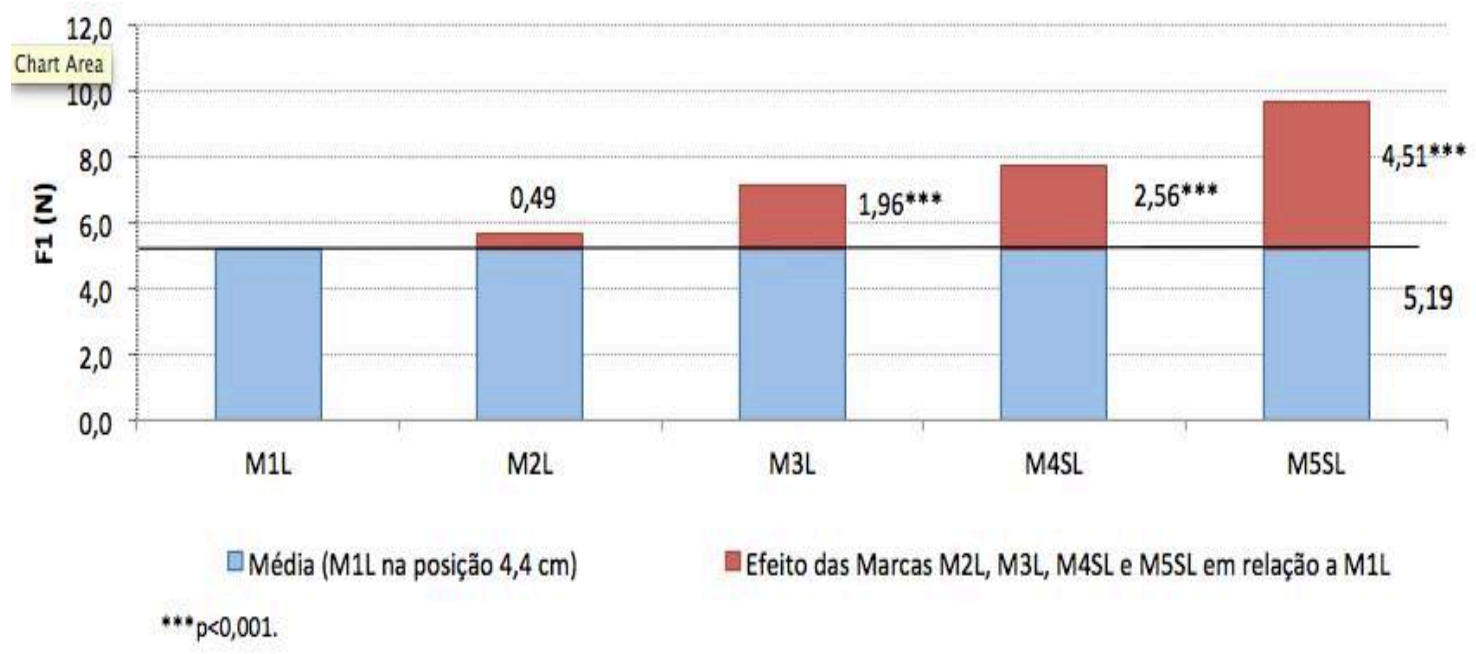


- Força F2 - Marca $(p<0,001)$ e posição $(p<0,028)$ foram estatisticamente significantes. Os trocartes M2L, M3L, M4SL e M5SL necessitaram de maior uso de força no $2^{\circ}$ pico do que os M1L $(0,93 \mathrm{~N}, 3,30 \mathrm{~N}, 4,06 \mathrm{~N}$ e $6,36 \mathrm{~N}$, respectivamente). Adicionalmente verificou-se que a força para $\mathrm{M} 2 \mathrm{~L}$ foi inferior $\left(p<0,001^{4}\right)$ ao de M3L e M4L, similares entre si $\left(p=0,145^{4}\right)$ e ambas se mostraram inferiores ao do M5SL $\left(p<0,001^{4}\right)$. Com relação à posição, observase que, a cada aumento de $1 \mathrm{~cm}$ no afastamento em relação ao centro, ocorre uma redução de $0,13 \mathrm{~N}$ na força F2 (Gráfico 9).

Gráfico 9 - Efeitos das marcas M2L, M3L, M4SL e MS5L sobre a média de F2 (N) do M1L ajustada pela posição, estimadas pelo modelo de regressão linear

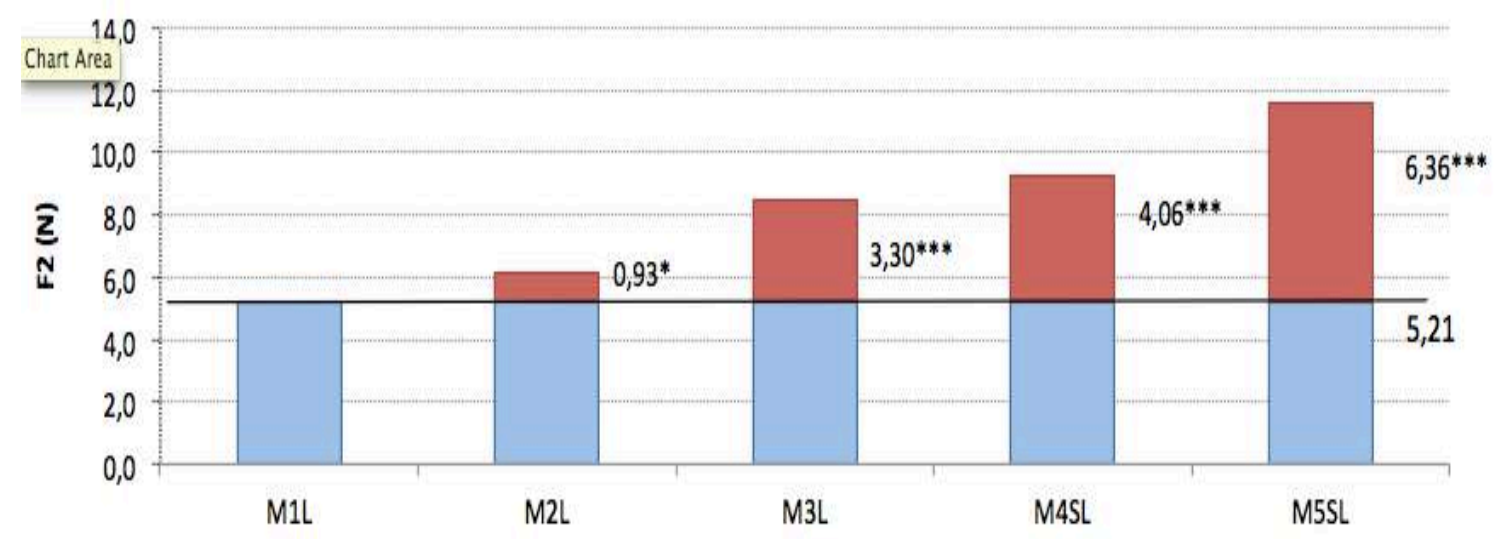

অMédia (M1L na posição 4,4cm) 『Efeito das Marcas M2L, M3L, M4SL e M5SL em relação a M1L $* p<0,05 . * * p<0,001$. 
A tabela 7 resume os resultados de distância e tempo de lâmina exposta da análise multivariada, mantendo M1L como marca referência.

Tabela 7 - Estimativas do modelo de regressão linear múltipla para tempo e distância de lâmina exposta, sendo M1L como marca referência

\begin{tabular}{|c|c|c|c|c|}
\hline & \multicolumn{2}{|c|}{ Lâmina Exposta - DLam (cm) } & \multicolumn{2}{|c|}{$\begin{array}{c}\text { Tempo de exposição da lâmina } \\
\text { TLam (s) }\end{array}$} \\
\hline & Coeficiente (IC95\%) & $\mathbf{p}$ & Coeficiente (IC95\%) & $\mathbf{p}$ \\
\hline Constante & $1,93(1,59 ; 2,28)$ & $<0,001$ & $0,50(0,35 ; 0,65)$ & $<0,001$ \\
\hline Marca $($ ref=M1L) & & 0,197 & & \\
\hline $\mathrm{M} 2 \mathrm{~L}$ & $-0,03(-0,42 ; 0,35)$ & 0,867 & $-0,13(-0,30 ; 0,03)$ & 0,117 \\
\hline M3L & $0,34(-0,12 ; 0,80)$ & 0,141 & $0,37(0,17 ; 0,57)$ & $<0,001$ \\
\hline Posição (cm) & $0,002(-0,057 ; 0,061)$ & 0,952 & $-0,01(-0,04 ; 0,01)$ & 0,410 \\
\hline $\mathrm{N}$ & 108 & & 108 & \\
\hline $\mathrm{R}^{2}(\%)$ & 9,4 & & 34,1 & \\
\hline
\end{tabular}

- Distância de lâmina exposta (DLam) - Marca do trocarte $(p=0,197)$ e posição $(\mathrm{p}=0,952)$ não foram significantes (gráfico 10$)$.

Gráfico 10 - Efeitos das marcas M2L e M3L sobre a média da distância de lâmina exposta - DLam (cm) do M1L, ajustada pela posição estimadas pelo modelo de regressão linear

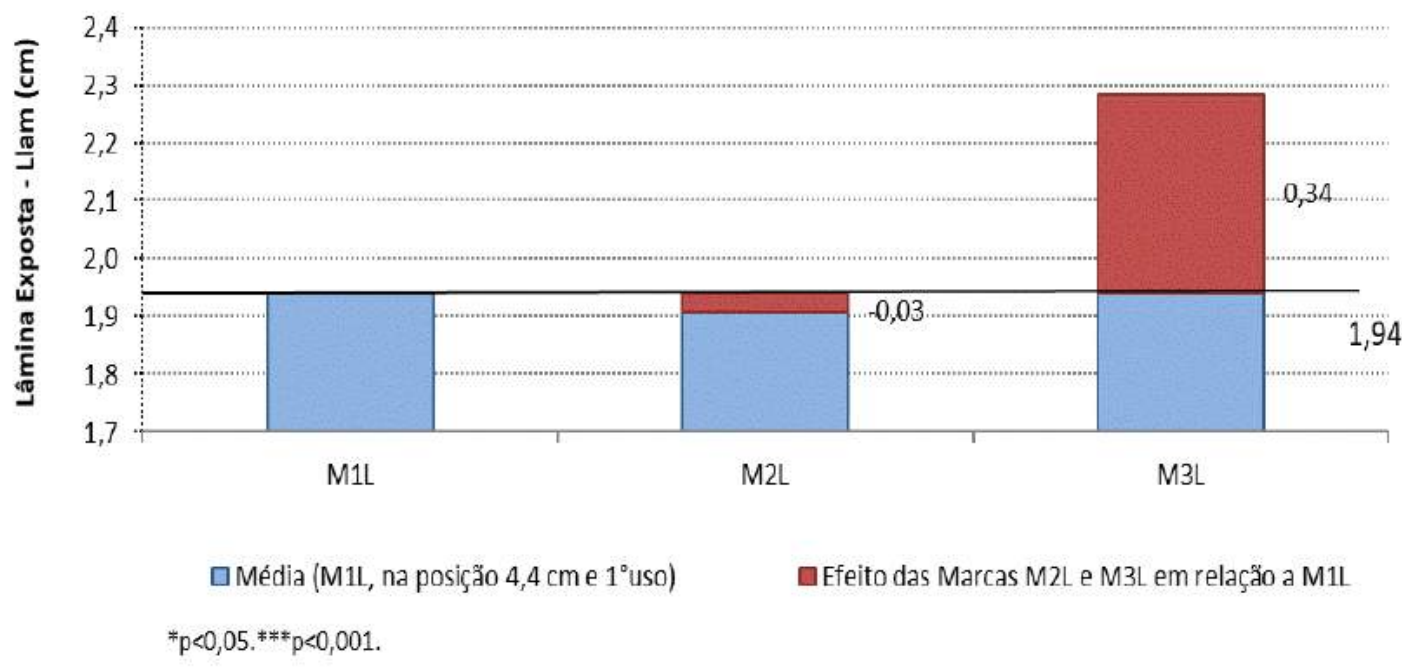


- Tempo de lâmina exposta (TLam) - Apenas a marca $(p<0,001)$ foi significante. A marca M3L apresentou maior tempo (0,37 segundos a mais) comparativamente à da marca M1L. A marca M2L apresentou tempo similar ao do M1L ( $\mathrm{p}=0,117)$ (Gráfico 11).

Gráfico 11 - Efeitos das marcas M2L e M3L sobre a média Tempo de lâmina exposta (s) do M1L, ajustada pela posição

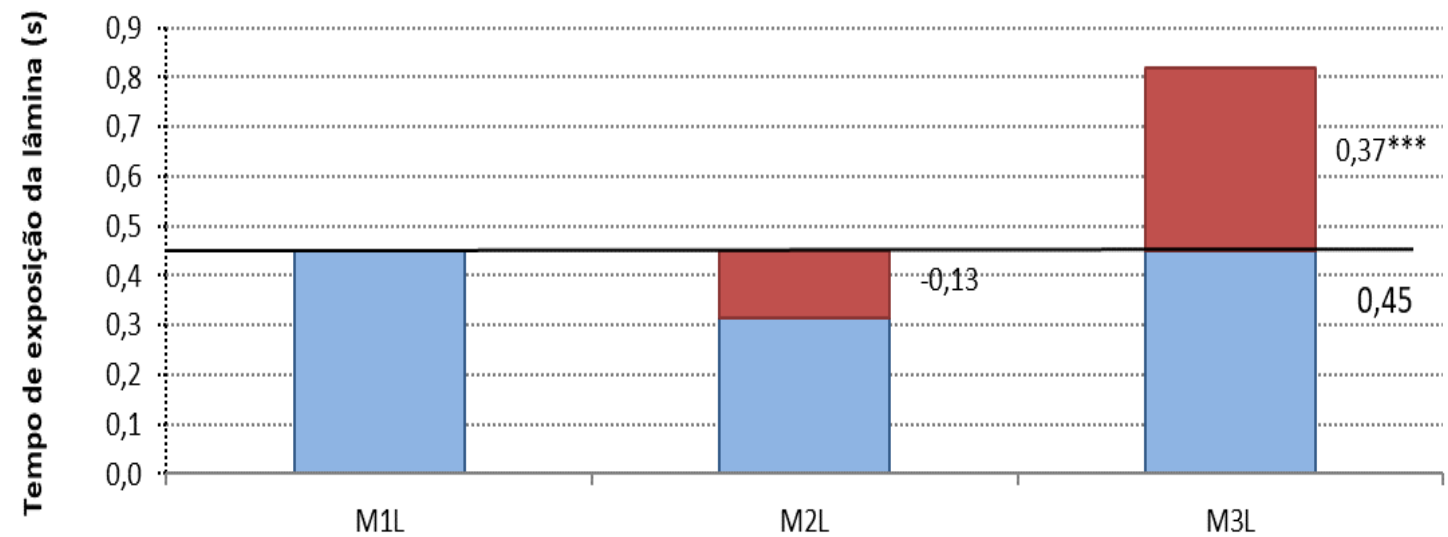

口Média (M1L, na posição 4,4 cm e $1^{\circ}$ uso) $\quad$ Efeito das Marcas M2L e M3L em relação a M1L ${ }^{* * *} p<0,001$. 
4.3) Sumário dos resultados

A tabela 8 resume os principais resultados das análises uni e multivariada

Tabela 8 - Resumo da comparação dos trocartes nas análises univariada e multivariada (Dd Deformação, F1 e F2 - Força de primeiro e segundo pico, DLam - Distância de lâmina exposta, TLam - Tempo de lâmina exposta)

UNIVARIADA

Dd (cm)

F1 (N)

F2 (N)

DLam (cm)

TLam (s)

$$
\begin{gathered}
\mathrm{M} 5 \mathrm{SL}=\mathrm{M} 4 \mathrm{SL}>\mathrm{M} 1 \mathrm{~L}>\mathrm{M} 3 \mathrm{~L}=\mathrm{M} 2 \mathrm{~L} \\
\mathrm{M} 5 \mathrm{SL}>\mathrm{M} 4 \mathrm{SL}=\mathrm{M} 3 \mathrm{~L}>\mathrm{M} 2 \mathrm{~L}=\mathrm{M} 1 \mathrm{~L} \\
\mathrm{M} 5 \mathrm{SL}>\mathrm{M} 4 \mathrm{SL}=\mathrm{M} 3 \mathrm{~L}>\mathrm{M} 2 \mathrm{~L}=\mathrm{M} 1 \mathrm{~L} \\
\mathrm{M} 3 \mathrm{~L}>\mathrm{M} 2 \mathrm{~L}=\mathrm{M} 1 \mathrm{~L} \\
\mathrm{M} 3 \mathrm{~L}>\mathrm{M} 2 \mathrm{~L}=\mathrm{M} 1 \mathrm{~L}
\end{gathered}
$$

MULTIVARIADA

$$
\begin{gathered}
\mathrm{M} 5 \mathrm{SL}=\mathrm{M} 4 \mathrm{SL}>\mathrm{M} 3 \mathrm{~L}=\mathrm{M} 2 \mathrm{~L}=\mathrm{M} 1 \mathrm{~L} \\
\mathrm{M} 5 \mathrm{SL}>\mathrm{M} 4 \mathrm{SL}=\mathrm{M} 3 \mathrm{~L}>\mathrm{M} 2 \mathrm{~L}=\mathrm{M} 1 \mathrm{~L} \\
\mathrm{M} 5 \mathrm{SL}>\mathrm{M} 4 \mathrm{SL}=\mathrm{M} 3 \mathrm{~L}>\mathrm{M} 2 \mathrm{~L}>\mathrm{M} 1 \mathrm{~L} \\
\mathrm{M} 3 \mathrm{~L}=\mathrm{M} 2 \mathrm{~L}=\mathrm{M} 1 \mathrm{~L} \\
\mathrm{M} 3 \mathrm{~L}>\mathrm{M} 2 \mathrm{~L}=\mathrm{M} 1 \mathrm{~L}
\end{gathered}
$$


5) Discussão 


\section{5) DISCUSSÃO}

\section{1) Aspectos gerais}

A técnica laparoscópica tornou-se a primeira opção para muitos procedimentos abdominais. Com o aumento do número de cirurgias, aumentou também o número de complicações, tornando-se também foco de preocupação para todos os cirurgiões que as realizam. Embora raras, as complicações decorrentes de acidentes de punção com trocartes têm alta morbidade, normalmente associadas a lesões de alças intestinais e fatais em lesões de grandes vasos abdominais (CORSON et al., 2001; FULLER et al., 2005; KAPLAN et al., 2016).

Muitos estudos tiveram como objetivo demonstrar essas complicações e apontar seus principais motivos. Eles mostraram que a natureza e extensão das lesões, associadas à punção peritoneal, dependiam de vários fatores: formato da ponta do trocarte, posição do paciente, técnica de punção e força necessária para perfuração de todas as camadas (WAXMAN et al., 1994; CORSON et al., 2001). Embora a técnica da punção seja o principal fator para se evitar complicações, o tipo de trocarte foi associado a maiores ou menores taxas de complicações (FULLER et al., 2003).

O presente estudo, com modelo suíno, foi proposto para, a partir de parâmetros da punção (perfil biodinâmico), comparar diferentes tipos de trocartes: cônicos com lâmina (M1L), piramidais com lâmina (M2L), piramidais com lâmina maior (M3L), piramidais sem lâmina (M4SL) e cônicos sem lâmina (M5SL). O que o diferencia de outros trabalhos é a demonstração e comparação de todos esses elementos em conjunto: força, 
avaliada pelo dispositivo, além de distância e tempo de perfuração e deformação da parede, avaliados pela filmagem em câmera lenta.

Em 2013, ANTONIOU et al. avaliaram todos os ensaios randomizados das bases de dados do Medline, EMBASE e Cochrane Central Register (720 cirurgias), que comparavam trocartes com e sem lâmina e suas respectivas complicações. Eles concluíram que os trocartes sem lâmina apresentavam menor risco relativo (sendo 3\% de complicações em relação a $10 \%$ dos laminados) de hemorragia nos portais de punção, principal complicação anotada, explicada por eles pela menor lesão tecidual provocada. Apesar de admitirem, ao final do estudo, que populações maiores de pacientes eram necessárias para estimar o risco relativo de lesões vicerais, os autores recomendaram que houvesse transição para trocartes sem lâmina a partir do trocarte de segunda punção, guiado pela óptica da laparoscopia.

Embora este estudo não tenha avaliado complicações, nota-se, pelos resultados que os trocartes laminados possuiam menores médias de deformações da parede (4,5 versus $7,1 \mathrm{~cm})$ e força $(5,85$ versus $8,7 \mathrm{~N})$ para perfuração das camadas. Pensando-se na primeira punção, feita às cegas, isso confere uma provável maior segurança para lesões de vísceras nesses modelos laminados, apesar da maior lesão tecidual da parede. A partir da segunda punção, feita sob visão, tal lesão ganha mais importância na taxa de morbidade. Dessa forma, a transição para trocartes não laminados, sugerida por ANTONIOU et al., 2013, a partir da segunda punção, parece razoável.

O que se percebe, revisando a literatura, é que não há unanimidade quanto ao risco relativo de cada tipo de trocarte. Os trocartes com lâminas retráteis são os mais usados em todo mundo pela menor força em sua introdução na parede abdominal, porém apresentam maior lesão tecidual dela, durante a perfuração (TARNAY et al., 1999). O segundo tipo de trocarte mais usado não possui lâmina, tendo uma ponta plástica 
cortante que divulsiona os tecidos com teórico menor trauma e menor chance de lesionar vísceras (BHOYRUL et al., 1996), sendo que alguns autores também o associam a menor dor pós operatória (TURNER et al., 1996).

SEEM et al. (1987), em seu "Manual de cirurgias endoscópicas de abdome", recomendavam o uso de trocartes de ponta cônica, em detrimento aos piramidais, para menor risco de complicações globais. Essa afirmação foi feita com base em comparações de trocartes permanentes, com lâminas não retráteis em que apenas o formato da ponta variava (cônica versus piramidal).

HURD et al. (1995) compararam três tipos de trocartes com lâmina retrátil (cônico, e dois piramidais com lâminas de $5 \mathrm{~mm}$ e $10 \mathrm{~mm}$ ) em modelo com coelhos. Seu objetivo principal era comparar taxas de complicações das punções. Cada coelho era puncionado com os três trocartes em direção a sua aorta e anotava-se o número de lesões desse vaso. Os resultados mostraram risco relativo de lesão dos trocartes piramidais (lâminas de $5 \mathrm{~mm}$ ) 37\% maior em comparação aos cônicos e $57 \%$ maior nos com lâminas de $10 \mathrm{~mm}$. Os autores concluiram que cônicos têm menor chance de complicação que os piramidais e que um maior tamanho da lâmina aumenta ainda mais esse risco.

Nosso estudo não mostrou diferença estatística entre os modelos laminados cônicos (M1L) e piramidais (M2L), mas houve diferenças no parâmetros de médias de forças (M2L com 6,7 e M3L com 9,07 N) e tempos de lâminas (M2L com 0,37 e M3L com 0,87 s) quando comparados segundo seus tamanhos de lâminas (em dois modelos piramidais). Esses resultados reforça que o tamanho da lâmina não necessariamente facilita a entrada do trocarte, já que a força e deformação inclusive foram maiores, mas aumenta o risco de lesão (HURD et al., 1995).

Não foi identificado trabalho que avaliasse o "corpo" do trocarte. Nota-se que 
alguns dos trocartes utilizados nessa tese possuem ranhuras pequenas (M1L) ou mais grosseiras (M3L) e outros são completamente lisos (M2L) (Figura 30). Isso provavelmente influencia nos parâmetros estudados. Foi observado que M3L, em comparação à M2L e M1L, possuía maior: força $(9,07$ versus 6,7 e 5,77 N respectivamente) e tempo de exposição de lâmina $(0,87$ versus 0,37 e $0,5 \mathrm{~s}$ respectivamente), com diferença estatística. O desenho do trocarte (ranhuras mais grosseiras) e o tamanho maior da lâmina parecem explicar essa diferença.



Figura 30 - Comparação entre as ranhuras dos trocartes com lâmina

Da mesma forma, entre os trocartes sem lâminas também houveram diferenças de resultados conforme o desenho com ranhuras e ponta cônica (M5SL) e sem ranhuras e 
ponta piramidal (M4SL) (Figura 31). O trocarte M5SL apresentou forças maiores de inserção quando comparado ao M4SL (10,24 versus 8,29 N).

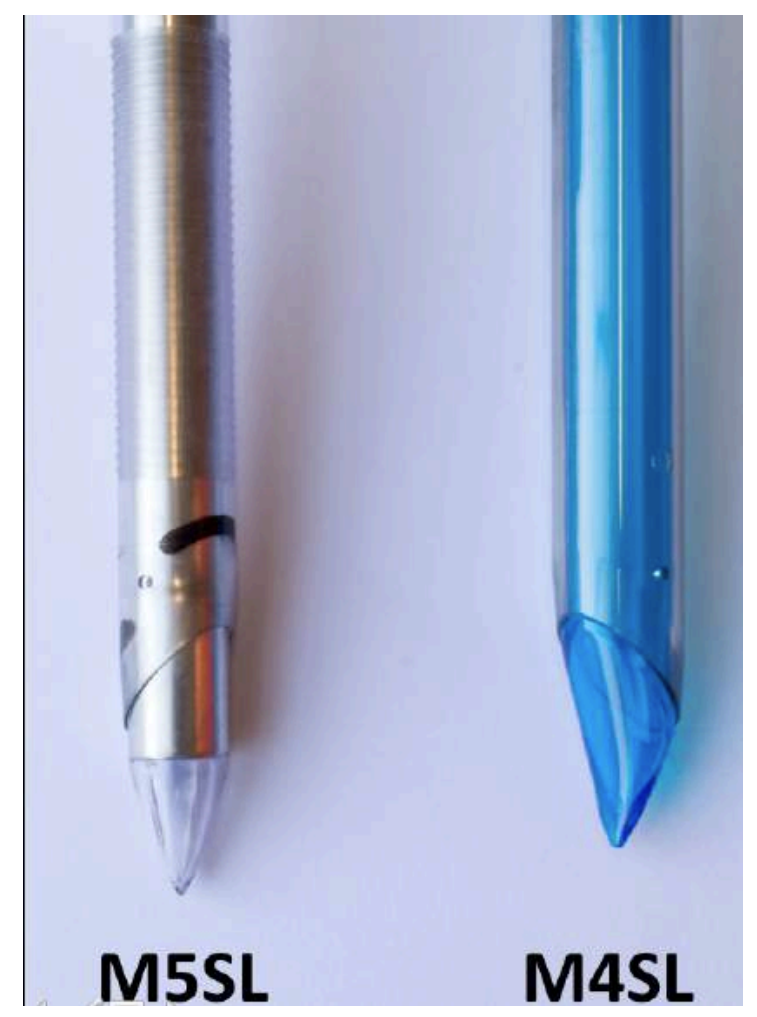

Figura 31 - Comparação entre as ranhuras dos trocartes sem lâmina

Como regra geral, a presença de ranhuras (ou ranhuras mais grosseiras), além da ponta piramidal, parecem estar relacionadas a maiores forças de inserção, deformação da parede e maiores tempos de lâmina exposta.

BÖHM et al. (1998) avaliaram vários tipos de trocartes com a intenção de sugerir um "formato ideal" com menores forças de introdução e menores lesões (em $\mathrm{cm}$ ) na parede abdominal. Concluíram, no entanto, que não há trocarte ideal porque os que necessitam de menor força em sua introdução também são os que causam maior lesão na parede abdominal. Os autores consideram força de introdução e lesão $(\mathrm{em} \mathrm{cm}) \mathrm{da}$ parede como os principais fatores predisponentes à lesão de vísceras abdominais. De 
fato, todos os trabalhos revisados da literatura mostram que trocartes laminados, apesar de necessitarem de menos força, podem produzir maiores danos à parede abdominal por serem cortantes, ao contrário dos sem lâmina que divulsionam as camadas. O presente trabalho confirmou maiores médias de forças de introdução quando agrupados e comparados trocartes não laminados versus laminados (8,7 versus 5,85 N).

Outros estudos desenvolveram dispositivos semelhantes, com intenção de medir a força necessária à perfuração da parede abdominal (TARNAY et al., 1999; NG et al., 2003). TARNAY et al. (1999) aferiram a pressão intrabdominal por transdutor colocado em agulha de Veress, permanentemente puncionada durante as perfurações. Também iniciaram seu trabalho com um sensor que ficaria entre a mão do examinador e o trocarte. No entanto, são descritas dificuldade de manuseio e danificação do sistema desse sensor, obrigando-os a seguir apenas com aferição da pressão pela agulha. Assim como no presente trabalho, os trocartes com lâmina mostraram menor força necessária em sua introdução. TARNAY et al. (1999) ressaltam que o controle do cirurgião durante a punção, com repentina parada de resistência da força, é fundamental para evitar lesões.

NG et al. (2003) realizaram um estudo em cirurgias de humanos (oito mulheres) submetidas à laparoscopia, em que se utilizou um transdutor de $3 \mathrm{~cm}$, muito semelhante ao utilizado nesta pesquisa, acoplado de forma estéril à luva do cirurgião. Assim como neste experimento, o dispositivo foi utilizado sem dificuldades em todos os tipos de trocartes, não se observando falhas na aquisição da força durante os movimentos de punção.

Não foram encontrados outros estudos com uso desses dispositivos para aferição de força. Uma possível razão para um número tão limitado de trabalhos com esse tema, segundo NG et al. (2003), seria a dificuldade em se trabalhar com um sistema 
experimental com transdutor piezoelétrico, ou em outras palavras, com auxílio de células "strain gauge" aplicadas em cirurgia. Esses estudos, realizados com pneumoperitôneo em suínos (TARNAY et al., 1999) e humanos (NG et al., 2003), tiveram como principal objetivo medir a referida força, não se atentando a outros detalhes do movimento.

O presente trabalho demonstrou que determinar o tempo e distância de lâmina exposta é tão ou mais importante que a força determinada. Neste caso, foi essencial o reforço da equipe de engenharia da FEI, liderada pelo Prof. Delijaicov, tanto na construção e calibragem do dispositivo, quanto na ajuda para aferição e explicação dos dados obtidos.

Apesar do modelo com pneumoperitoneo se aproximar mais da prática clínica, foi decidido por fazer o estudo abrindo-se a parede abdominal do suíno e colocando-o no suporte metálico. Essa opção foi adotada porque permitiu adquirir imagens quadro a quadro e em alta definição. Filmagens com óticas convencionais laparoscópicas foram tentadas sem sucesso, por não manterem o mesmo padrão de alta definição em câmera lenta. Essa limitação pode ser vencida a partir do lançamento de novas tecnologias e câmeras/ópticas laparoscópicas que permitirão fazer o mesmo estudo em modelo com pneumoperitôneo. A escolha de um aparelho smartphone para a filmagem das punções satisfez as condições mínimas de alta definição (250 quadros por segundo) e reprodução em câmera ultra lenta.

Um possível viés do trabalho, difícil de ser controlado, é dado pelo tônus muscular da parede abdominal do animal. Diferentes porcos, mesmo que da mesma raça e peso semelhantes, têm respostas distintas aos anestésicos e, portanto, terão contrações musculares distintas.

Logo nas primeiras punções notou-se que a posição da punção na linha mediana do 
porco alteraria as variáveis estudadas. Com objetivo de otimizar o uso dos porcos, novo estudo estatístico foi realizado. A regressão linear múltipla (teste de KolmogorovSmirnov ) mostrou que as variáveis poderiam ser comparadas sem esse viés. Apesar dessas limitações, as propostas iniciais foram cumpridas e a presente pesquisa permitiu que se chegasse a conclusões importantes. 


\section{2) Considerações finais}

As complicações intraoperatórias das laparoscopias podem ser decorrentes de dificuldades técnicas, mas também por falta de cuidados ou de treinamento no estabelecimento de acessos (PASSEROTTI et al., 2008). Os estudos de morbimortalidade são feitos no intuito de alertar complicações para prevenção e estabelecimento de ensinamentos para melhoria das técnicas. $O$ trabalho aqui apresentado é uma continuação de uma linha de pesquisa inicialmente publicada em 2009 por PASSEROTTI et. al., sendo agora pesquisados todos os parâmetros em movimento realizado por humano, com um sensor de força acoplado ao trocarte, mantendo-se o modelo suino. Além disso, as características dos trocartes foram pormenorizadas e comparadas com a literatura, mostrando diferenças importantes de resultado para cada modelo. Nota-se, entretanto, que, mais do que o tipo de trocarte, o treinamento e padronização da técnica de punção são o principal ponto para prevenção de complicações.

As filmagens realizadas identificaram os perigos inerentes a cada tipo de trocarte. Desse modo, o treinamento prévio dos cirurgiões é primordial e deve ser incentivado por meio de modelos experimentais e a gravação dessas punções pode ser útil nesse processo. Além disso, ficou claro que os transdutores de força utilizados podem futuramente ter um uso didático no aprendizado de jovens cirurgiões, mostrando a intensidade de força aplicada pela mão do cirurgião em todos os momentos da punção. 


\section{3) Perspectivas futuras}

1. Proposta de novos modelos de trocartes

2. Introdução curricular (em especialidades cirúrgicas) do aprendizado da colocação dos trocartes, com ênfase nas complicações desse ato.

3. Aplicação do sensor de mão para avaliação da força de introdução para treinamento e ensino de residentes

4. Desenvolvimento de futuras luvas com sensor, para acompanhamento da força de punção e melhor segurança do ato. 
6) Conclusões 


\section{6) CONCLUSÕES}

1) Trocartes com lâmina, quando comparados aos sem lâmina, possuem: menores deformações e menores forças de inserção para perfuração da parede abdominal do suíno.

2) Entre os trocartes com lâmina, M1L e M2L são semelhantes entre si em todos os parâmetros analisados. No entanto, os dois têm menores força de inserção e tempo de lâmina expostos em comparação ao M3L.

3) Análise da distância de lâmina exposta não mostrou diferença estatística entre os trocartes laminados.

4) Entre os trocartes sem lâmina, M5SL apresentou maiores forças de inserção e mesma deformação em comparação a M4SL. 
7) Referências Bibliográficas 


\section{7) REFERÊNCIAS BIBLIOGRÁFICAS}

Ahmad G, Duffy JM, Phillips K, Watson A. Laparoscopic entry techniques. Cochrane Database Syst Rev . 2008;16(4):2

Ahmad G, O'Flynn H, Duffy JM, Phillips K, Watson A. Laparoscopic entry techniques. Cochrane Database Syst Rev . 2012;15(2):2

Antoniou SA, Antoniou GA, Koch OO, Pointner R, Granderath FA. Blunt versus bladed trocars in laparoscopic surgery: a systematic review and meta analysis of randomized trials. Surg Endosc. 2013;27(7):2312-20.

Bhoyrul S, Mori T, WayLW. Radially expanding dilatation: a superior method of laparoscopic trocar access. Surg Endosc. 1996;10:775-778.

Bhoyrul S, Vierra MA, Nezhat CR, Krummel TM, Way LW. Trocar injuries in laparoscopic surgery. J Am Coll Surg. 2001;192(6):677-83.

Böhm B, Knigge M, Kraft M, Gründel K, Boenick U. Influence of different trocar tips on abdominal wall penetration during laparoscopy. Surg Endosc. 1998; 12(12):1434-8. 
Byron JW, Fujiyoski CA , Miyazawa K. Evaluation of the direct trocar insertion technique at laparoscopy. Obstet Gynecol. 1989;74:423-425

Chapman RA. High sensitivity isometric force transducers made with piezo-electric or piezo-resistive strain gauges. J Physiol. 1970;210(1):4-6.

Corcione F, Miranda L, Settembre A, Capasso P, Piccolboni D, Cusano D, Bakhtri M, Manzi F . Open Veress Assisted technique: results in 2700 cases. Minerva Chir. 2007;62(6): 443-6.

Corson SL, Batzer FR, Gocial B, Maislin G. Measurement of the force necessary for laparoscopic trocar entry. J Reprod Med. 1989;34:282- 4.

Corson SL, Chandler JG, Way LW. Survey of laparoscopic entry injuries provoking litigation. J Am Assoc Gynecol Laparosc. 2001;8:341-347.

Desu MM, Raghavarao D. Sample Size Methodology. Boston. Academic Press; 1990.

Esposito C, Ascione G, Garipoli V, De Bernardo G, Esposito G. Complications of pediatric laparoscopic surgery. Surg Endosc. 1997;11(6):655-7. 
Fleiss JL. The Design and Analysis of Clinical Experiments. New York: John Wiley \& Sons; 1986.

Fuller J, Ashar BS, Carey-Corrado J. Trocar-associated injuries and fatalities: an analysis of 1399 reports to the FDA. J Minim Invasive Gynecol. 2005;12(4):302-7.

Fuller J, Scott W, Ashar B, Corrado J. Laparoscopic trocar injuries: a report from a U.S. Food and Drug Administration (FDA) Center for Devices and Radiological Health (CDRH) Systematic Technology Assessment of Medical Products (STAMP) Committee: FDA Safety communication. 2003;1-14.

Hashizume M, Sugimachi K. Needle and trocar injury during laparoscopic surgery in Japan. Surg Endosc. 1997;11:1198-1201.

Hasson HM. Open laparoscopy. Biomed Bull. 1984;5(1):1-6.

Hilgers TW. A simple, safe technique for placement of the veress needle and trocar in laparoscopy. J Laparoendosc Surg. 1992;2(4):189-92.

Hurd WW, Wang L, Schemmel MT. A comparison of the relative risk of vessel injury with conical versus pyramidal laparoscopic trocars in a rabbit model. Am J Obstet Gynecol. 1995;173:1-3. 
Isaza N, Garcia P, Dutta S. Advances in pediatric minimal access therapy: a cautious journey from therapeutic endoscopy to transluminal surgery based on the adult experience. J Pediatr Gastroenterol Nutr. 2008;46(4):359-69.

Kaplan JR, Lee Z, Eun DD, Reese AC. Complications of minimally invasive surgery and their management. Curr Urol Rep. 2016;17(6):47.

Kirk RE. Experimental Design: procedures for the Behavioral Sciences. 4ed. Thousand Oaks, California. Sage; 2013.

Leary S et al. American Veterinary Medical Association Guidelines for the euthanasia of animals. Schaumburg. AVMA. 2013.

Leibl BJ, Schmedt CG, Schwarz J, Kraft K, Bittner R. Laparoscopic surgery complications associated with trocar tip design: review of literature and own results. $\mathrm{J}$ Laparoendosc Adv Surg Tech. 1999;9(2):135-40.

Montes SFP, Rodríguez IG, Ugarteburu RG, Villamil LR, Mendez BD, Gil PS, Madera JM. Intraoperative laparoscopic complications for urological cancer procedures. World J Clin Cases. 2015;3(5):450-456. 
Mühe E. Long-term follow up after laparoscopic cholecystectomy. Endoscopy. 1992;24:754-758.

Ng PS, Sahota DS, Yuen PM. Measurement of trocar insertion force using a piezoelectric transducer. J Am Assoc Gynecol Laparosc. 2003;10(4):534-8.

Oliveira MAP. Trocar, trocater ou trocarte? Braz J Videoendosc Surg. 2012;v.2, p.2.

Oshinsky GS, Smith AD. Laparoscopic needles and trocars: an overview of designs and complications. J Laparoendosc Surg. 1992;2(2):117-25.

Passerotti CC, Nguyen HT, Retik AB, Peters CA. Patterns and predictors of laparoscopic complications in pediatric urology: the role of ongoing surgical volume and access techniques. J Urol. 2008;180(2):681-5.

Passerotti CC, Begg N, Penna FJ, Passerotti AM, Leite KR, Antunes AA, Srougi M, Retik AB, Nguyen HT. Safety profile of trocar and insufflation needle access systems in laparoscopic surgery. J Am Coll Surg. 2009;209(2):222-32.

Schafer M, Lauper M, Krahenbuhl L. Trocar and Veress needle injuries during laparoscopy. Surg Endosc. 2001;15(3):275-80. 
Seem K. Operative manual for endoscopic abdominal surgery. Year Book Medical. Chicago. 1987;130-51.

Smith S. Complications of laparoscopic and hysteroscopic surgery. Practical manual of operative laparoscopy and hysteroscopy.Springer-Verlag. New York 1996:199-217.

Spaner SJ, Warnock GL. A brief history of endoscopy, laparoscopy, and laparoscopic surgery. J Laparoendosc Adv Surg Tech. 2009;7(6): 369-73.

Tarnay CM, Glass KB, Munro MG. Entry force and intraabdominal pressure associated with six laparoscopic trocar-cannula systems: a randomized comparison. Obstet Gynecol. 1999;94:83-88.

Turner DJ. A new radially expanding access system for laparoscopic procedures versus conventional cannulas. J Am Assoc Gynecol Laparosc. 1996;3:609-615.

Tuveri M, Tuveri A. Laparoscopic cholecystectomy: complications and conversions with the 3-trocar technique: a 10-year review. Surg Laparosc Endosc Percutan Tech. 2007;17(5):380-4.

Vilos GA, Ternamian A, Dempster J, Laberge PY. Laparoscopic entry: a review of techniques, technologies, and complications. J Obstet Gynaecol Can. 2007;29:433-465. 
Vilos GA, Ternamian A, Dempster J, Laberge PY. No 193-Laparoscopic Entry: a review of techniques, technologies, and complications. J Obstet Gynaecol Can. 2017;39:e69-e84.

Waxman K, Birkett DH, Sackier JM, Este-McDonald J, Duquette J. Clinical and laboratory evaluation of an electrosurgical laparoscopic trocar. Surg Endosc. $1994 ; 8: 1076-9$. 
APÊNDICES 


\section{Apêndice 1}

\section{Especificação dos modelos dos trocartes}

Para manter a reprodutibilidade deste estudo, os nomes das marcas dos trocartes e da câmera utilizados estão disponibilizados abaixo:

M1L - Modelo cônico com lâmina 1 cm (D12LT, Endopath Xcel - Ethicon EndoSurgery, Guaynabo, Puerto Rico, USA)

M2L - Modelo piramidal com lâmina 1 cm (179096PF, Covidien Versaport Plus V2 Bladed - Autosuture, Connectcut, USA)

M3L - Modelo piramidal com lâmina 1,2 cm (FN 100-108, Femcare - Nikomed Shielded Trocar \& Canula Hampshire, UK)

M4SL - Modelo piramidal sem lâmina (41051, Taut - Adapt, Illinois, USA)

M5SL - Modelo cônico sem lâmina (B12LT, Endopath Xcel bladeless - Ethicon EndoSurgery, Guaynabo, Puerto Rico, USA)

Gravação dos vídeos realizada em câmera lenta com aparelho telefônico Iphone 6s (Apple) 
Apêndice 2

Parecer do comitê de ética - Aprovado

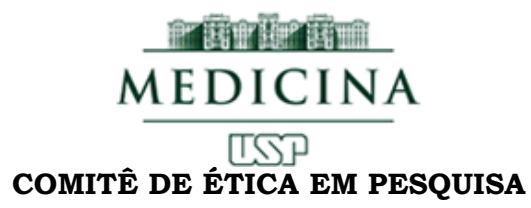

\section{CIÊNCIA}

O Comitê de Ética em Pesquisa da Faculdade de Medicina da Universidade de São Paulo, em sessão de 09 de Outubro de 2013, TOMOU CIÊNCIA do(s) documento(s) abaixo mencionado(s) no Protocolo de Pesquisa $n^{\circ}$ 036/11, intitulado: "PERFIL BIODINÂMICO DE ENTRADA DOS TROCARES E AGULHAS DE VERESS EM CIRURGIAS LAPAROSCÓPICAS" apresentado pelo DEPARTAMENTO DE CIRURGIA.

- Mudança de pesquisador executante para Danilo Galante Moreno com finalidade acadêmica de Doutorado.

Pesquisador (a) Responsável: Carlo Camargo Passerotti

CEP-FMUSP, 09 de Outubro de 2013

$$
\text { 2llominn. }
$$

Prof. Dr. Roger Chammas Coordenador

Comitê de Ética em Pesquisa 


\title{
Apêndice 3
}

Artigo enviado para publicação

\section{Evaluation of different shaped trocars during}

\section{laparoscopy insertion in a porcine model}

Danilo Galante Moreno ${ }^{1,2 *}$, Cesar Augusto Martins Pereira ${ }^{1}$, Ricardo Kyoiti Sant Anna $^{2}$, Rafael Ulysses de Azevedo ${ }^{2}$, Luiz Felipe Savio ${ }^{2}$, Ricardo Jordão Duarte ${ }^{1}$, Sergio Delijaicov ${ }^{1}$, Miguel Srougi $^{1}$, Hiep Thieu Nguyen ${ }^{1,2}$, Carlo Camargo Passerotti ${ }^{1,2}$

1 Laboratory of Medical Research, Department of Urology, University of Sao Paulo, Sao Paulo, Brazil.

2 Center for Robotic Surgery, Oswaldo Cruz German Hospital, Sao Paulo, Brazil.

\begin{abstract}
Background: The number of laparoscopic procedures increases annually with an estimated $3 \%$ of complications, one third of them linked to Verres' needle or trocar insertion. The safety and efficacy of ports insertion during laparoscopic surgery may be related the technique but also to trocar design. This study aims to compare physical parameters of abdominal wall penetration for 5 different trocars.
\end{abstract}


Materials and Methods: Eleven pigs were studied. Five different commercially available trocars were randomically inserted at the midline. Real time video recording of the insertions was achieved to measure the excursion of the abdominal wall and the time and distance the cutting surface of the bladed trocars was exposed inside the abdominal cavity. An especially designed hand sensor was developed and placed between the trocar and the hand of the surgeon to record force required for abdominal wall perforation.

Results: Greater deformations and forces occurred in non-bladed as compared to bladed trocars. The same occurred with conical trocars as compared to pyramidal pointed except for peritoneum perforation. Greater distance and time of blade exposure occurred in pyramidal laminae as compared to conical.

Conclusion: The bladed trocars have lower forces and deformations in their introduction, and should be those that cause less injury and are more suitable for first entry. Conical and pyramidal trocars with the same blade size showed similar force, deformation, time and distance of exposed blade.

Key-words: laparoscopy; trocar; safety; animal model 


\section{INTRODUCTION}

Laparoscopic surgery became a preferred access route for several surgical procedures ${ }^{1}$. However, the enthusiasm with new technology often omits a clear evaluation of their possible complications ${ }^{2}$. It is estimated that the rate of complications attributed to the laparoscopic access ranges from 3 to $16 \%$ and include puncture injuries (Veress' needle or trocar insertion), insufflation, tissue dissection, and ineffective hemostasis ${ }^{3,4}$.

One third of all laparoscopic complications are related to abdominal access ${ }^{3,5}$. Although trocar placement under direct vision into the peritoneal cavity is considered safer by several authors ${ }^{7}$, others use the "blind" technique in which the Veress needle is used to inflate the abdomen with subsequent introduction of the trocars ${ }^{8}$, one of the main moments for possible occurrence of complications ${ }^{9}$. Guidelines to prevent these adverse events are available but the ideal technique for cavity access is yet debatable ${ }^{6}$.

The technological evolution created several types and brands of trocars in order to increase the safety of the wall perforation ${ }^{10}$. However, comparative studies of different trocars with objective and reproducible parameters are still few in the literature.

This study aims to compare physical parameters of abdominal wall penetration for 5 different trocars in an in vivo animal model which may help develop a safer method of insertion. 


\section{MATERIALS AND METHODS}

\subsection{Ethics}

The study protocol was approved by the local Ethics Committee (\#036/11).

The work has been reported in accordance with the ARRIVE guidelines (Animals in Research: Reporting In Vivo Experiments). All procedures performed in studies involving animals were in accordance with the ethical standards of the institution or practice at which the studies were conducted. All applicable international, national, and/or institutional guidelines for the care and use of animals were followed. This article does not contain any studies with human participants performed by any of the authors.

Informed consent does not apply to this type of study.

There is no funding.

\subsection{Experimental model and experiment setting}

Eleven female pigs weighting 20-22 $\mathrm{kg}$ were studied. Animals came from outsourced specialized facilities external to the laboratory where the experiments were conducted. Experiments were performed immediately at animals arrival that were not housed in the local. Animals were anesthetized with a combination of telazol $(5 \mathrm{mg} / \mathrm{kg}$, intramuscular), xylazine $(1.5 \mathrm{mg} / \mathrm{kg})$ and atropin $(0.04 \mathrm{mg} / \mathrm{kg})$ for orotracheal intubation followed by isoflurane (2\%). Animals were euthanized at the end of the procedure with a lethal dose of $\mathrm{KCl}(2 \mathrm{mEq} / \mathrm{kg})$. 
Full thickness abdominal wall incisions were performed bilaterally $4 \mathrm{~cm}$ lateral to the median line from the ribs (superiorly) to the inferior iliac crest (inferiorly). A metal frame was created from welded copper pipes to support the wall strip and allow trocar penetration visualization (Figure 1). A constant and uniform tension was achieved due to standardization of the support height and incision size.

Five different trocars were randomically inserted at the midline, one at a time, at distances of $1 \mathrm{~cm}$ between them, starting $1 \mathrm{~cm}$ from the umbilicus. Skin was incised before each insertion to avoid any additional resistance. Thirty six insertions per trocar were performed (total 180 insertions). A single experienced surgeon performed all tests.

\subsection{Measuring devices}

Real time video recording of the insertions was achieved with the aid of a highresolution color camera (250 frames per second), placed on a tripod, parallel to the abdominal wall, at a fixed distance from the middle line. An especially designed hand sensor was developed from piezoelectric cells (strain gage) and placed between the trocar and the hand of the surgeon to record force required for abdominal wall perforation (Figure 2). Computerized analysis of the pressure applied in the sensor depicted characteristically curves corresponding to a double hump representing the force peak required for fascia (aponeurosis) perforation (F1) and a second force peak necessary for perforation of the peritoneum (F2) (figure 3). 


\subsection{Parameters evaluated}

Penetration forces (F1 and F2) were recorded by the hand device.

Video recording allowed the measurement of the deformation distance (Dd) as defined by the excursion of the abdominal wall in centimeters between the resting position and the last recorded frame before the exposure of the trocars tip; and the time (Tbl) and distance (Dbl) the cutting surface of the bladed trocars was exposed inside the abdominal cavity (figure 4).

\subsection{Trocars}

Five commercially available $12 \mathrm{~mm}$ trocars accessible in the country were studied:

B1 - Bladed $(1 \mathrm{~cm})$ conical trocar (D12LT, Endopath Xcel - Ethicon Endo-Surgery, Guaynabo, Puerto Rico, USA)

B2 - Bladed (1 cm) pyramidal trocar (179096PF, Covidien Versaport Plus V2 Bladed Autosuture, Connectcut, USA)

B3 - Bladed (1.2cm) pyramidal trocar (FN 100-108, Femcare - Nikomed Shielded Trocar \& Canula Hampshire, UK)

NB4 - Non-bladed pyramidal trocar (41051, Taut - Adapt, Illinois, USA)

NB5 - Conical non-bladed trocar (B12LT, Endopath Xcel bladeless - Ethicon EndoSurgery, Guaynabo, Puerto Rico, USA) 


\subsection{Statistical analysis}

Student's t test, Analysis of Variance (ANOVA) and Kruskal-Wallis test were used when appropriate. Variables are expressed as mean \pm standard deviation (range).

Sample size calculation was based on a minimal difference of $1.0 \mathrm{~cm}$ for deformation distance with an estimated ideal sample of 36 penetrations per trocar.

\section{RESULTS}

Results for all trocars are depicted in table 1.

Greater deformations $(4.54 \pm 1.0$ versus $7.10 \pm 1.04 \mathrm{~cm})$ and forces $(5.85 \pm 1.44$ versus $8.7 \pm 2.27 \mathrm{~N}$ for $\mathrm{F} 1$ and $6.38 \pm 1.89$ versus $10.32 \pm 2.54 \mathrm{~N}$ for $\mathrm{F} 2$ ) occurred in non-bladed compared to bladed trocars $(\mathrm{p}<0,001)$. The same occurred with conical trocars as compared to pyramidal pointed (deformation - $6.01 \pm 1.18$ versus $5.26 \pm$ $1.78 \mathrm{~cm}, \mathrm{p}<0,001$ and $\mathrm{F} 1-7.47 \pm 2.81$ versus $6.67 \pm 1.79 \mathrm{~N}, \mathrm{p}=0,01$ ) except for peritoneum perforation (F2) (table 2).

Distance $(\mathrm{B} 3-2.34 \pm 0.83 ; \mathrm{B} 1-1.88 \pm 0.49$ and $\mathrm{B} 2-1.86 \pm 0.91 \mathrm{~cm})$ and time of blade exposure $(\mathrm{B} 3-0.75 \pm 0.47 ; \mathrm{B} 1-0.39 \pm 0.30$ and $\mathrm{B} 2-0.23 \pm 0.17 \mathrm{~s})$ was different for trocar B3 ( $\mathrm{p}<0,001$ for all parameters) as compared to others (table 3). 


\section{DISCUSSION}

Trocar puncture accidents are rare but associated to high morbidity due to viscera lesion or even mortality in cases of vascular injury ${ }^{11-13}$. A correct insertion technique seems to minimize complications; however, trocar design is also linked to the rate of complications ${ }^{12}$. Blunt trocars have been found in some studies to cause decreased trauma and lead to a lesser chance to injury intraabdominal organs ${ }^{14}$ and less pain ${ }^{15}$. Other authors advocate conical trocars in opposition to pyramidal devices ${ }^{16}$. A consensus; however, is not found and conflicting results are seen in different series.

We proposed an experimental model to evaluate physical parameters of different designed trocars as an indicator for safety and striking differences were indeed found, which could be useful in the development of new trocars.

\subsection{Methodology}

We previously developed a model to measure trocars' penetration force in animals $^{1}$ using an apparatus constructed to insert trocars at a constant speed and to measure the axial force applied to the trocar during insertion as a function of time. This setup; however, did not consider the rotational movement, ergonomics and variable force applied by surgeon's hand in real situation. The model used in the current study tried to fix these limitations.

Hand-sensors were used previously to assess Verres needle insertion ${ }^{17}$. The device was; however, abandoned for technical reasons. Some authors used a pressure 
sensor attached to the trocars and a vertical continuous movement of the hand in order to be insensitive to torsion ${ }^{18-19}$. The insensitiveness to torsion would constitute an advantage according to some ${ }^{18}$. We; however, believe that torsion should be considered as the highest applied force is of interest. A new hand-sensor was developed during our study in conjunction with an engineering school. It worked satisfactorily and it can be used in future studies in anima nobili and in simulators for teaching purposes.

High-resolution recording of the images during trocar insertion allowed a correct evaluation of the abdominal wall dynamics and the exposure of the cutting blade.

As a limitation of the developed technology, the effect of a pneumoperitoneum is not reproduced.

\subsection{Trocars Design}

Previous experimental studies analyzed the force necessary to insert a trocar in animal models. All of them found lower forces for bladed trocars as compared to blunt brands ${ }^{1,19}$. Some clinical series also studied the safety of bladed compared to blunt trocars. Antoniou et al. ${ }^{10}$ compiled 720 procedures in a metanalysis to show a decreased relative risk of bleeding from the abdominal wall for non-bladed trocars $(3 \%$ compared to $9 \%$ ) but no difference in regards to visceral injury. Our study reproduced these previous results with lower forces for bladed trocars. We added to these results a lower deformation of the abdominal wall representing decreased chance of contact of the trocar with viscera. Although non-bladed trocars do not have a cutting surface, viscera may be injured by blunt trauma. Moreover, higher degrees of abdominal wall 
deformation denote more traumatic insertions and seem to be related to postoperative local pain ${ }^{15}$

The shape of the tip of the trocars also influences the dynamics of insertion.

Bohm et al. ${ }^{18}$ showed in a porcine model that conical tips needed a higher force than purely pyramidal tips. HURD et al. ${ }^{20}$ studied in rabbits the risk of vascular injury inserting trocars aimed at the vena cava. Risk for injury was higher for pyramidal tipped trocars compared to conical. The blade size of pyramidal trocars also influenced results with higher risk for $10 \mathrm{~mm}$ blades compared to $5 \mathrm{~mm}$ blades. Our experiment also showed dissimilarity in results when 2 pyramidal-tipped bladed trocars with different blade sizes. Larger blades provoked higher forces, higher distance and time of exposed blade. Besides, conical (B1) and pyramidal (B2) trocars with the same blade size showed similar force, deformation, time and distance of exposed blade.

\section{CONCLUSIONS}

Our results shown that bladed trocars demand lower forces for penetration leading to less deformation in their introduction and should be those that cause less injury and are more suitable for first puncture for clinical practice. Conical and pyramidal trocars tips appear to be similar, although blade size brings different results. Trocar inserting technique should be more clearly understood and a protocol for training should be included during laparoscopy training. 


\section{CONFLICT OF INTEREST STATEMENT}

The authors had no conflict of interest.

\section{REFERENCES}

1) Passerotti CC, Begg N, Penna FJ, Passerotti AM, Leite KR, Antunes AA, Srougi M, Retik AB, Nguyen HT, Safety profile of trocar and insufflation needle access systems in laparoscopic surgery, J Am Coll Surg. 209 (2009) 222-32.

2) Leibl BJ, Schmedt CG, Schwarz J, Kraft K, Bittner R, Laparoscopic surgery complications associated with trocar tip design: review of literature and own results, $\mathrm{J}$ Laparoendosc Adv Surg Tech. 9 (1999) 135-40.

3) Hashizume M, Sugimachi K, Needle and trocar injury during laparoscopic surgery in Japan, Surg Endosc. 11 (1997) 1198-1201.

4) Trottier DC, Martel G, Boushey RP, Complications in laparoscopic intestinal surgery: prevention and management, Minerva Chir 64 (2009) 339.

5) Magrina JF, Complications of laparoscopic surgery, Clin Obstet Gynecol. 45 (2002) 469.

6) Vilos GA, Ternamian A, Dempster J, Laberge PY, No 193-Laparoscopic Entry: A Review of Techniques, Technologies, and Complications, J Obstet Gynaecol Can. 39 (2017) e69-e84. 
7) Hasson HM, Open laparoscopy, Biomed Bull. 5 (1984) 1-6.

8) Corcione F, Miranda L, Settembre A, Capasso P, Piccolboni D, Cusano D, Bakhtri M, Manzi F, Open Veress Assisted technique. Results in 2700 cases, Minerva Chir. 62 (2007) 443-6.

9) Montes SF, Rodríguez IG, Ugarteburu RG, Villamil LR, Mendez BD, Gil PS, Madera JM, Intraoperative laparoscopic complications for urological cancer procedures. World J Clin Cases. 3 (2015): 450-456

10) Antoniou SA, Antoniou GA, Koch OO, Pointner R, Granderath FA, Blunt versus bladed trocars in laparoscopic surgery: a systematic review and meta analysis of randomized trials, Surg Endosc. 27 (2013) 2312-20.

11) Corson SL, Chandler JG, Way LW, Survey of laparoscopic entry injuries provoking litigation, J Am Assoc Gynecol Laparosc. 8 (2001) 341-347

12) Fuller J, Scott W, Ashar B, Corrado J, Laparoscopic trocar injuries: a report from a U.S. Food and Drug Administration (FDA) Center for Devices and Radiological Health (CDRH) Systematic Technology Assessment of Medical Products (STAMP) Committee, (2005) 1-14.

13) Kaplan JR, Lee Z, Eun DD, Reese AC, Complications of minimally invasive surgery and their management, Curr Urol Rep. 17 (2016) 47.

14) Bhoyrul S, Mori T, Way LW, Radially expanding dilatation: a superior method of laparoscopic trocar access, Surg Endosc.10 (1996) 775-778.

15) Turner DJ, A new radially expanding access system for laparoscopic procedures versus conventional cannulas, J Am Assoc Gynecol Laparosc. 3 (1996) 609-615. 
16) Seem K, Operative manual for endoscopic abdominal surgery. Chicago: Year Book Medical, (1987) 30-51.

17) Tarnay CM, Glass KB, Munro MG, Entry force and intraabdominal pressure associated with six laparoscopic trocar-cannula systems: a randomized comparison. Obstet Gynecol. 94 (1999) 83-88.

18) Böhm B, Knigge M, Kraft M, Gründel K, Boenick U, Influence of different trocar tips on abdominal wall penetration during laparoscopy, Surg Endosc. 2 (1998) 1434-8.

19) Shafer DM, Khajanchee Y, Wong J, Swanström LL, Comparison of five different abdominal access trocar systems: analysis of insertion force, removal force, and defect size, Surg Innov. 13 (2006)183-9.

20) Hurd WW, Wang L, Schemmel MT, A comparison of the relative risk of vessel injury with conical versus pyramidal laparoscopic trocars in a rabbit model, Am J Obstet Gynecol. 173 (1995) 1731-3. 


\section{TABLES}

Table 1. Global results for all trocars

\begin{tabular}{|l|l|l|l|}
\hline Trocar & $\begin{array}{l}\text { Deformation distance } \\
(\mathbf{c m})\end{array}$ & F1 (N) & F2 (N) \\
\hline B1 & $5.03 \pm 0.55(3.88-6.04)$ & $5.27 \pm 0.77(2.63-6.83)$ & $5.22 \pm 1.22(1.84-7.49)$ \\
\hline B2 & $4.26 \pm 1.19(2.29-7.36)$ & $5.46 \pm 1.11(3.06-8.0)$ & $5.84 \pm 1.28(3.62-8.82)$ \\
\hline B3 & $4.33 \pm 0.99(1.74-6.06)$ & $6.82 \pm 1.74(2.90-11.20)$ & $8.07 \pm 1.79(4.61-11.9)$ \\
\hline NB4 & $7.2 \pm 1.27(4.95-9.9)$ & $7.73 \pm 1.71(4.78-11.30)$ & $9.17 \pm 1.84(5.91-12.98)$ \\
\hline NB5 & $7.0 \pm 0.74(5.23-8.68)$ & $9.67 \pm 2.36(3.58-15.38)$ & $11.46 \pm 2.65(7.22-19.18)$ \\
\hline
\end{tabular}

B1 - Bladed conical 1,0 laminae trocar, B2 - Bladed pyramidal 1,0 cm laminae trocar, B3 - Bladed pyramidal 1,2 cm laminae trocar, NB4 - Non-bladed pyramidal trocar, NB5 - Non-bladed conical trocar. 